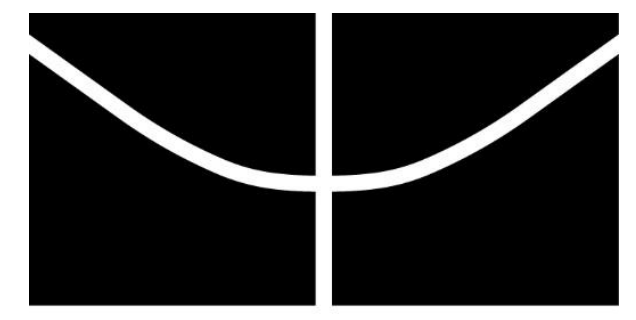

\author{
Universidade de Brasília \\ Instituto de Ciências Biológicas \\ Departamento de Botânica \\ Programa de Pós-Graduação em Botânica
}

\title{
Revisão taxonômica das espécies de Paspalum L., grupo Parviflora (Poaceae, Paspaleae)
}

Aluno: Clapton Olimpio de Moura

Orientadora: Dra. Regina Célia de Oliveira 


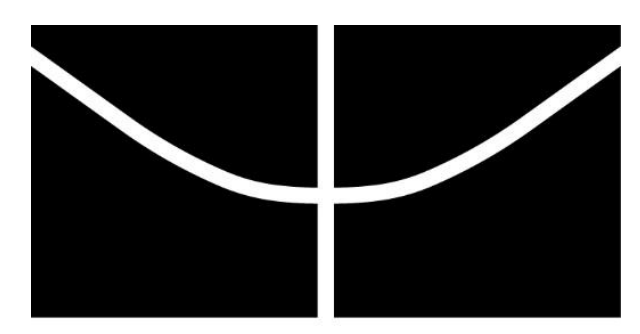

Universidade de Brasília

Instituto de Ciências Biológicas

Departamento de Botânica

Programa de Pós-Graduação em Botânica

\title{
Revisão taxonômica das espécies de Paspalum L., grupo Parviflora (Poaceae, Paspaleae)
}

\author{
Dissertação apresentada ao Programa de \\ Pós-Graduação em Botânica da \\ Universidade de Brasília, como parte dos \\ requisitos para a obtenção do título de \\ Mestre em Botânica.
}

Aluno: Clapton Olimpio de Moura Orientadora: Drạ. Regina Célia de Oliveira 
BANCA EXAMINADORA

Dra. Regina Célia de Oliveira

Departamento de Botânica - Universidade de Brasília

Presidente da Banca (Orientadora)

Dr. Jose Francisco Montenegro Valls

Embrapa Recursos Genéticos e Biotecnologia

Examinador Interno

Dr. Cassiano Aimberê Dorneles Welker

Instituto de Biologia - Universidade Federal de Uberlândia

Examinador Externo

Dra. Sueli Maria Gomes

Departamento de Botânica - Universidade de Brasília

Suplente 


\section{RESUMO}

Poaceae é uma das maiores famílias botânicas em número de espécies e uma das mais importantes para a espécie humana, ecológica e economicamente. O gênero Paspalum L. possui mais de 350 espécies e é um dos mais diversos dentre as gramíneas (Poaceae). Nativo das Américas, possui poucas espécies fora do novo continente. Historicamente o gênero foi subdividido em grupos Informais, ou seja, grupos de espécies sem categoria taxonômica. O grupo Parviflora distingue-se por possuir touceiras com as folhas normalmente concentradas na base, espiguetas diminutas, com gluma superior e lema inferior geralmente delicados. Atualmente o grupo conta com sete espécies: P. clavuliferum C. Wright, P. crispatum Hack., P. hyalinum Nees ex Trin., P. minarum Hack., P. multicaule Poir., P. parviflorum Rhode ex Flüggé e P. scalare Trin. Todas possuem registro para o Brasil. Foram realizadas análises morfológicas e micromorfológicas das espécies do grupo Parviflora. As contribuições em Microscopia Eletrônica de Varredura são inéditas por utilizarem todas as peças das espiguetas, não só o antécio superior, e geraram caracteres importantes para a distinção das espécies do grupo. As espécies do grupo foram circunscritas; algumas espécies, como P. hyalinum e P. scalare necessitam de abordagens além da morfológica (exemplo: citogenética) para que possam ser melhor delimitadas intraespecificamente.

Palavras-chave: Brasil, Gramineae, Micromorfologia, Paniceae I.s., Panicoideae. 


\begin{abstract}
Poaceae is one of the largest botanical families in number of species and one of the most important for the human species, ecologically and economically. Paspalum L. has more than 350 species and is one of the most diverse genera among the grasses. Native of the Americas, has few species outside of the new continent. Historically the genus was subdivided into Informal groups (groups of species without taxonomic category). The Parviflora group is distinguished by having culms with leaves normally concentrated in the base, tiny spikelets with upper glume and lower lemma usually delicate. Currently the group has seven species: P. clavuliferum C. Wright, P. crispatum Hack., P. hyalinum Nees ex Trin., P. minarum Hack., P. multicaule Poir., P. parviflorum Rhode ex Flüggé and P. scalare Trin. All are registered to Brazil. Morphological and micromorphological analyzes of the species of the Parviflora group were carried out. The contributions in Scanning Electron Microscopy are inedited, because were used all the parts of the spikelets, not only the upper anthecium, and they generated important characters for the distinction of the species of the group. The species of the Parviflora group were circumscribed; Some species such as $P$. hyalinum and $P$. scalare require approaches other than morphology (e.g. cytogenetics) to be better delimited intraspecifically.
\end{abstract}

Key words: Brazil, Gramineae, Micromorphology, Paniceae I.s., Panicoideae. 
"A selva é como ela é, vaidosa e ambiciosa, irada e luxuriosa. Pros moleque da quebrada um futuro mais ameno, essa é a meta." 


\section{Agradecimentos}

Para quem me conhece as palavras a seguir não são nenhuma novidade; já sabem que esqueço das coisas com muita facilidade (nomes então...), então se você contribuiu de qualquer forma (direta ou indireta) para a conclusão deste trabalho, saiba que tem meus eternos e sinceros agradecimentos.

Entre aqueles que consigo nomear, a professora Regina Célia de Oliveira merece os primeiros agradecimentos, claro. Serei sempre grato a todas as portas que abriu pra mim na botânica, desde que comecei a dar monitorias em 2013. Espero que muitos frutos ainda sejam gerados através desta amizade. Grato por tudo, principalmente pela paciência.

Muito obrigado a todos os professores que participaram das minhas bancas, durante o mestrado, Professor Jose Francisco Montenegro Valls, Marisa Toniolo Pozzobon, Renata Corrêa Martins, Cassiano Aimberê Dorneles Welker e os suplentes Christopher William Fagg e Sueli Maria Gomes. Vocês foram peças fundamentais, com suas correções e dicas, para a conclusão deste trabalho.

Para aqueles que são meu chão, não são necessárias palavras. Mas deixarei registrado aqui meu amor e gratidão por vocês (Clarindo, Doriana, Clariça, Clayane, Victor e Victoria). Obrigado por entenderem minha ausência, e sempre estarem lá.

Yan Felipe, grato por tudo, não fosse essa parceria (da zona sul, zona show) talvez eu teria chegado atrasado nas provas de seleção, nas defesas e talvez a viagem de coleta ao Mato Grosso não fosse nem possível, tu é o cara.

A Luciana Rebellato, que nos deu abrigo na Chapada dos Guimarães, um grande 
abraço e meus sinceros agradecimentos, valeu por toda hospitalidade. Espero que nos encontremos novamente.

Ao universo, obrigado por ter enviado o senhor Miguel (ou Joaquim!?) jogar lixo onde não deveria, o que possibilitou nosso 'resgate' do meio do mato em Alto Araguaia, depois de muitas horas tentando desatolar o carro (seguir os caminhos da Chase pode ser muito divertido, recomendo).

Um agradecimento especial a galera do Trote Ecológico, que sempre me inspiram, me fortalecem e me deixam sempre mais curioso e apaixonado pelo Cerrado, vocês são geniais. Valeu pela parceria de vida, Caputo, Carol, Tonhão, Cão, Novinho, Julia Barbosa, Glauber, Pinto, Marquinhos Junim e todos aqueles que não vou conseguir citar (tudo) e que deverão retirar abraços de gratidão ao vivo.

Sou agradecido pelos parceiros de orientação Rebecca, André, Mayco, Anádria, Janae e Ana Izabel. Valeu por todo conhecimento compartilhado e por todo suporte que deram quando precisei.

A todos os professores do departamento de botânica (e PPGBot) que participaram de forma fundamental na minha formação até aqui, um grande abraço!

Agradeço também ao CNPq pela bolsa de mestrado, à FAP-DF e UnB, pelos recursos utilizados nesta pesquisa.

Caso seu nome não esteja aqui, sinta-se abraçado. Aqui é só um texto, são palavras juntas que de alguma forma fazem sentido. $\mathrm{O}$ que sinto por cada um, com certeza não cabe aqui. 


\section{SUMÁRIO}

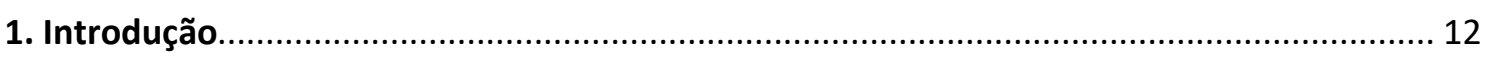

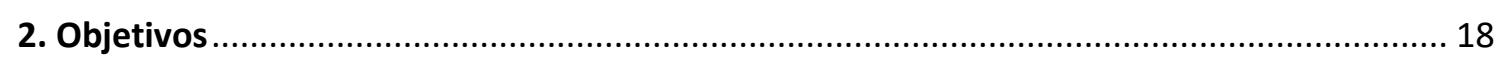

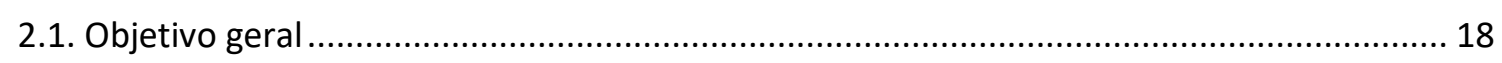

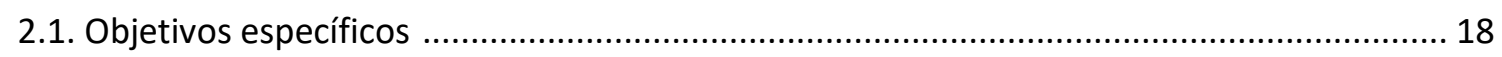

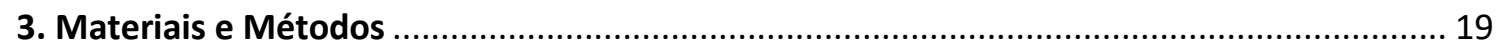

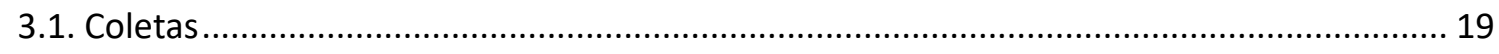

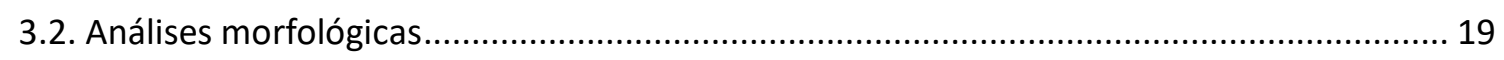

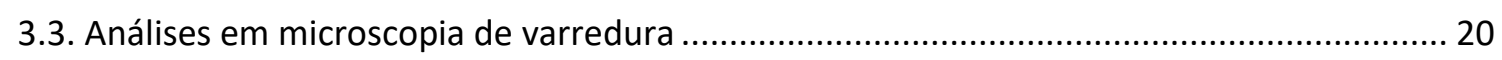

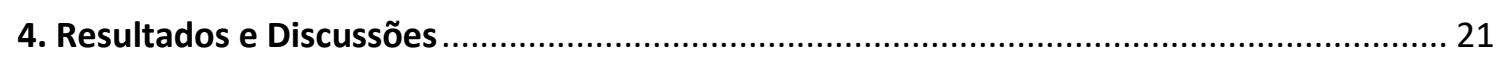

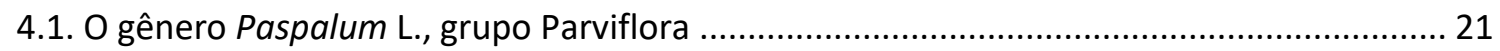

4.1.1 Chave de identificação para espécies de Paspalum L., grupo Parviflora ........................... 23

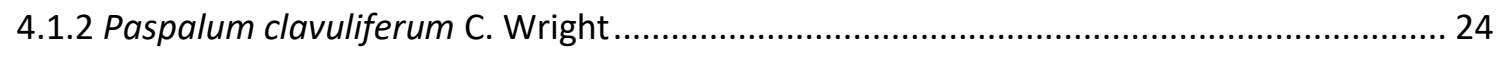

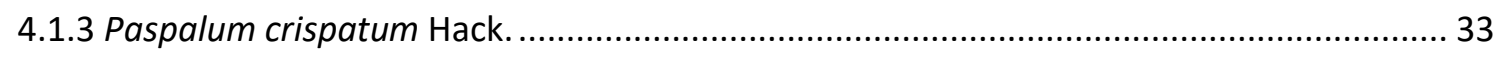

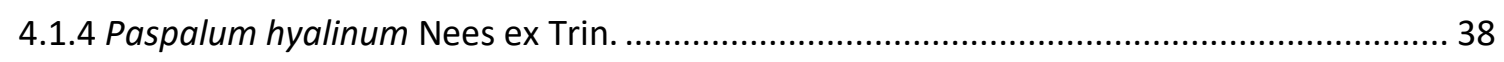

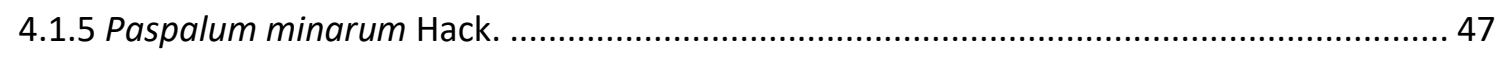

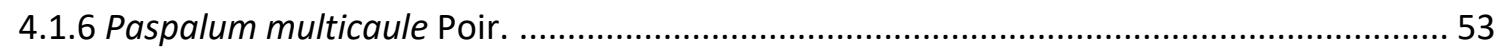

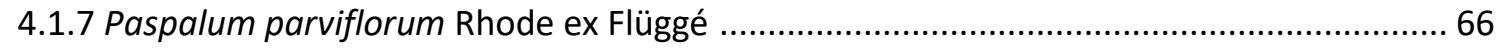

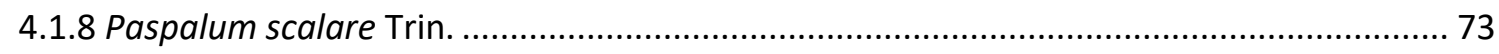

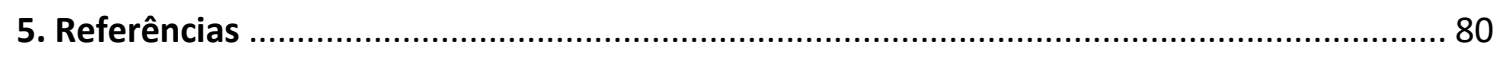

ANEXO I - Artigo submetido a revista Phytotaxa (Magnolia Press) ........................................... 85 


\section{Lista de figuras e tabelas}

Figura 1. Mapa com os registros de distribuição de Paspalum L., grupo Parviflora, no Brasil .. 19

Figura 2. Espigueta de Paspalum clavuliferum (Moura, C.O. 42); A - Gluma superior, B - Lema inferior, C - Lema superior, D - Pálea. Barra de escala $=1 \mathrm{~mm}$

Figura 3. Microfotografia de Paspalum clavuliferum (Moura, C.O. 42); A - Gluma superior, B Lema inferior, C - Lema superior, D - Pálea, E - Tricomas clavados, F - Papilas conjugadas .... 23

Figura 4. Mapa com os registros de distribuição (pontos vermelhos) confirmados de Paspalum clavuliferum 24

Figura 5. Espigueta de Paspalum crispatum (Wood, J.R.I. 24345); A - Gluma superior, B - Lema inferior, C-Lema superior, D - Pálea. Barra de escala $=1 \mathrm{~mm}$ 31

Figura 6. Microfotografia de Paspalum crispatum (Wood, J.R.I. 24345); A - Gluma superior, B Lema inferior, C - Lema superior, D - Pálea, E - Tricomas encaracolados, F - Papilas simples. 32 Figura 7. Mapa com os registros de distribuição (pontos vermelhos) confirmados de Paspalum crispatum. 33

Figura 8. Espigueta de Paspalum hyalinum (Moura, C.O. 95); A - Gluma superior, B - Lema inferior, C - Lema superior, D - Pálea. Barra de escala $=1 \mathrm{~mm}$ 36

Figura 9. Microfotografia de Paspalum hyalinum (Moura, C.O. 68); A - Gluma superior, B - Lema inferior, C - Lema superior, D - Pálea, E e F - Papilas simples 37

Figura 10. Mapa com os registros de distribuição (pontos vermelhos) confirmados de Paspalum hyalinum. 38

Figura 11. Espigueta de Paspalum minarum (Pimenta, K.M. 275); A - Gluma superior, B - Lema inferior, C - Lema superior, D - Pálea. Barra de escala $=1 \mathrm{~mm}$ 45 
Figura 12. Microfotografia de Paspalum minarum (Pimenta, K.M. 275); A - Gluma superior, B Lema inferior, C - Lema superior, D - Pálea, E e F - Papilas simples 46

Figura 13. Mapa com os registros de distribuição (pontos vermelhos) confirmados de Paspalum minarum 47

Figura 14. Espigueta de Paspalum multicaule (Moura, C.O. 46); A - Gluma superior, B - Lema inferior, $\mathrm{C}-$ Lema superior, D - Pálea. Barra de escala $=1 \mathrm{~mm}$ 51

Figura 15. Microfotografia de Paspalum multicaule (Moura, C.O. 46); A - Gluma superior, B Lema inferior, C-Lema superior, D - Pálea, E - Tricomas capitados, F- Papilas conjugadas . 52

Figura 16. Mapa com os registros de distribuição (pontos vermelhos) confirmados de Paspalum multicaule 53

Figura 17. Espigueta de Paspalum parviflorum (Faria, J.E.Q. 3506 - 35x029); A - Gluma superior, B - Lema inferior, C - Lema superior, D - Pálea. Barra de escala $=1 \mathrm{~mm}$ 65

Figura 18. Microfotografia de Paspalum parviflorum (Faria, J.E.Q. 3506); A - Gluma superior, B - Lema inferior, C - Lema superior, D - Pálea, E - Tricomas colunares, F- Papilas simples .... 66

Figura 19. Mapa com os registros de distribuição (pontos vermelhos) confirmados de Paspalum parviflorum. 67

Figura 20. Espigueta de Paspalum scalare (Graciano-Ribeiro 66); A - Gluma superior, B - Lema inferior, C - Lema superior, D - Pálea. Barra de escala $=1 \mathrm{~mm}$ 72

Figura 21. Microfotografia de Paspalum scalare (Graciano-Ribeiro 66); A - Gluma superior, B Lema inferior, C - Lema superior, D - Pálea, E - Tricomas falcados, F - Papilas conjugadas .... .73

Figura 22. Mapa com os registros de distribuição (pontos vermelhos) confirmados de Paspalum scalare 74 
Figura 23. Illustration of Paspalum sp. nov. A. Habit. B. and C. Racemes with solitary spikelets. D. upper lemma. E. Upper glume. F. Upper anthecium, palea view. G. Lower lemma. Scale bar: $A=1 \mathrm{~cm} ; B, C, D, E, F$ and $G=1 \mathrm{~mm}$

Figura 24. Photographs of Paspalum sp. nov. in the field. A. Canga vegetation, on the ironstone outcrops. B. and C. Inflorescences. D. Raceme woth spikelets showing anthers and stigmas. E. Basal portion of a receme. F. Spikelets in detail

Figura 25. Distribution map of Paspalum sp. nov. The dark lines indicate the Carajás National Forest (FLONA Carajás) and the Campos Ferruginosos National Park (PARNA Campos Ferruginosos); red circles are occurrence sites; black patches, canga plateaus; grey, mining pits. 89 


\section{INTRODUÇÃO}

Poaceae Barnhart é umas das maiores famílias botânicas, em riqueza de espécies, com mais de 12000 espécies descritas e distribuídas em 771 gêneros (SORENG et al., 2015). As espécies de Poaceae ocorrem em todos os continentes e são componentes fundamentais nos diversos ecossistemas campestres e savânicos (SORENG et al., 2015; JONES et al., 2014; STRÖMBERG, 2011). Estima-se que as primeiras linhagens da família tenham surgido em meados do período Cretáceo, a cerca de 100 milhões de anos, no supercontinente Gondwana, considerado seu centro de origem e distribuição (JONES et al., 2014; PRASAD et al., 2011; STRÖMBERG, 2011; BOUCHENAK-KHELLADI et al., 2010).

A família é atualmente dividida em 12 subfamílias, com suporte filogenético (SORENG et al., 2015; ALISCIONI et al., 2012). Para o Brasil são registradas 1482 espécies, distribuídas em 225 gêneros e 11 subfamílias, sendo Puelioideae L.G. Clark et al. a única que não possui representantes no país. São aceitos como endêmicos do Brasil, 21 gêneros e 491 espécies de Poaceae (FLORA DO BRASIL 2020, 2017).

Por meio de uma perspectiva econômica e ecológica, as gramíneas formam um dos grupos vegetais mais importantes para o homem. Dentre as diversas utilidades das espécies da família destacam-se o uso na alimentação, produção de biocombustíveis, forragem, paisagismo, construção civil e produção de artesanatos (LU et al., 2013; PIMENTA, 2013; FURTADO et al., 2011; STRÖMBERG, 2011; BOUCHENAK-KHELLADI et al., 2010; ZULOAGA \& MORRONE, 2005).

Panicoideae A. Braun é uma das maiores e mais importantes subfamílias de Poaceae. Estudos recentes reforçaram sua monofilia e reestruturaram as relações 
taxonômicas internas do grupo, organizando a subfamília em 12 tribos (SORENG et al., 2015). A tribo Paniceae I.s., parafilética (SORENG et al., 2015; MORRONE et al., 2012), foi subdividida em duas tribos monofiléticas, Paniceae R. Br. sentido restrito (s.s.) e Paspaleae, esta última sendo reestabelecida de PRESL (1830). A filogenia de Paniceae sentido amplo (I.s.) foi feita baseando-se em dados morfológicos, moleculares, distribuição geográfica e número básico de cromossomos. Paniceae s.s. tem número básico $x=9$ cromossomos e Paspaleae, $x=10$. Paspaleae é formado por um grupo de espécies majoritariamente americanas e Paniceae s.s. possui distribuição pantropical (MORRONE et al., 2012).

Com mais de 350 espécies, Paspalum L. é o maior gênero dentro da tribo Paspaleae e possui extensa distribuição no continente americano, sendo pouco representado no velho mundo (RUA et al., 2010; ZULOAGA \& MORRONE, 2005). As espécies do gênero são abundantes em formações vegetais campestres, onde possuem grande importância ecológica, mas também podem ser encontradas em habitats florestais, próximo a cursos d'água, ambientes arenosos, pedregosos e em áreas antropizadas (RUA et al., 2010; ALISCIONI \& DENHAM, 2008; ZULOAGA \& MORRONE, 2005).

O Brasil abriga, em seu território, uma vasta riqueza de espécies de Paspalum, 213 das mais de 350 descritas para o gênero, sendo 77 endêmicas (FLORA DO BRASIL 2020, 2017). O Brasil central é considerado o um dos centros de diversidade do gênero, sendo o Cerrado, principal domínio fitogeográfico da região, o responsável por abrigar cerca de 157 espécies do gênero (FLORA DO BRASIL 2020, 2017; ZULOAGA \& MORRONE, 2005).

Paspalum foi descrito por Linnaeus em sua obra Systema Naturae de 1759 (TROPICOS, 2017). ALISCIONI \& DENHAM (2008), ZULOAGA \& MORRONE (2005) e RUA 
(1996) caracterizaram o gênero pelas inflorescências com espiguetas dispostas unilateralmente na ráquis, espiguetas plano-convexas ou côncavo-convexas, gluma inferior geralmente ausente, gluma superior voltada para a ráquis, antécio inferior com pálea inferior geralmente ausente, antécio superior de consistência endurecida a membranácea e número cromossômico básico de $x=10$. Apesar de Paspalum possuir o estado de caráter plesiomórfico de número cromossômico básico $x=10$, algumas espécies do grupo podem apresentar números básicos diferentes, como $x=6$ ou $x=9$ (SOUZA-CHIES et al., 2006).

No tocante à delimitação infragenérica, várias classificações foram propostas, porém, essa tem sido uma tarefa extremamente laboriosa em Paspalum. CHASE (1929; 1939 - não publicado) aceitou a subdivisão de Paspalum em dois subgêneros, Ceresia (Pers.) Rchb. e Paspalum, sendo que, neste último, reuniu as espécies em 25 grupos informais. Posteriormente ZULOAGA \& MORRONE (2005) aceitaram três subgêneros em Paspalum: Anachyris (Nees) Chase, Ceresia e Paspalum, subdividido em 28 grupos informais. DENHAM (2005) reconheceu o subgênero Harpostachys (Trin.) S.Denham. Atualmente, 39 grupos informais são listados para o gênero (SCATAGLINI et al., 2014) e nenhuma classificação formal tem sido integralmente adotada.

A relutância em aderir a qualquer uma das classificações propostas tem sido causada principalmente pelo fato de nenhuma delas possuir amparo filogenético. Diversos estudos têm demonstrado que Paspalum é um grupo parafilético e que sua circunscrição precisa ser reavaliada (SCATAGLINI et al., 2014; ZILLI et al., 2014; RUA et al., 2010; GIUSSANI et al., 2009; SOUZA-CHIES et al., 2006; DENHAM et al., 2002; RUA, 1996). RUA et al. (2010) destacam que o principal entrave para uma boa resolução nas 
propostas filogenéticas de Paspalum é a sobreposição na distribuição de caracteres, causados majoritariamente por homoplasias, formação de híbridos e pela ocorrência de alopoliploidia, comuns no gênero.

O grupo informal Parviflora foi estabelecido por CHASE (1929) e circunscrito inicialmente com seis espécies: Paspalum clavuliferum C. Wright, P. microstachyum J. Presl, P. multicaule Poir, P. parviflorum Rhode ex Flüggé, P. pictum Ekman e $P$. standleyi Chase. Subsequentemente CHASE (1939 - não publicado) adicionou mais seis espécies, sul-americanas ao grupo: P. crispatum Hack., P. delicatum Swallen, P. hyalinum Nees ex Trin. (com seus sinônimos: P. abstrusum Trin., P. gossypinum Mez e P. polychaetum Mez), P. minarum Hack, P. nudatum Luces e P. scalare Trin. (e P. scalare var. glabriglume Döll). Neste mesmo trabalho excluiu P. microstachyum do grupo e o realocou no grupo Inaequivalvia.

No trabalho de BARRETO (1974) sobre as espécies de Paspalum do Rio Grande do Sul a única espécie do grupo Parviflora ali encontrada foi $P$. hyalinum. BARRETO (1974) também utilizou o sistema de grupos informais, e agrupou $P$. hyalinum no grupo Paniculata, juntamente com $P$. juergensii Hack., P. orbiculatum Poir. e P. paniculatum L.

RODRÍGUEZ (1999) estabelece a seção Parviflora Rodríguez, considerando todas as espécies do grupo Parviflora (CHASE, 1939 - não publicado), a exceção de P. delicatum e P. standleyi, sendo composta por: P. clavuliferum, P. crispatum, P. hyalinum, P. minarum, P. multicaule, P. nudatum, P. parviflorum, P. pictum, P. ramianum Camacho e P. scalare. Neste trabalho, RODRÍGUEZ (1999) propõe ainda a sinonimização de $P$. delicatum a $P$. pictum, e a transferência de $P$. standleyi para o grupo Orbiculata.

NICOLA et al. (2014) realizaram a revisão do grupo Gardneriana e transferiram para 
este três espécies do grupo Parviflora ( $P$. nudatum, $P$. delicatum e $P$. pictum), e também discordam da sinonimização feita por RODRÍGUEZ (1999), entre P. delicatum e P. pictum, tratando os dois táxons de forma independente. Além disto, DENHAM (2005) sinonimiza P. ramianum a $P$. axillare Swallen.

Embora, tenha sido CHASE (1929) quem estabeleceu o grupo Parviflora em Paspalum, NASH (1912) foi o primeiro a utilizar o nome Parviflora associado a $P$. parviflorum, porém sem a proposição de grupo informal ou categoria taxonômica formal. Nesse trabalho foram listadas as espécies de Paspalum para a Flora Norte Americana, e essas espécies foram agrupadas em um sistema parecido com o de grupos informais, porém sem essa indicação. Além de $P$. parviflorum, outras duas espécies, do grupo Parviflora, foram citadas, sendo elas: P. clavuliferum e P. multicaule, ambas agrupadas em Notata, juntamente com $P$. notatum Flüggé e $P$. minus Fourn.

$\mathrm{Na}$ recente filogenia proposta para o gênero (SCATAGLINI et al., 2014), três espécies do grupo Parviflora foram representadas, $P$. multicaule, $P$. hyalinum e $P$. parviflorum, e os resultados obtidos mostram que o grupo é parafilético, sendo $P$. hyalinum e $P$. parviflorum associados à espécies do grupo Plicatula e $P$. multicaule aparecendo como grupo irmão de $P$. maculosum Trin.

Morfologicamente, o grupo Parviflora é caracterizado por plantas monocárpicas ou policárpicas, delicadas, geralmente ramificadas na porção basal, com colmos de tamanhos diferentes na touceira, inflorescências com um a muitos ramos unilaterais espiciformes, espiguetas pequenas, solitárias ou aos pares, gluma superior e lema inferior frágeis (ZULOAGA \& MORRONE, 2005; CHASE, 1929; 1939 - não publicado).

Atualmente, sete espécies compõe o grupo Parviflora ( $P$. clavuliferum, $P$. 
crispatum, P. hyalinum, P. minarum, P. multicaule, P. parviflorum e P. scalare). Todas possuem registro para o território brasileiro e são encontradas na região neotropical, do México e Caribe até o Paraguai e sul do Brasil (FLORA DO BRASIL 2020, 2017; TROPICOS, 2017).

Diversas mudanças de espécies entre os grupos informais de Paspalum já ocorreram (NICOLA et al., 2014; BARRETO, 1974; CHASE, 1929; 1939 - não publicado), algumas destas nem sempre acompanhadas de uma justificativa clara e/ou detalhada (RODRÍGUEZ 1999). Sendo assim, adota-se aqui o seguinte conceito para Grupo informal: Conjunto de espécies, de um mesmo gênero, associadas a uma espécie central (que geralmente dá o nome ao grupo) por características morfológicas, tendo como finalidade a eficiência na identificação destas espécies. 


\section{OBJETIVOS}

\subsection{Objetivo geral}

A finalidade do presente trabalho foi a revisão taxonômica das espécies de Paspalum, grupo Parviflora (POACEAE), através de análises morfológicas e micromorfológicas.

\subsection{Objetivos específicos}

- Elaborar descrições morfológicas e micromorfológicas.

- Aumentar as coleções de herbário.

- Adicionar dados ecológicos e fitogeográficos.

- Produzir mapas de distribuição, imagens das espécies.

- Contribuir para o projeto Flora do Brasil 2020. 


\section{MATERIAIS E MÉTODOS}

\subsection{Coletas}

A coleta de materiais seguiram as técnicas usuais em taxonomia vegetal, descritas por WALTER \& CAVALCANTI (2005). Foram realizadas coletas em regiões restritas do Distrito Federal e dos estados de Goiás, Mato Grosso e Tocantins. Foram adicionados 25 números, de $P$. clavuliferum (2), P. hyalinum (7), P. multicaule (11) e P. scalare (5) aos materiais estudados.

\subsection{Análises morfológicas}

A morfologia foi analisada através de materiais herborizados e coletados em campo, sendo cerca de 285 materiais analisados. Os materiais herborizados, e estudados aqui, são provenientes dos seguintes herbários: $A L C B, B H C B, B H Z B, C E N, C E S J, C G M S$, FLOR, FURB, HEPH, HUEFS, HUFU, IAC, IBGE, ICN, IPA, MBM, RB, TEPB, UB, UEC, UFMT e VIC. Os acrônimos dos herbários seguem o Index Herbariorum (THIERS, 2017).

Além das exsicatas e de material coletado em campo, também foram feitas análises de imagens disponíveis em sites especializados, como speciesLink (splink.cria.org.br), Flora do Brasil 2020 (floradobrasil.jbrj.gov.br) e Tropicos $^{\circledR}$ (tropicos.org).

Para a coleta de dados quantitativos, relativos ao comprimento da bainha e comprimento e largura da lâmina foliar, foi padronizado a utilização apenas da segunda folha a partir da sinflorescência. A padronização das terminologias dos estados de caráter foi feita através das descrições de RADFORD (1986), quando disponível. 
Os dados de distribuição geográfica no Brasil, de ambiente e fenológicos foram baseados no material revisado dos herbários e coletados em campo. Para áreas fora do Brasil os dados de distribuição geográfica foram extraídos de TROPICOS (2017).

Os dados de tipos foram extraídos de TROPICOS (2017) e foram verificados individualmente com base na análise de cada Obra Princeps e através de imagens disponíveis em bancos de dados digitais. Os espécimes tipo observados (através de fotografia digital) estão indicados com um ponto de exclamação (!), logo após o acrônimo do herbário onde a amostra está depositada, como no exemplo:

“Paspalum cerradoense Oliveira, R. C. \& Valls, Phytotaxa 203(2): 160. 2015.

Tipo: R.C. Oliveira et al. 2693, BRASIL (HT: UB!, IT: CEN, MO)."

\subsection{Análises em Microscopia Eletrônica de Varredura}

Para os estudos em Microscópio Eletrônico de Varredura (MEV), foram utilizadas três espiguetas de cada uma das espécies do grupo Parviflora, com exceção de $P$. crispatum, ao qual foram incluídas apenas uma espigueta por superfície, por possuir-se pouco material disponível. Analisou-se a ornamentação da gluma superior, lemas e pálea superior.

As espiguetas foram obtidas de material herborizado, montadas com fita adesiva dupla-face de carbono em stubbs e metalizados com ouro, camada de $10 \mathrm{~nm}$, por um minuto. O processo de preparação e as eletromicrofotografias foram feitas no Laboratório de Microscopia Eletrônica da Universidade de Brasília. Foram selecionadas para as microfotografias as amostras/superfícies que melhor representavam o conjunto analisado. No total, foram geradas 155 microfotografias das espiguetas analisadas. 


\section{RESULTADOS E DISCUSSÕES}

\subsection{O gênero Paspalum L., grupo Parviflora}

Plantas monocárpicas ou policárpicas, densamente ramificadas na porção proximal (exceto $P$. scalare que também é ramificada distalmente), colmos floríferos com diferentes alturas na mesma touceira, espiguetas pequenas, de 0,6 a 2,5 mm de comprimento, solitárias ou aos pares, gluma superior e lema inferior delicados, eventualmente com rupturas naturais.

As sete espécies relacionadas como afins a Paspalum parviflorum, i.e., grupo Parviflora, ocorrem na região Neotropical, do México e Caribe até Argentina e Brasil (TROPICOS, 2017). No Brasil ocorrem em todos os estados, sendo que P. minarum e P. scalare são endêmicas do país. P. crispatum é típica do Cerrado, ocorrendo no Brasil, Bolívia e Paraguai (FIGURA 1).

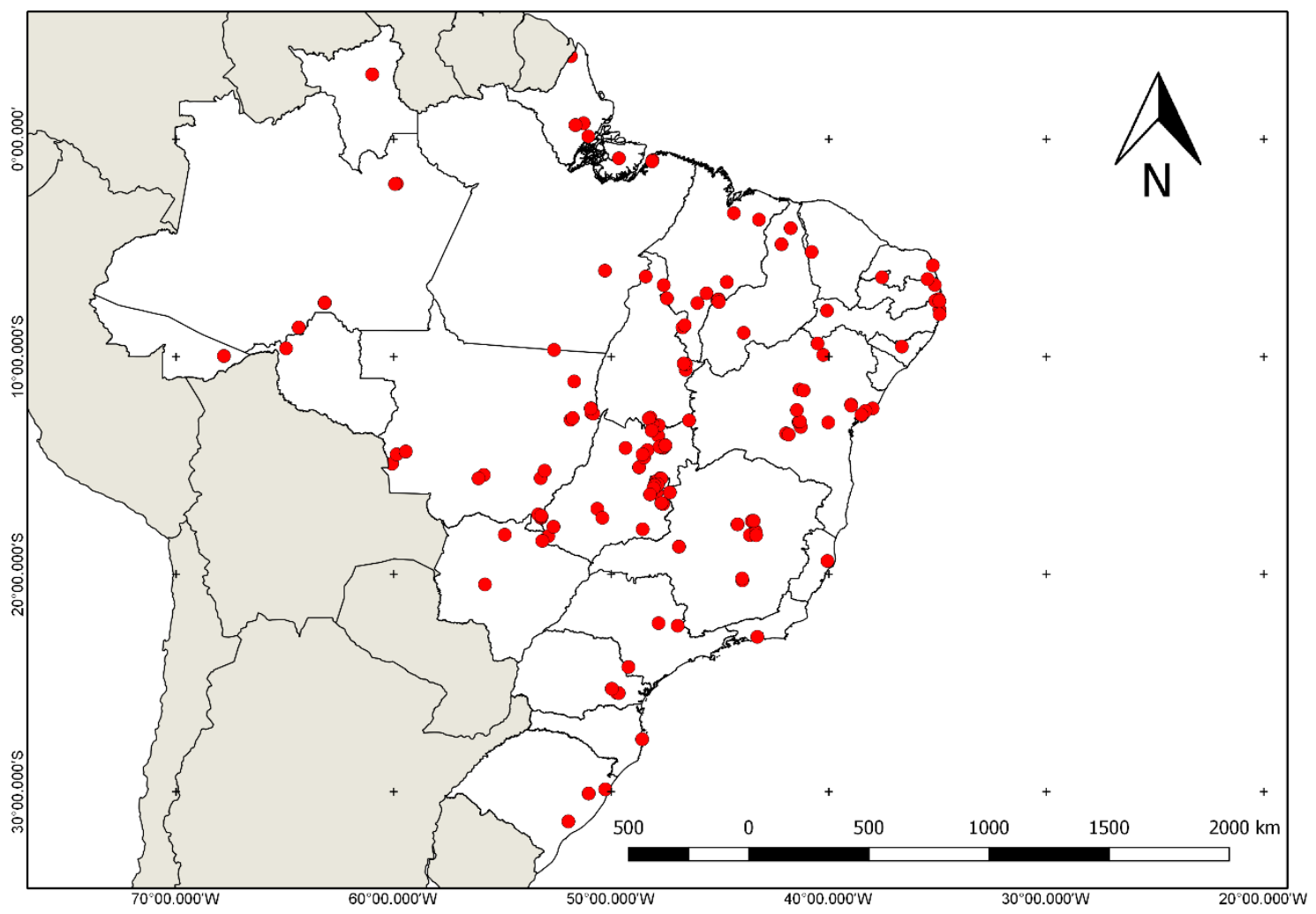

Figura 1. Mapa com os registros de distribuição de Paspalum L., grupo Parviflora, no Brasil. 
Os caracteres micromorfológicos que demonstraram ter valor taxonômico, para a distinção das espécies dentro do grupo Parviflora foram: a presença e formato (capitado, falcado, colunar e claviforme) dos tricomas, na gluma e lema inferior; e ocorrência de papilas (simples ou conjugadas) no lema superior e pálea. 


\subsubsection{Chave de identificação para espécies de Paspalum L., grupo Parviflora.}

1. Espiguetas pareadas

2. Plantas monocárpicas

P. clavuliferum

2'. Plantas policárpicas 3

3. Lema inferior e gluma com tricomas falcados, lema inferior sem depressão por toda a porção mediana P. scalare

3'. Lema inferior e gluma com tricomas encaracolados, lema inferior com depressão por toda a porção mediana P. crispatum

4. Plantas monocárpicas . 5

5. Lema inferior e gluma com tricomas capitados, espiguetas orbiculares de $1,0-1,4 \times 0,9-1,1 \mathrm{~mm}$ P. multicaule

5'. Lema inferior e gluma com tricomas colunares, espiguetas elípticas de 0,6 $-1,0 \times 0,4-0,6 \mathrm{~mm}$ P. parviflorum

4'. Plantas policárpicas 6

6. Espiguetas de $1,8-2,5 \times 1,0-1,3 \mathrm{~mm}$, cicatriz em forma de ' $\mathrm{V}$ ' na base do lema inferior presente, lema inferior sem porção hialina P. minarum

6 '. Espiguetas de 1,0 - 2,0 0 0,5 - 1,0 mm, cicatriz em forma de ' $V$ ' na base do lema inferior ausente, lema inferior geralmente com porção hialina. P. hyalinum 
4.1.2 Paspalum clavuliferum C. Wright, Anales Acad. Ci. Med. Habana 8: 203. 1871.

Tipo: C. Wright 3444, CUBA (HT: GH!, IT: B!, NY!, US).

Paspalum falcula Döll, Fl. Bras. 2(2): 60. 1877.

Tipo: P. Salzmann 675, BRASIL (LT: W!, ILT: US!).

Paspalum pittieri Hack. ex Beal, Grass. N. Amer. 2: 88. 1896.

Tipo: C.G. Pringle 2359, MEXICO (HT: MSC, IT: K!, MO!, NY!, US!, W!).

Plantas monocárpicas, cespitosas, colmo florífero de 5,0 - $47 \mathrm{~cm}$, ramificações proximais, 2 a 4 nós, glabros; bainhas foliares de 1,1-7,6 $\mathrm{cm}$ de comprimento, pilosa na face abaxial, os tricomas lineares de base tuberculada; colar presente, geralmente uma linha em coloração amarelada ou acastanhada; lígula membranosa, 0,5 - 1,5 mm de comprimento, com cílios ao redor, geralmente maiores que a lígula; lâmina foliar 1,1 $10,8 \times 0,08-0,30 \mathrm{~cm}$, planas, lineares a linear-lanceoladas, base truncada a obliqua, ápice agudo, pilosa em ambas as superfícies, na maioria das vezes com maior concentração do que na bainha, os tricomas lineares de base tuberculada, margem ciliada, com tricomas escabrosos intercalados com tricomas lineares de base tuberculada, estes em menor concentração. Sinflorescências terminais e axilares, com 1 a 2 (3) ramos unilaterais espiciformes, quando 2, conjugados ou subconjugados no ápice do colmo florífero, frequentemente arqueados, de 0,9 $-5,6 \mathrm{~cm}$ de comprimento, normalmente terminando com uma espigueta desenvolvida; pedúnculo de 3,2 a 17,5 cm de comprimento; ráquis membranácea, com cerca de 0,4 $\mathrm{mm}$ de largura; pedicelos de 0,5 - 1,0 mm de comprimento, pilosos, tricomas menores que $0,5 \mathrm{~mm}$ de comprimento; espiguetas $1,0-1,5 \times 0,7-0,8 \mathrm{~mm}$, planoconvexas, elíptico-obovadas, pareadas, frequentemente uma das espiguetas do par pode estar ausente; gluma superior 1,0 - 1,5 
X 0,7 - 0,8 mm, membranácea, delicada (frequentemente dando aparência de estar aderida ao antécio), trinervada, geralmente do mesmo tamanho do antécio superior, podendo ser pouco menor, deixando parte do lema superior exposto, com tricomas claviformes, geralmente recobrindo toda superfície; lema inferior 1,0 - 1,5 X 0,7 - 0,8 mm, membranáceo, trinervado, a central podendo estar ausente, com tricomas claviformes, comumente concentrados nas margens; antécio superior 1,0 - 1,5 X 0,7 - 0,8 mm, crustáceo, estramíneo, glabro, papiloso, lustroso (FIGURA 2); lodículas com cerca de 0,2 mm; 3 anteras e 2 estigmas; cariopse 0,6 X 0,9 mm, oboval; hilo oboval.

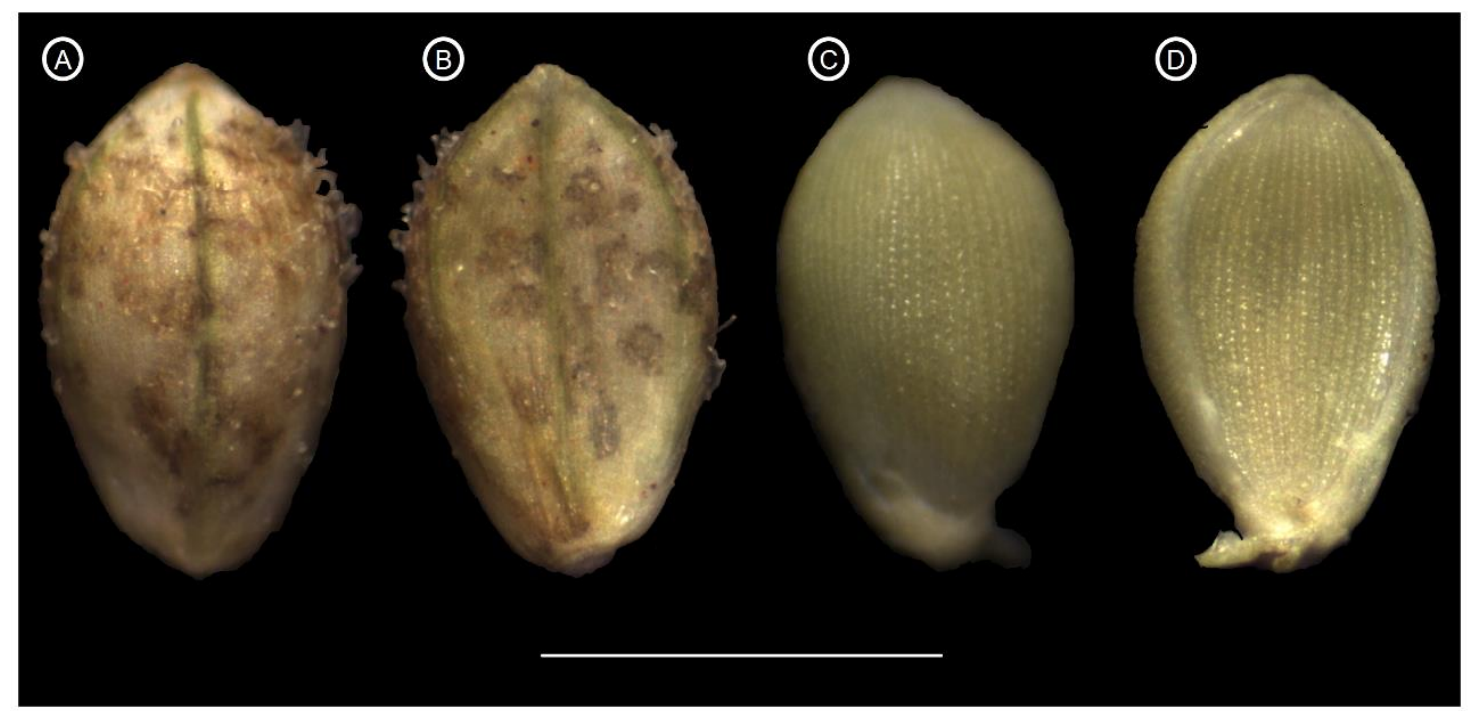

Figura 2. Espigueta de Paspalum clavuliferum (Moura, C.O. 42); A - Gluma superior, B - Lema inferior, $C$ - Lema superior, D - Pálea. Barra de escala $=1 \mathrm{~mm}$.

P. clavuliferum apresenta tricomas claviformes ornamentando a gluma superior e lema inferior, e papilas conjugadas na superfície do lema superior e pálea superior (FIGURA 3). 

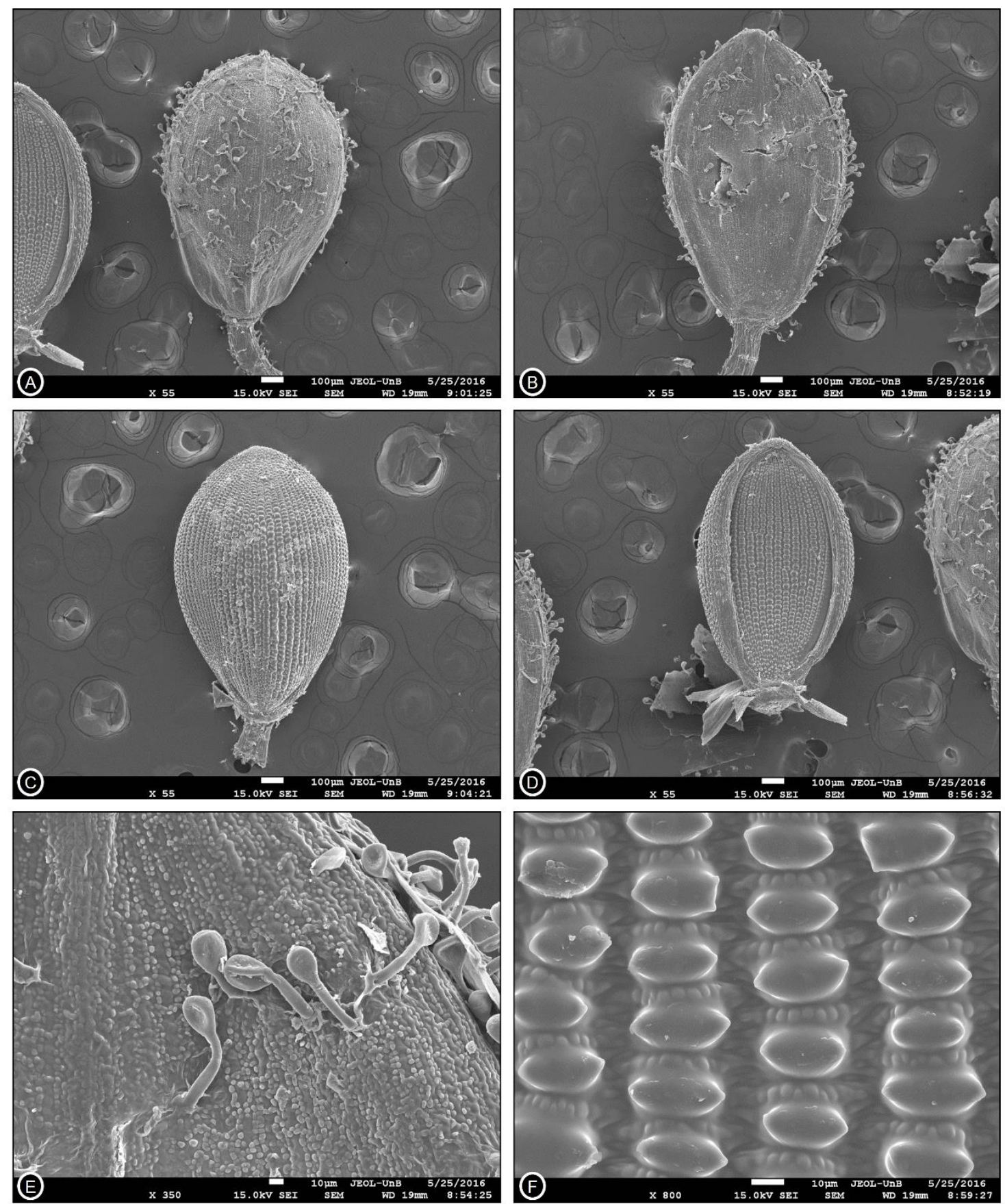

Figura 3. Microfotografia de Paspalum clavuliferum (Moura, C.O. 42); A - Gluma superior, B Lema inferior, $\mathrm{C}$ - Lema superior, D - Pálea, E - Tricomas clavados, F - Papilas conjugadas.

\section{Distribuição geográfica e aspectos ecológicos}

Ocorre na região Neotropical, desde o México e Antilhas até a Bolívia e Brasil. No Brasil, é encontrada nos estados de Alagoas, Bahia, Ceará, Distrito Federal, Goiás, Maranhão, Mato Grosso, Minas Gerais, Paraíba, Pernambuco, Piauí, Rio de Janeiro, Rio 
Grande do Norte, Sergipe e Tocantins (FIGURA 4). Possui registro para os domínios da Caatinga, Cerrado e Mata Atlântica. Está presente em formações campestres, savânicas e cerradão, geralmente habitando ambientes úmidos ou encharcados, de solo arenoso e/ou rochoso, mas também podendo ser encontrada em ambientes secos de cerrado e antropizados.

De acordo com a International Union for Conservation of Nature (IUCN), P. clavuliferum está classificado como Least Concern (LC) ou seja, pouco preocupante. Estão nesta categoria espécies que tem ampla distribuição e são abundantes na natureza.

Época de florescimento e frutificação: concentrada entre nos meses de Fevereiro, Março, Abril, Maio, Junho, Julho, Outubro e Dezembro.

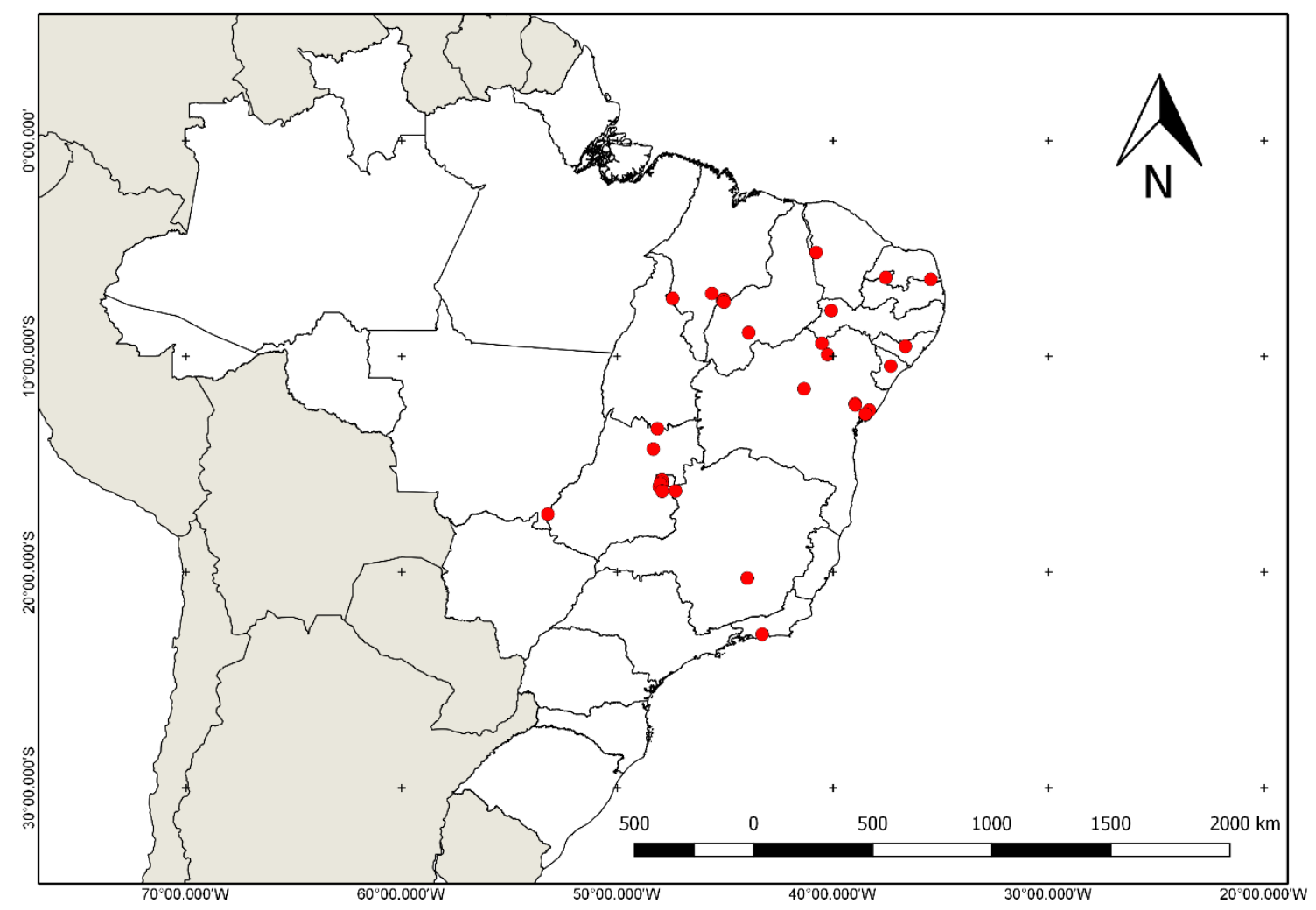

Figura 4. Mapa com os registros de distribuição (pontos vermelhos) confirmados de Paspalum clavuliferum. 


\section{Comentários Taxonômicos}

Paspalum clavuliferum se assemelha a $P$. multicaule por causa do hábito e da pilosidade das espiguetas. Distinguem-se por $P$. clavuliferum possuir espiguetas elípticoobovadas, dispostas aos pares, embora frequentemente uma das espiguetas do par abortada e por apresentar uma espigueta desenvolvida no ápice do ramo florífero. Já $P$. multicaule, apresenta espiguetas orbiculares, sempre solitárias e terminam em espiguetas ou a própria ráquis subdesenvolvida.

Outra espécie frequentemente confundida com $P$. clavuliferum em identificações de herbário é $P$. pictum, do grupo Gardneriana. Embora existam semelhanças, $P$. clavuliferum pode ser distinguida de $P$. pictum por possuir tricomas claviformes na gluma superior e lema inferior, e por estas peças cobrirem todo o antécio superior (eventualmente a gluma sendo pouco menor que o antécio) e as papilas do antécio superior são pouco proeminentes, inconspícuas. Em P. pictum as espiguetas são glabras, a gluma superior tem de $1 / 2$ a $3 / 4$ do tamanho do antécio superior, e este é conspicuamente papiloso (ZULOAGA \& MORRONE, 2005).

CHASE (1939 - não publicado) e ZULOAGA \& MORRONE (2005) descrevem a espécie com a lígula variando entre 0,5 a 1,0 mm de comprimento e raramente com 1,5 $\mathrm{mm}$. Foram registradas com frequência no presente trabalho, lígulas de $1,5 \mathrm{~mm}$ de comprimento. ZULOAGA \& MORRONE (2005) citam pedúnculos com até $27 \mathrm{~cm}$ comprimento, aqui só foram observados até $17,5 \mathrm{~cm}$. Aqui pode haver um problema na padronização do ponto inicial do pedúnculo. Espiguetas que podem variar de 1,1 a 1,6 mm de comprimento foram relatadas (CHASE, 1939 - não publicado; ZULOAGA \& MORRONE, 2005). Entre os exemplares analisados no presente trabalho, a amplitude de 
variação do comprimento das espiguetas foi diferente, variando de 1,0 a $1,5 \mathrm{~mm}$. Além disso, foram observados hilos obovais, enquanto que ZULOAGA \& MORRONE (2005) descrevem os mesmos como punctiformes.

\section{Histórico dos sinônimos}

Paspalum clavuliferum foi descrito por C. Wright, na obra Anales de la Academia de Ciencias Medicas (1871), baseado em sua coleta de número 3444, feita em Cuba orientali, Cuba.

Posteriormente, J. C. Döll descreve, na Flora Brasiliensis (1877), P. falcula Döll tendo como tipos os espécimes de número 675 e 1830 de P. Salzmann, coletados na Bahia, Brasil. Nesta mesma obra, Döll cita o sinônimo P. hortícola Salzm. ex Döll tendo por base anotações de Salzmann, em sua coleta 1830.

Em 1896, W. J. Beal, descreve P. pittieri Hack. ex Beal, na obra Grasses of North America for Farmers and Students. Beal, descreve este nome a partir de anotações de E. Hackel, até então sem descrição válida, utilizando a coleta de C. G. Pringle 2359, feita no estado de Jalisco, México. Em seguida, no ano de 1901, Hackel publica uma descrição para P. pittieri Hack., excluindo Beal da autoria e indica o voucher Pittier 507, coletado em Llanos de Tunicares, Costa Rica.

ZULOAGA \& MORRONE (2005) lectotipificaram o voucher P. Salzmann 1830 (B, K, P e W) de $P$. falcula. Porém, CHASE (1929; 1939 - não publicado) destacou que nenhum exemplar com este número havia sido encontrado, na época, e o único espécime analisado aqui, com indicação de síntipo, feita por F. O. Zuloaga e O. Morrone, foi P. Salzmann 675 (W 1904-0012180 e US 00140645). Nenhum material de P. Salzmann com 
número 1830 foi encontrado. Assim, recomenda-se que o voucher P. Salzmann 675 (W) seja adotado como lectótipo do nome.

\section{Materiais Examinados}

ALAGOAS. Igaci: Posto Agropecuário, Julho, 1959, A. Sarmento 318 (UB, IPA, CEN). BAHIA. Alagoinhas: $18 \mathrm{~km} \mathrm{~N}$ of Alagoinhas, along Highway BR-116, Abril, 1976, G. Davidse 11710 (MBM). Camaçari: Área controle da Caraíba Metais, 1229'35"S/1240'17"S 3818'47"W/3829'40”W, 1983, L.R. Noblick 2527 e 2550 (HUEFS). Entre Rios: BR - 101 Entre Rios - Esplanada, km 56, Julho, 1980, L. Coradin 3032 e 3034 (CEN). Feira de Santana: Campus UEFS, 1211'51'S 385'14”W, 2006, E. Melo 4441 (HUEFS) e, 1215'S 3858'W, 1982, L.R. Noblick 2074B (HUEFS). Juazeiro: 1922, C.

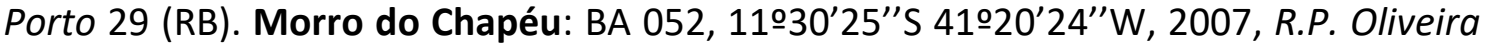
1257 (HUEFS). Senhor do Bonfim - Juazeiro: BA 130, 955'S 4015'W, Fevereiro, 1974, R.M. Harley 16327 (CEN, UB, IPA, HUEFS). CEARÁ. Crateús: BR-045, km 17, Crateús - Tauá - beira da estrada, Junho, 1979, L. Coradin 2019 (CEN). Estrada Crateús - Tucuns a 9,7 km de Crateús, $5^{\circ} 11^{\prime} 00^{\prime \prime}$ S, 4047'00"O, Maio, 1988, L. B. Bianchetti 677 (CEN). Quixadá: Junco to Quixadá, Maio, 1934, J.R. Swallen 4454 (RB). Sobral: Março, 1945, Black 74, 93C e 117C (UB). Quixeramobin: Km 54/Quixeramobin - Crateús, Junho, 1979, L. Coradin 1996 (CEN). Santa Quiteria: CE-032, km 70/Sobral - Canindé/beira de estrada, Junho, 1979, L. Coradin 1955 (CEN). DISTRITO FEDERAL. Brasília: Parque Nacional de Brasília, Cascalheira do Centro de Visitantes, $15^{\circ} 44^{\prime} 06^{\prime \prime} \mathrm{S} 47^{\circ} 55^{\prime} 37^{\prime \prime} \mathrm{W}$, Fevereiro, 2006, C. $R$. Martins 893 (UB). Fazenda Sucupira, Cerrado a direita da estrada principal (antes da ponte), $15^{\circ} 54^{\prime} 12^{\prime \prime} S, 48^{\circ} 00^{\prime} 37^{\prime \prime} \mathrm{O}$, Março, 2007, C. G. Fontes 78 (UB). 154' $53^{\prime \prime} S$ 
47055'34”W, Junho, 2004, C.R. Martins 423 (UB). (Gama): Parque Vivencial do Gama (Prainha), 1602'20"S 4803'04”W, Abril, 2015, C.O. Moura 42 (UB). (Park Way): Fazenda Água Limpa, 1554'44”S 47ํ5'33,3”W, Março, 2015, C.O. Moura 43 (UB). (Riacho Fundo): Área de Relevante Interesse Ecológico Santuário da Vida Silvestre do Riacho Fundo, 1550'50”S 47ํ5'50”'W, Abril, 1999, R. Rodrigues-da-Silva 132 (UB). ESPÍRITO SANTO. Linhares: Reserva Florestal da CVRD, Fevereiro, 2007, P. L. Viana 2580 (BHCB). GOIÁS. Chapada dos Veadeiros: Março, 1969, H.S. Irwin 24516 (UB). Luziânia: km 20 da BH - Brasília, Maio, 1981, J.C. Dianese 43 (UB). Minaçu: Cerca de 200 metros antes do portão de entrada da obra à jusante da barragem, $13^{\circ} 21^{\prime} 02^{\prime \prime} \mathrm{S} 48^{\circ} 08^{\prime} 21^{\prime \prime} \mathrm{O}$, Março, 2001, G. Pereira-Silva 4809 (CEN). Niquelandia: Clareira no cerrado, estrada para Codemin, $14^{\circ} 17^{\prime} 38^{\prime \prime}$ S, $48^{\circ} 19^{\prime} 47^{\prime \prime}$ O, Janeiro, 2006, J.F.B. Pastore 1390 (CEN). Rio Quente: Pousada do Rio Quente, perto de Morrinhos, Janeiro, 1969, J. F. M. Valls 689 (ICN). MATO GROSSO. Santa Rita do Araguaya: Rio Araguaya, Abril, 1930, A. G. Chase 11790 (RB). MARANHÃO. Balsas: 11,5 km a nordeste de Vale verde e cerca de $18 \mathrm{~km}$ a sudoeste de São Raimundo na BR 230, 0705 S 04537W, Março, 1985, J. F. M. Valls 8420 (CEN, ICN). Carolina: $3 \mathrm{~km}$ ao norte da bifurcação para estreito e para Balsas na saída de Carolina (BR - 230), 0719S 04726W, Março, 1985, J. F. M. Valls 8349 (CEN). Caxias - Barra do Corda: Fevereiro, 1934, J.R. Swallen 3517 (IAC). Loreto: Ilha de Balsas, 7이'S 457'W,

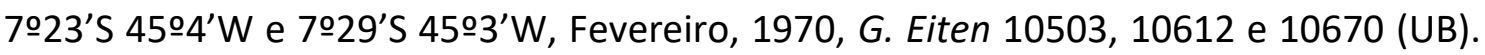
Loreto: Estrada para fazenda Morros ao sul de Loreto. $7^{\circ} 21^{\prime} 21^{\prime \prime} \mathrm{S} 45^{\circ} 3^{\prime} 57^{\prime \prime} \mathrm{W}$, Fevereiro, 1999, M.F. Simon 145 (CEN, UB). MINAS GERAIS. Itabirito: Sítio Largatixa, próximo a BR

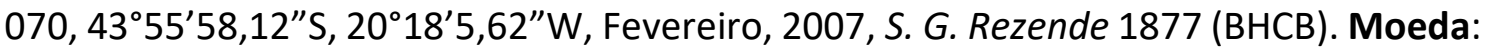
Serra da moeda, 2017'4,25”S 4358'14”W, 2010, J.C. Camargos 145 (BHCB). Unai: Entrada da Fazenda à direita, na estrada de acesso para a UHE Queimado, cerca de 2,5 


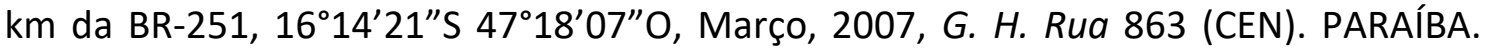
Condado: Posto Agrícola, 1933, Luetzelburg 23681 (UB, IPA). PERNAMBUCO. Ouricuri: de Jutaí a Santa Cruz, entre o rio das Garças e o riacho Volta, Maio, 1971, E.P. Heringer 446 (CEN, UB). Ouricuri: Faz. Estaca, Abril, 1983, G. C. Lima 057 (CEN). Parnamirim: Km 5 da estrada Parnamirim-Petrolina, Abril, 1984, Fátima Araújo 17 (CEN). Petrolina: Rodovia - Petrolina - Afrânio km 75, Abril, 1979, L. Coradin 1326 (CEN). Petrolina: Distrito de Nilo Coelho, Março, 1991, P. E. Nogueira 239 (ICN). PIAUÍ. Caracol: Parque Estadual Serra das Confusões, 854'0"'S 4354'26"W, Fevereiro, 2011, K.M. Pimenta 233, 234, 237 e 238 (HUEFS). RIO DE JANEIRO. Rio de Janeiro: Horto Florestal - Gávea, Dezembro, 1928, J. G. Kuhlmann s.n. (RB). RIO GRANDE DO NORTE. Santo Antônio: Próximo ao povoado de Lagoa Limpa, 625'47"S 3526'84"W, Maio, 2009, R.C. Oliveira 2425 (UB). Serra Negra do Norte: Estação Ecológica do Seridó, Abril, 2007, R.C. Oliveira 1876 (HUEFS). SERGIPE. São Miguel do Aleixo: Julho, 2014, Gonçalves, F.B. 285 (RB). TOCANTINS. Tocantinópolis: Estrada vicinal junto à Ferrovia Norte Sul, km 18G., 0638'50"S 4729'56"'W, Fevereiro, 2005, Pereira-Silva (9440). 
4.1.3 Paspalum crispatum Hack., Repert. Spec. Nov. Regni Veg. 7: 370. 1909.

Tipo: T. Rojas 10789, PARAGUAY (HT: W!, IT: B, BM, G, K, LIL, NY!, P!, US!, W!).

Plantas policárpicas, cespitosas, colmo florífero de $45-70 \mathrm{~cm}$, ramificações proximais, 5 a 9 nós, de glabros a pilosos, quando pilosos, geralmente nos nós mais basais; bainhas foliares de $4,7-10 \mathrm{~cm}$ de comprimento, pilosa na face abaxial, geralmente os tricomas concentrados na base da bainha e/ou nas bainhas mais basais, tricomas lineares, alguns de base tuberculada, com até $5 \mathrm{~mm}$ de comprimento; colar presente, as vezes inconspícuo, formando um enrugamento nas bordas, com coloração levemente mais escurecida; lígula membranosa, 1,0 - 2,0 mm de comprimento, com cílios ao redor, com até $5 \mathrm{~mm}$; lâmina foliar $2,0-5,4 \times 0,08-0,25 \mathrm{~cm}$, planas, lineares a linear-lanceoladas, base truncada, ápice agudo, pilosa em ambas as superfícies, os tricomas de dois tipos, lineares de base tuberculada, com até $5 \mathrm{~mm}$ e lineares não tuberculados, mais finos, de até $2 \mathrm{~mm}$, margem ciliada, com tricomas lineares de base tuberculada. Sinflorescências terminais, com 2 a 8 ramos unilaterais espiciformes, não conjugados, de $0,6-4,5 \mathrm{~cm}$ de comprimento, os basais mais longos que os apicais; pedúnculo de 13,7 - $21 \mathrm{~cm}$ de comprimento; ráquis membranácea, com cerca de 0,5 $\mathrm{mm}$ de largura; pedicelos de $0,5-1,0 \mathrm{~mm}$ de comprimento, pilosos; espiguetas $1,4-1,8$ X 0,4 - 0,6 mm, plano-convexas, com depressão na região mediana do lema inferior, elípticas, pareadas, frequentemente uma das espiguetas do par pode estar ausente, ou subdesenvolvida; gluma superior $1,2-1,8 \times 0,4-0,6 \mathrm{~mm}$, membranácea, delicada, bi a trinervada, quando binervada a central suprimida, igual ou menor que o antécio superior, nunca menor que $2 / 3$, com tricomas encaracolados geralmente recobrindo toda superfície; lema inferior $1,4-1,8 \times 0,4-0,6 \mathrm{~mm}$, membranáceo, tetra a 
pentanervado, a central comumente ausente, com tricomas encaracolados; antécio superior 1,4-1,8 X0,4-0,6 mm, de consistência cartácea, estramíneo, glabro, papiloso, levemente lustroso (FIGURA 5); lodículas com cerca de 0,2 mm; 3 anteras e 2 estigmas; cariopse não vista.

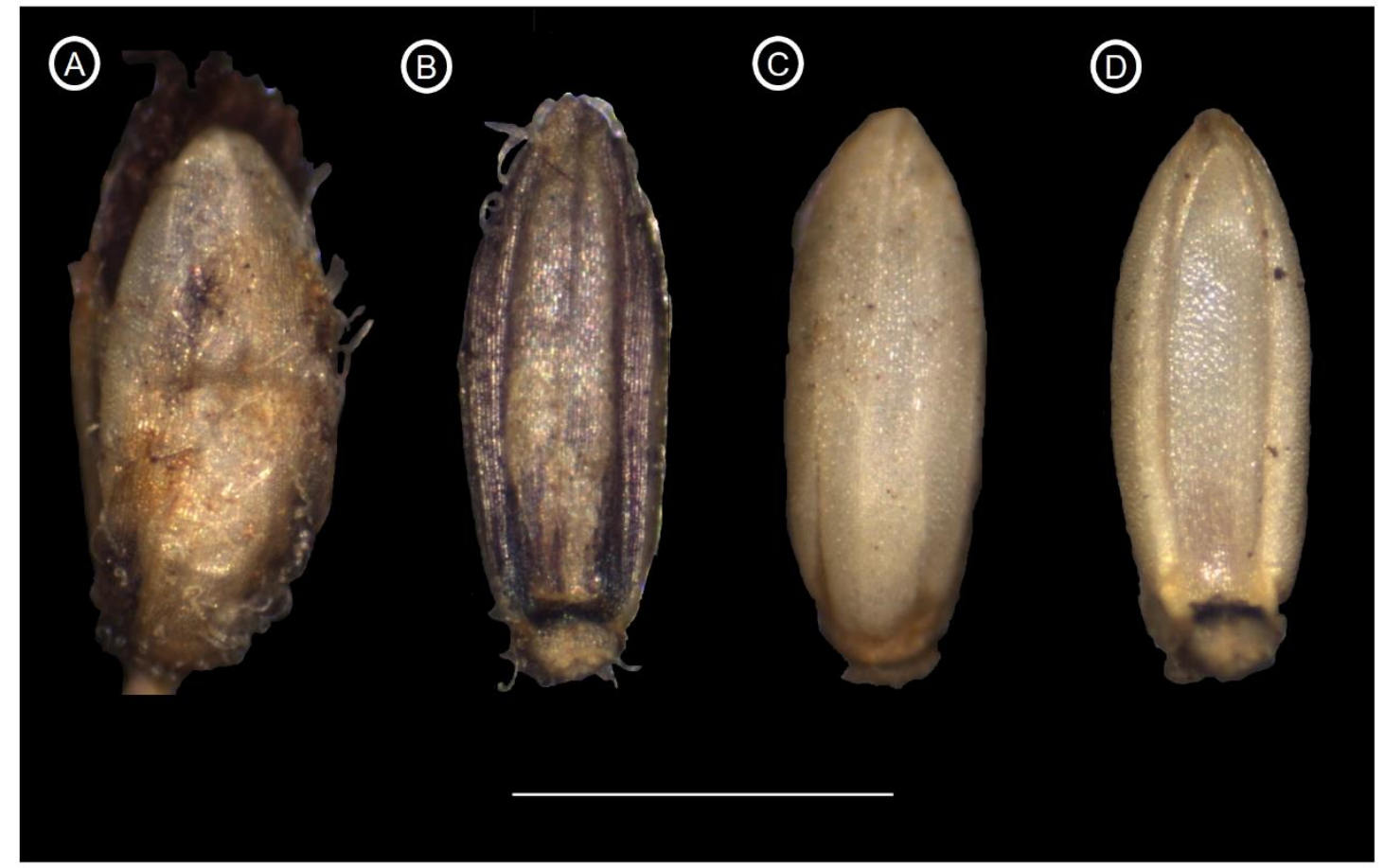

Figura 5. Espigueta de Paspalum crispatum (Wood, J.R.I. 24345); A - Gluma superior, B - Lema inferior, $C$ - Lema superior, D - Pálea. Barra de escala $=1 \mathrm{~mm}$.

P. crispatum apresenta tricomas encaracolados ornamentando a gluma superior e lema inferior, e papilas simples na superfície do lema superior e pálea superior (FIGURA 6). 

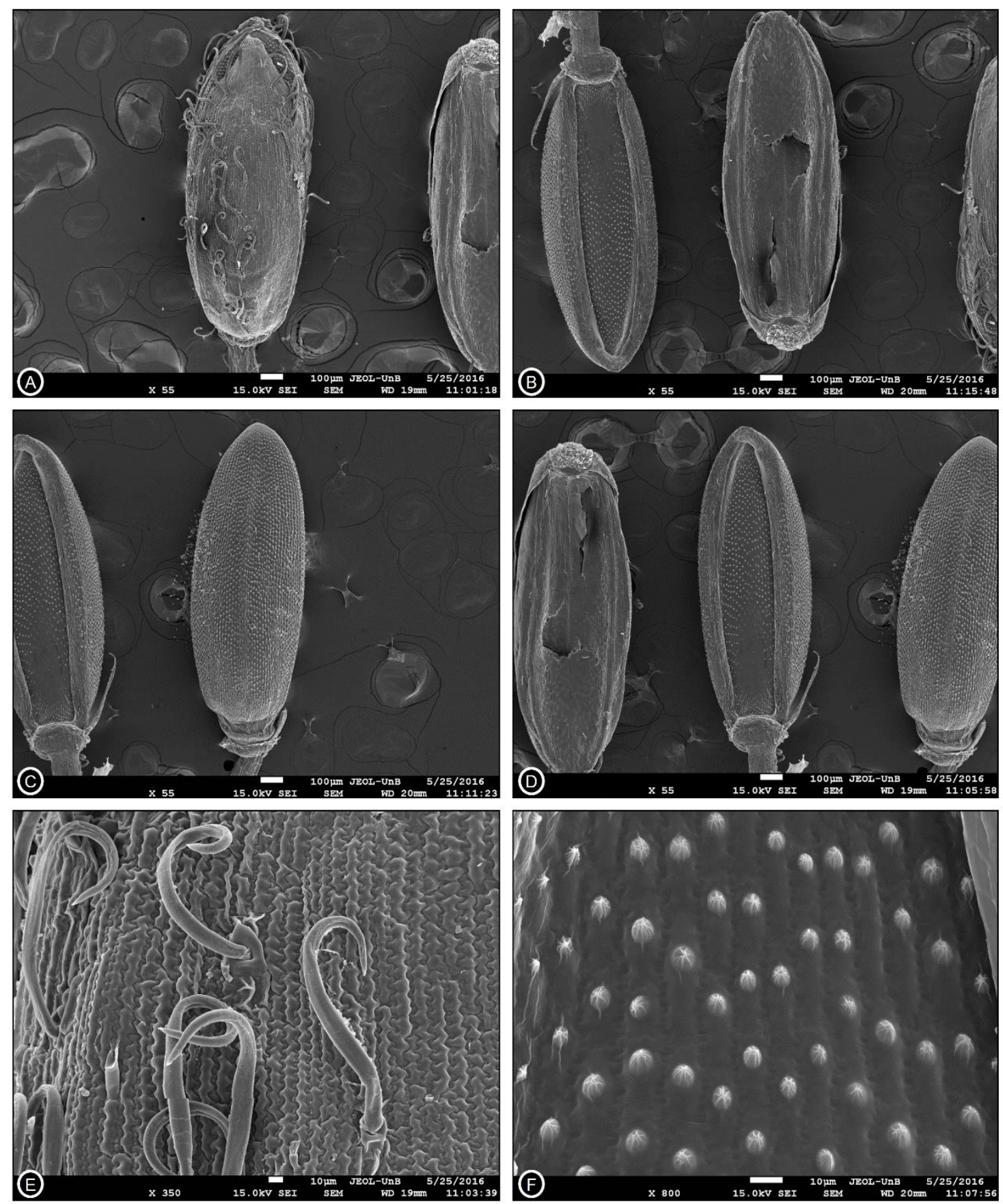

Figura 6. Microfotografia de Paspalum crispatum (Wood, J.R.I. 24345); A - Gluma superior, B Lema inferior, C - Lema superior, D - Pálea, E - Tricomas encaracolados, F - Papilas simples.

\section{Distribuição geográfica e aspectos ecológicos}

Ocorre na região Neotropical, na porção central da América do Sul, possuindo registros para Bolívia, Brasil e Paraguai. No Brasil, é encontrado nos estados de Goiás e Mato Grosso (FIGURA 7). Possuindo registros apenas para o domínio Cerrado. Está 
presente em formações campestres, habitando ambientes de brejo e campo de várzea, com solo arenoso e úmido.

Época de florescimento e frutificação: Março e Abril.

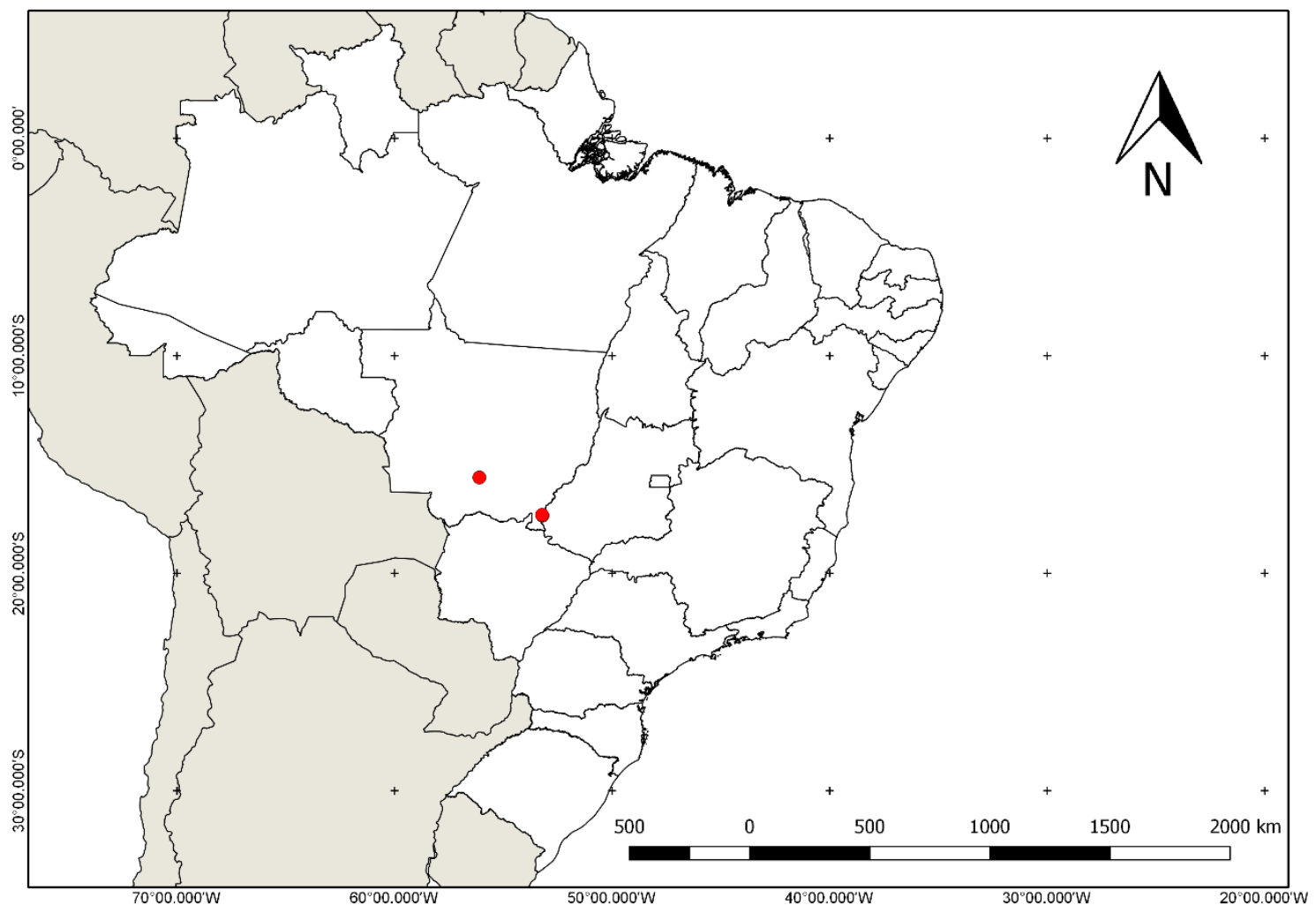

Figura 7. Mapa com os registros de distribuição (pontos vermelhos) confirmados de Paspalum crispatum.

\section{Comentários Taxonômicos}

Paspalum crispatum é afim a $P$. scalare, sendo diferenciadas pelos tricomas encaracolados na gluma superior e lema inferior e pela depressão, que se estende da base até próximo ao ápice, na região mediana do lema inferior. A gluma superior e o lema inferior de $P$. scalare são ornamentadas por tricomas falcados, a depressão do lema inferior, quando visível, é limitada à porção proximal.

O último registro de coleta de $P$. crispatum para o Brasil é de 1975, feito por G. 
Hatschbach (36088, MOBOT), nos arredores do município de Santo Antônio de Leverger, Mato Grosso. Este material, com determinação feita por A.S. Vega \& Z. Rúgolo de Agrasar, não foi analisado neste estudo.

Foram encontrados colmos floríferos com $45-70 \mathrm{~cm}$ de altura. CHASE (1939 - não publicado) e ZULOAGA \& MORRONE (2005) encontraram maior amplitude de variação, com colmos entre $30-75 \mathrm{~cm}$ de altura. Além disso, em ZULOAGA \& MORRONE (2005) foram registradas lígulas com cerca de $0,5 \mathrm{~mm}$, ramos unilaterais espiciformes de 1,5 $5,5 \mathrm{~cm}$ e pedicelos entre $0,5-1,5 \mathrm{~mm}$, os valores analisados neste trabalho para lígulas, ramos unilaterais espiciformes e pedicelos, foram respectivamente $1,0-2,0 \mathrm{~mm}, 0,6-$ $4,5 \mathrm{~cm}$ e $0,5-1,0 \mathrm{~cm}$.

As espiguetas examinadas apresentam uma variação de largura entre 0,4 - 0,6 mm, já em CHASE (1939 - não publicado) e ZULOAGA \& MORRONE (2005) essa variação é de 0,6 - 0,7 mm. CHASE (1939 - não publicado) relatou lema inferior normalmente tetranervado. Entretanto, nos exemplares analisados a nervura central é comumente desenvolvida, assim sendo, o lema é tetra/pentanervado. A observação de ZULOAGA \& MORRONE (2005) de lemas trinervados, não foi confirmada.

\section{Materiais Examinados}

GOIÁS. Santa Rita do Araguaya: Rio Araguaya, Abril, 1930, A. Chase 12051 (RB). MATO GROSSO. Cuiabá: Tucury, Março, 1918, J.G. Kuhlmann 1676 \& C. Rondon 1676 (RB). Santa Rita do Araguaya: Rio Araguaya, Abril, 1930, A. Chase 11841, 11844 (RB). 
4.1.4 Paspalum hyalinum Nees ex Trin., Gram. Panic. 103. 1826.

Tipo: K.F.P. von Martius s.n., BRASIL (LT: LE, ILT: BM, M, SI, US!).

Paspalum abstrusum Trin., Mém. Acad. Imp. Sci. Saint-Pétersbourg, Sér. 6, Sci. Math., Seconde Pt. Sci. Nat. 3,1(2-3): 135. 1834.

Tipo: F. Sellow 501, BRASIL (HT: LE, IT: B, US!).

Paspalum gossypinum Mez, Repert. Spec. Nov. Regni Veg. 15: 68. 1917.

Tipo: A. Weberbauer 4590, PERU (HT: B, IT: BAA, G, MO, US).

Paspalum polychaetum Mez, Bot. Jahrb. Syst. 56(Beibl. 125): 11. 1921.

Tipo: H.R. Wullschlaegel 580, SURINAME (HT: BR, IT: B, US).

Plantas policárpicas, cespitosas, colmo florífero de $18,5-63 \mathrm{~cm}$, ramificações proximais, 3 a 11 nós, geralmente glabros; bainhas foliares de 2,9 $-9,0 \mathrm{~cm}$ de comprimento, glabra a pilosa na face abaxial, os tricomas lineares de base tuberculada, de até 5,0 mm de comprimento; colar presente, as vezes inconspícuo, podendo aparecer apenas como uma mudança de coloração, enrugamento na região e/ou com a presença de tricomas lineares de até 6,0 $\mathrm{mm}$; lígula membranosa, 0,1-0,5 $\mathrm{mm}$ de comprimento, geralmente com cílios ao redor, de até $6,0 \mathrm{~mm}$ de comprimento; lâmina foliar 1,2 - 5,8 X 0,04-0,20 cm, planas a involutas, lineares a linear-lanceoladas, base truncada, ápice agudo, pilosa na face adaxial ou em ambas as superfícies, menos comumente glabras, os tricomas de dois tipos, lineares de base tuberculada, com até $5 \mathrm{~mm}$ de comprimento e menores sem base tuberculada, de até $2 \mathrm{~mm}$, margens glabras a ciliadas, com tricomas lineares de base tuberculada. Sinflorescências terminais, com (1) 2 a 9 (20) ramos unilaterais espiciformes, não conjugados ou eventualmente alguns conjugados, de $(0,3)$ $0,5-5,8 \mathrm{~cm}$ de comprimento; pedúnculo de $4,4-21,8 \mathrm{~cm}$ de comprimento; ráquis membranácea, de 0,4-0,8 $\mathrm{mm}$ de largura; pedicelos de 0,2-0,6 $\mathrm{mm}$ de comprimento, 
pilosos, tricomas menores que $0,4 \mathrm{~mm}$ de comprimento; espiguetas $1,0-2,0 \times 0,5-1,0$ $\mathrm{mm}$, plano-convexas, elípticas, solitárias; gluma superior $1,0-2,0 \times 0,5-1,0 \mathrm{~mm}$, membranácea, delicada, binervada, geralmente do mesmo tamanho do antécio superior, podendo ser levemente maior ou menor, glabra; lema inferior 1,0 - 1,9 X 0,5 1,0 mm, membranáceo, geralmente com a porção central hialina, binervado, mas ocasionalmente trinervado; antécio superior $0,9-1,9 \times 0,5-1,0 \mathrm{~mm}$, crustáceo, estramíneo, glabro, liso, lustroso (FIGURA 8); lodículas de 0,1-0,2 mm; 3 anteras roxas e 2 estigmas; cariopse não vista.

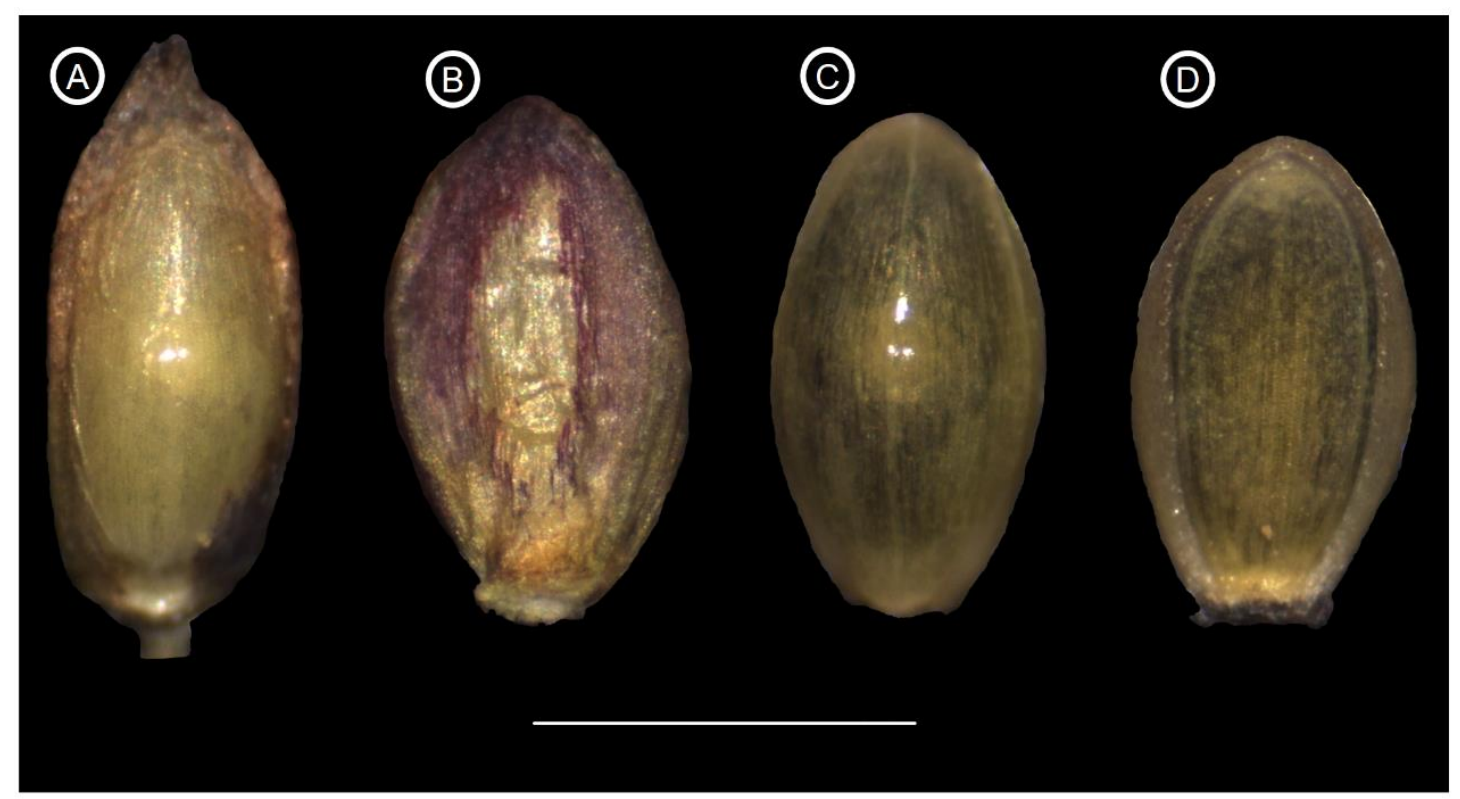

Figura 8. Espigueta de Paspalum hyalinum (Moura, C.O. 95); A - Gluma superior, B - Lema inferior, C - Lema superior, D - Pálea. Barra de escala $=1 \mathrm{~mm}$.

P. hyalinum não apresenta tricomas ornamentando a gluma superior e lema inferior, e possui papilas simples na superfície do lema superior e pálea superior (FIGURA 9). 

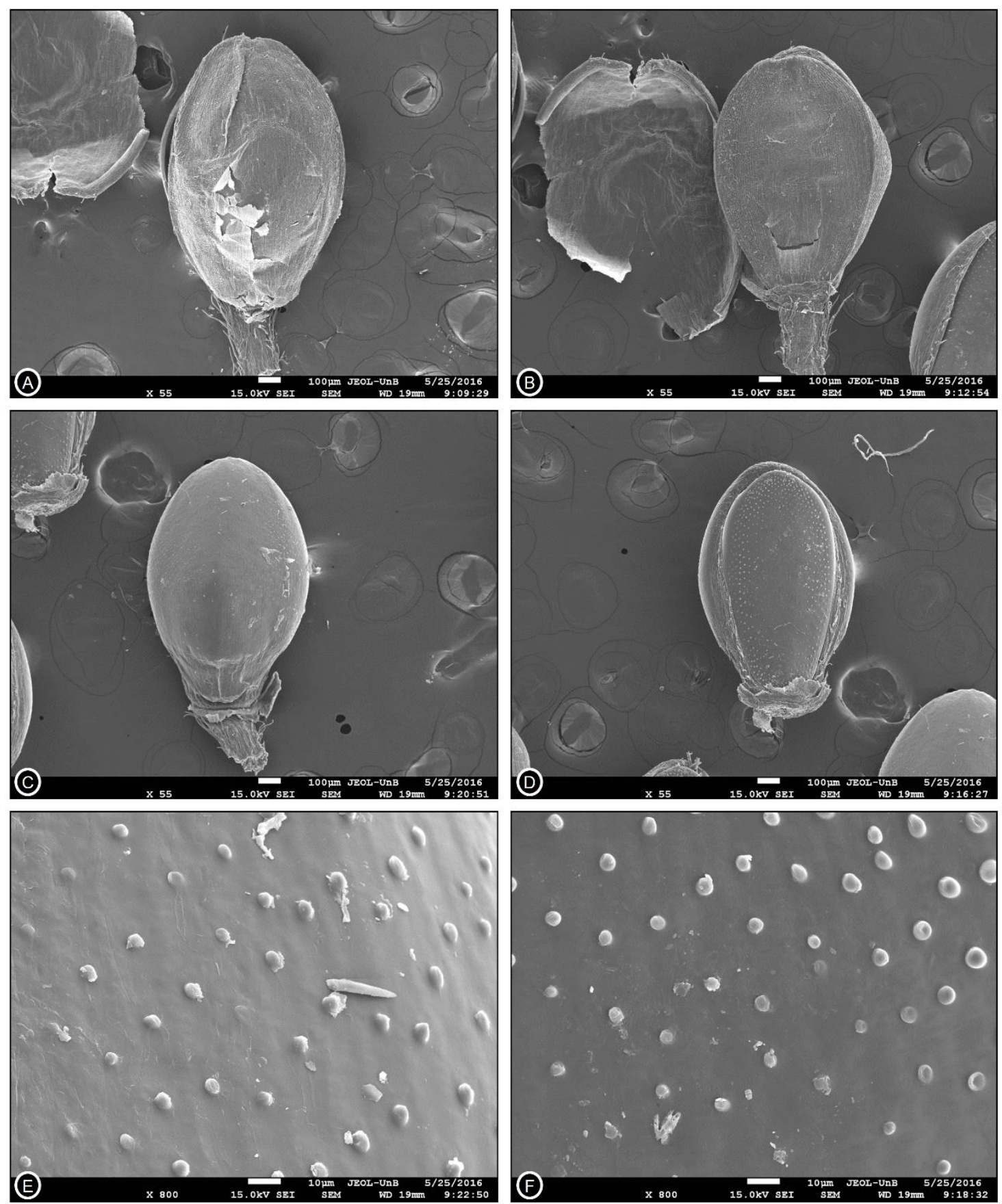

Figura 9. Microfotografia de Paspalum hyalinum (Moura, C.O. 68); A - Gluma superior, B Lema inferior, C - Lema superior, D - Pálea, E e F - Papilas simples.

\section{Distribuição geográfica e aspectos ecológicos}

Ocorre na região Neotropical, desde o norte da América do Sul até o sul do Brasil.

No Brasil é encontrado nos estados do Acre, Amazonas, Bahia, Distrito Federal, Goiás, Mato Grosso, Minas Gerais, Paraná, Rio Grande do Sul, Santa Catarina e São Paulo 
(FIGURA 10). Possui registro para os domínios da Amazônia, Caatinga, Cerrado, Mata Atlântica e Pampa. Está presente em formações campestres e savânicas, habitando ambientes de campo limpo, seco e úmido, campo rupestre, brejos, várzeas e cerrados, comumente em solos arenosos e úmidos.

Época de florescimento e frutificação: Durante os meses de Janeiro, Fevereiro, Março, Abril, Maio, Junho, Outubro, Novembro.

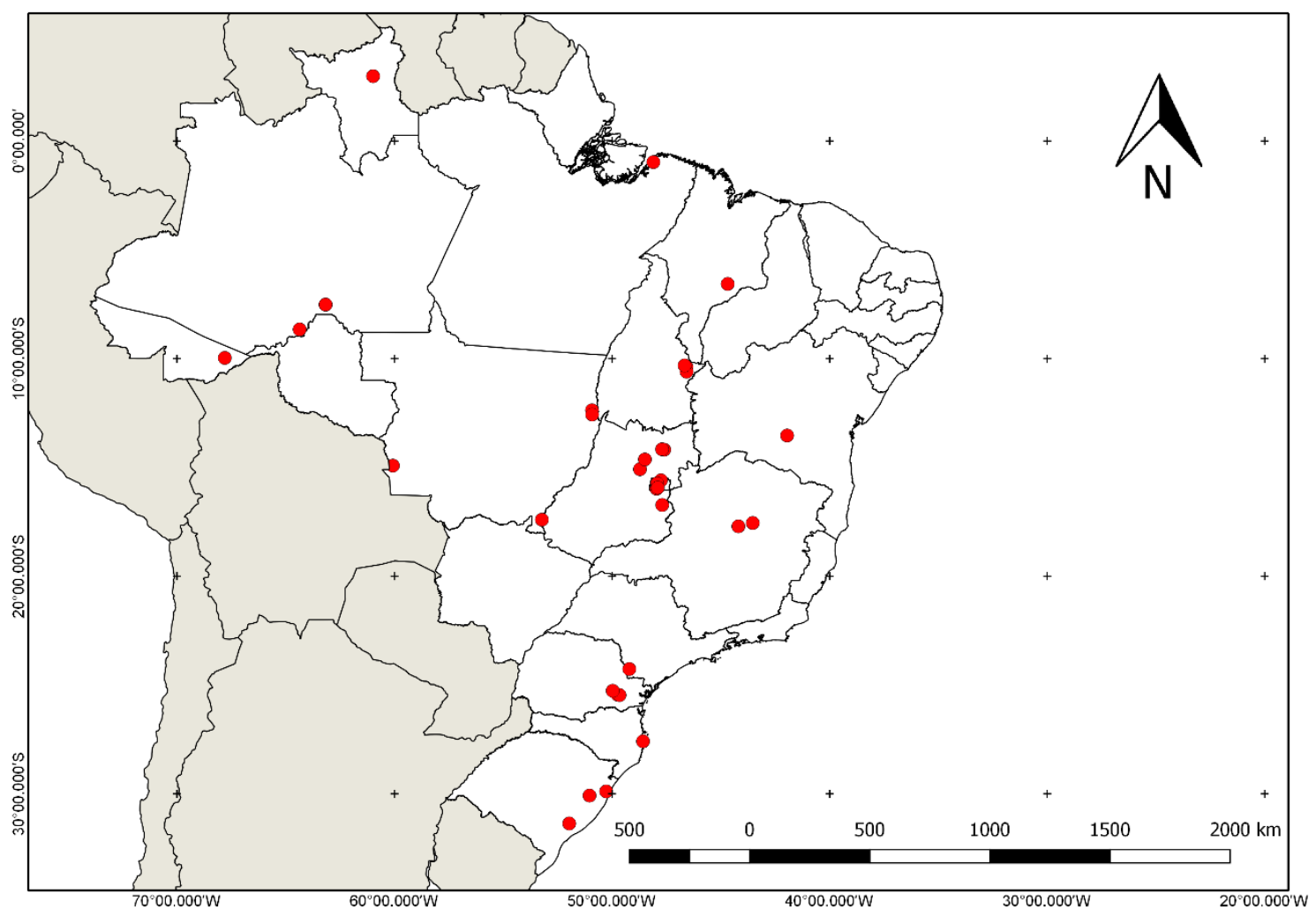

Figura 10. Mapa com os registros de distribuição (pontos vermelhos) confirmados de Paspalum hyalinum.

\section{Comentários Taxonômicos}

No grupo Parviflora, $P$. hyalinum é afim de $P$. minarum e eventualmente pode ser confundido em identificações de herbário com $P$. parviflorum. Diferencia-se de $P$. minarum por possuir no centro da gluma superior e lema inferior uma porção hialina 
(eventualmente inconspícua), pelo comprimento das espiguetas, em $P$. hyalinum variando de 1,0-2,0 mm, enquanto em $P$. minarum a amplitude é vai de $1,8-2,5 \mathrm{~mm}$.

Não é incomum a identificação equivocada entre $P$. parviflorum e $P$. hyalinum, porém as duas espécies são bem distintas. Enquanto $P$. hyalinum possui espiguetas que variam de $1,0-2,0 \times 0,5-1,0 \mathrm{~mm}, P$. parviflorum possui as menores espiguetas do grupo, $0,6-1,0 \times 0,4-0,6 \mathrm{~mm}$. Além disto, $P$. parviflorum possui tricomas ornamentando a gluma superior e lema inferior, característica ausente em $P$. hyalinum.

\section{Histórico dos sinônimos}

Paspalum hyalinum foi descrito por C.B.v. Trinius, em sua obra De Graminibus Paniceis (1826), com base em coletas do Brasil e anotações de C.G.D. Nees von Esenbeck para a Flora Brasiliensis. Em 1829, C.G.D. Nees von Esenbeck descreveu na Flora Brasiliensis seu Enumeratio Plantarum o sinônimo Paspalus hyalinus Nees, tendo como tipos coletas de C. F. P. v. Martius.

Além dos anteriores, três nomes estão associados à $P$. hyalinum. C.B.v. Trinius descreveu em 1834 (Mémoires de l'Académie Impériale des Sciences de SaintPétersbourg. Sixième Série.) Paspalum abstrusum Trin., e indicou a coleta 501 de F. Sellow como tipo. Outros dois sinônimos foram descritos por C. C. Mez, Paspalum gossypinum Mez (Repertorium Specierum Novarum Regni Vegetabilis, 1917) e Paspalum polychaetum Mez (Botanische Jahrbücher für Systematik, Pflanzengeschichte und Pflanzengeographie, 1921).

E. J. Judziewicz sinonimizou todos os nomes anteriores em $P$. hyalinum (Flora of the Guianas. Series A, Phanerogams, 1990). Em 2003, F. Zuloaga \& O. Morrone 
lectotipificaram as coletas de K.F.P. von Martius s.n. (LE), no Brasil. Neste trabalho só foi possível verificar exsicatas presentes em US (US 951762, Barcode: 00140708).

\section{Materiais Examinados}

ACRE. Rio Branco: Território do Rio Branco, campos do Miâu, Vale do Lurumuí, Novembro, 1927, Rondon s.n. (RB). AMAZONAS. Canutama: Campinas à ca. 20 km de Joana D'Arc, 839'27"S 6421'39"W, Abril, 2007, F.A. Carvalho 1343 (BHCB). Humaitá: Campo do Retiro, pequeno capão de cerrado, no campo, borda da estrada, Junho, 1966, Andrade - Lima 66-4686 (CEN). Humaitá: Campo para Oeste da Estrada, BR 319, Km 696, 7³1'S 6310’W, Abril, 1980, A. Janssen 319 (CEN). Humaitá: BR 319, Km 667, para o Sul da estrada, $7^{\circ} 31^{\prime}$ S 6310'W, Maio, 1980, A. Janssen 411 (CEN). BAHIA. Rio de Contas: Campo do Queiroz, 1332'S 41957'W, Outubro, 2012, R.P. Oliveira 2176 (HUEFS). DISTRITO FEDERAL. Brasília: Parque Nacional de Brasília, Cascalheira do Centro de Visitantes, distante cerca de 300m da administração do Parque Nacional de Brasília, Cerrado antropizado com baixo índice de colonização, $15^{\circ} 44^{\prime} 06^{\prime \prime} \mathrm{S} 47^{\circ} 55^{\prime} 36^{\prime \prime} \mathrm{W}$, Fevereiro, 1995, C. R. Martins 8 (UB). Bacia do Rio São Bartolomeu, Abril, 1980, F. P. Heringer 4471 (UB). Reserva Ecológica do IBGE, 1555'51"S 4754'00”W, Junho, 2008, C. B. R. Munhoz 4109 (IBGE, UB). (Lago Oeste): Margem do Parque Nacional de Brasília, ca. de 3km da entrada do Poço Azul, 2004, R.C. de Oliveira 1507 (IBGE). (Park Way): Fazenda Água Limpa, 1558'13.7”S 47ํ5'58.9”W, Maio, 2015, C.O. Moura 48 (UB).

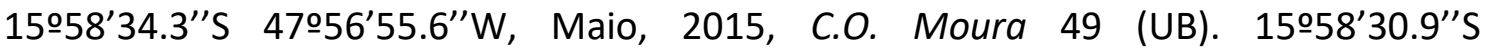
47057'18.3”W, Maio, 2015, C.O. Moura 53 (UB). Divisa com o Cristo Redentor (Jardim Botânica de Brasília) e o IBGE, mata de galeria do córrego Taquara, 1555’454"S 
4754’200”O, Maio, 2000, C. Munhoz 1326 (UB). (Sobradinho): Próximo à Embrapa

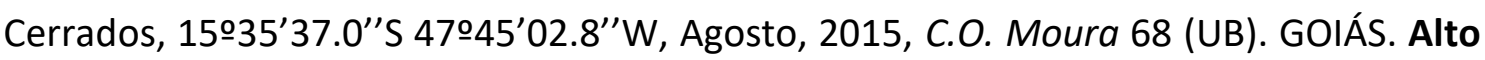
Paraíso de Goiás: Trilha Almécegas II - Fazenda São Bento, 1411'09.3”'S 47ํ6'10.4W, Julho, 2015, C.O. Moura 57, 58 (UB). Chapada dos veadeiros, Portal da Chapada, Estrada GO - 239 Alto Paraíso - São Jorge, 9 Km de Alto Paraíso, Junho, 2005, G. H. Rua 618 (CEN). Cavalcante: Estrada Campos Belos - Alto Paraíso do Norte, Km 145, 14ำ $10^{\prime} \mathrm{S} 47^{\circ} 42^{\prime} \mathrm{W}$, Outubro, 1980, L. Coradin 3846 (CEN). Cocauzinho: 1505S 04843W, Junho, 1994, R. C. Oliveira 267 (CEN). Cristalina: Serra dos Topásios, do outro lado do riacho (lado oposto a estrada), $16^{\circ} 43^{\prime} 37^{\prime \prime} S 47^{\circ} 41^{\prime} 37^{\prime \prime} \mathrm{O}$, Junho, 2004, J. B. A. Bringel 165 (CEN). Niquelândia: Fazenda Engenho ca. 11Km de Niquelândia/Dois Irmãos, 1438'03"S 4829'19"W, 1997, F.C.A. Oliveira 779, 778 (IBGE). Teresina de Goiás: Junto à divisa de Alto Paraíso e Teresina ao longo da rodovia GO-118 (Local do Cruzeiro), Maio, 1991, J. F. M. Valls 12882 (CEN). MATO GROSSO. Água Boa: 20,7 Km ao norte do rio Areões e cerca de $49 \mathrm{~km}$ ao sul de Água Boa, ao longo da BR 158, Junho, 1990, J. F. M. Valls 12508 (CEN). Alto Araguaia: Próximo ao trilho do trem, 1724'08.2”S 5313'28.6”'W, Fevereiro, 2016, C.O. Moura 95 (UB). Novo Santo Antônio: Parque Estadual do Araguaia, 12²2'29,9”S $50^{\circ} 55^{\prime} 15,3^{\prime \prime} \mathrm{W}$, Junho, 2005, H. Jancoski 116 (CEN). Fazenda Silvana, 12³4'13,1"S $50^{\circ} 54^{\prime} 51,3^{\prime \prime} \mathrm{W}$, Agosto, 2005, H. Jancoski 274 (CEN). Vila Bela da Santíssima Trinda: Topo da Cachoeira do Jatobá, $14^{\circ} 55^{\prime} 06^{\prime \prime} \mathrm{S} 60^{\circ} 04^{\prime} 26^{\prime \prime} \mathrm{W}$, Março, 2013, J. E. Q. Faria 3509 (CEN). MINAS GERAIS. Fazenda do "Seu Geraldão", Acesso por Inhaí, Parque Nacional

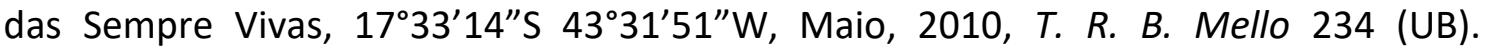
Itumirim: Serra da Bocaina/ Morro Janela, Março, 1987, D. A. C. 6480 (UB). Joaquim Felício: Serra do Cabral, início da subida, Abril, 1996, G. Hatschbach 64720 (CEN).

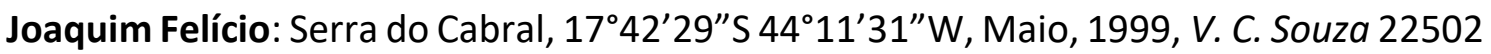


(UB). Ouro Branco: Serra de Ouro Branco, Março, 2005, H. M. Longhi-Wagner 9546 (CEN). Ouro Preto: Abril, 1925, A. Chase 9376 (RB). Serra do Espinhaço: Pico de Itacolomí cerca de 3Km da Serra de Ouro Preto, Janeiro, 1971, H. S. Irwin 29486 (UB). Serro: Estrada para Dantas, Dezembro, 1997, A. Zanin 705 (UB). PARÁ. BR-316: 36,2 km do entroncamento da BR-316 para Vígia, $00^{\circ} 58^{\prime} \mathrm{S}, 48^{\circ} 06^{\prime} \mathrm{W}$, Outubro, 1987, Veiga \& Silva 197 (CEN). PARANÁ. Balsa Nova: BR-376 Km 552, entre as pontes sobre o Rio da Pombas

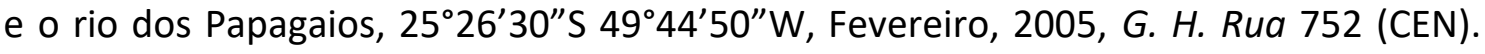

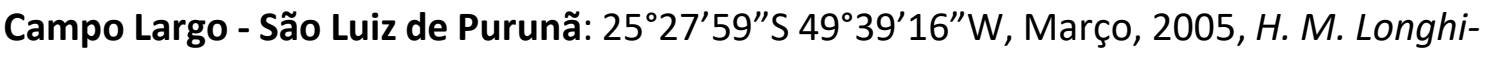
Wagner 9417 (CEN). Guartelá: Canyon Rio lapó, Março, 1993, G. Hatschbach 59109 (CEN). Jaguariaiva: Parque Estadual do Cerrado, cerrado aberto, junto ao Canyon, Março, 2005, H. M. Longhi-Wagner 9462 (CEN). Jaguariaiva: Saída do Parque Estadual do Cerrado, Março, 2005, H. M. Longhi-Wagner 9482 (CEN). Ponta Grossa: 35,6km da bifurcação para Palmeira e Curitiba (BR-227) a sudeste de Ponta Grossa, 2516'03"S 4958'08”W, Fevereiro, 2002, J. F. M. Valls 14841 (CEN). Tibagi: Estr. Castro-Tibagi, Fda. Palmito, Janeiro, 1959, G. Hatschbach 5435 (MBM). RIO GRANDE DO SUL. Osório: Balneário de Atlântida, Maio, 1979, J. Valls 4786 (CEN). Osório: Parque Histórico General Osório, Maio, 1972, J. Valls 2092 (CEN). São Lourenço do Sul: Fazenda Pedra Mole, Setembro, 2011, C. Bonilha 564 (UB). Viamão: Itapuã, Março, 2007, H. Longhi-Wagner 10271 (ICN). RORAIMA. Boa Vista - Mucajaí: BR 174, Km 13, Novembro, 1977, L. Coradin 985 (CEN). Boa Vista: Cauamé, Ao longo da BR 174, Km 9, Outubro, 1977, L. Coradin 661 (CEN). $110 \mathrm{~km}$ do nordeste de Boa Vista, $8 \mathrm{~km}$ do Sudoeste de Bonfim, Fazenda Valparaíso, Outubro, 1977, L. Coradin 809 (CEN). Caracaraí: Boa Vista, BR - 174, km 80, Entrada para Serra da Prata, $2^{\circ} 59^{\prime} \mathrm{N} 60^{\circ} 59^{\prime} \mathrm{W}$, Novembro, 1981, L. Coradin 5064 (CEN). Novembro, 1977, L. Coradin 1068 (CEN). SANTA CATARINA. Florianópolis: Porto da 
Lagoa, 1992, F.A. Silva-Filho 953 (MBM). Ilha de Santa Catarina: Praia de Canasvieiras, Julho, 1971, J. Valls 1550 (CEN). SÃO PAULO. Itararé: Unidade de Pesquisa e Desenvolvimento de Itararé, $24^{\circ} 16^{\prime} 06^{\prime \prime}$ S $49^{\circ} 12^{\prime} 19^{\prime \prime} \mathrm{W}$, Maio, 2006, J. L. S. Tannus 1210 (CEN). Jabaquara: Março, 1965, O. Handro 1120 (HEPH, UB). São Paulo: Casa de força, Janeiro 1941, B. Pickel 5213 (CEN). B. Pickel 7931 (IPA). TOCANTINS. Mateiros: Parque Estadual do Jalapão, Mumbuca - Brejo do Antônio, Local de extração do Capim Dourado, $10^{\circ} 22^{\prime} 17^{\prime \prime S} 46^{\circ} 34^{\prime} 58^{\prime \prime} \mathrm{O}$, Junho, 2002, T. B. Cavalcanti 2899 (CEN). Estrada de terra Mateiros - Ponte Alta do Tocantins, a $21 \mathrm{Km}$ de Mateiros, $10^{\circ} 36^{\prime} 08^{\prime \prime} \mathrm{S} 46^{\circ} 34^{\prime} 21^{\prime \prime} \mathrm{O}$, Junho, 2002, T.B. Cavalcanti 2782 (CEN). Região do Jalapão, estrada Mumbuca - Boa Esperança, vereda Porco Podre, $10^{\circ} 18^{\prime} 54^{\prime \prime}$ S 46 39'46"O, Dezembro, 2005, G. H. Rua 703 (CEN). 
4.1.5 Paspalum minarum Hack., Oesterr. Bot. Z. 51: 235. 1901.

Tipo: A.F.M. Glaziou 20131, BRASIL (HT: W!, IT: K!, P!, US).

Plantas policárpicas, cespitosas, colmo florífero de $39-65 \mathrm{~cm}$, ramificações proximais, 3 a 7 nós, glabros; bainhas foliares de 7,9-19 cm de comprimento, de glabras a pilosas na face abaxial, quando pilosas comumente nas mais basais, ou aparecendo apenas um tufo de tricomas na base, próximo ao nó, os tricomas lineares de até $3 \mathrm{~mm}$; colar presente, geralmente apresentando tricomas de tamanhos variáveis, menores que $8 \mathrm{~mm}$, eventualmente inconspícuo; lígula membranosa, 0,5 - 2,1 mm de comprimento, com cílios ao redor, lineares cerca de $5 \mathrm{~mm}$; lâmina foliar 1,0 - $15 \times 0,05-0,20 \mathrm{~cm}$, planas a involutas, essas mais comuns, lineares a linear-lanceoladas, base truncada, ápice agudo, geralmente pilosa em ambas as superfícies, os tricomas de dois tipos, lineares de base tuberculada com até $5 \mathrm{~mm}$ e lineares não tuberculados de até $3 \mathrm{~mm}$, margem geralmente ciliada, com tricomas filiformes. Sinflorescências terminais, com 1 a 9 ramos unilaterais espiciformes, não conjugados, de 2,0 - $11 \mathrm{~cm}$ de comprimento; pedúnculo de 9,5-20,8 cm de comprimento; ráquis membranácea, de 0,5-1,0 mm de largura; pedicelos de 0,5-1,0 mm de comprimento, pilosos; espiguetas $1,8-2,5 \times 1,0$ - 1,3 mm, plano-convexas, elípticas, solitárias; gluma superior 1,8 - 2,5 X 1,0 - 1,3 mm, membranácea, delicada, bi(tri)nervada, igual ou levemente maior que o antécio superior, glabra; lema inferior 1,7 - 2,4 X 1,0 - 1,3 mm, membranáceo, bi(tri)nervado, glabro; antécio superior $1,7-2,4 \times 1,0-1,3 \mathrm{~mm}$, crustáceo, estramíneo, liso, lustroso (FIGURA 11); lodículas com cerca de $0,2 \mathrm{~mm} ; 3$ anteras e 2 estigmas roxos; cariopse não vista. 


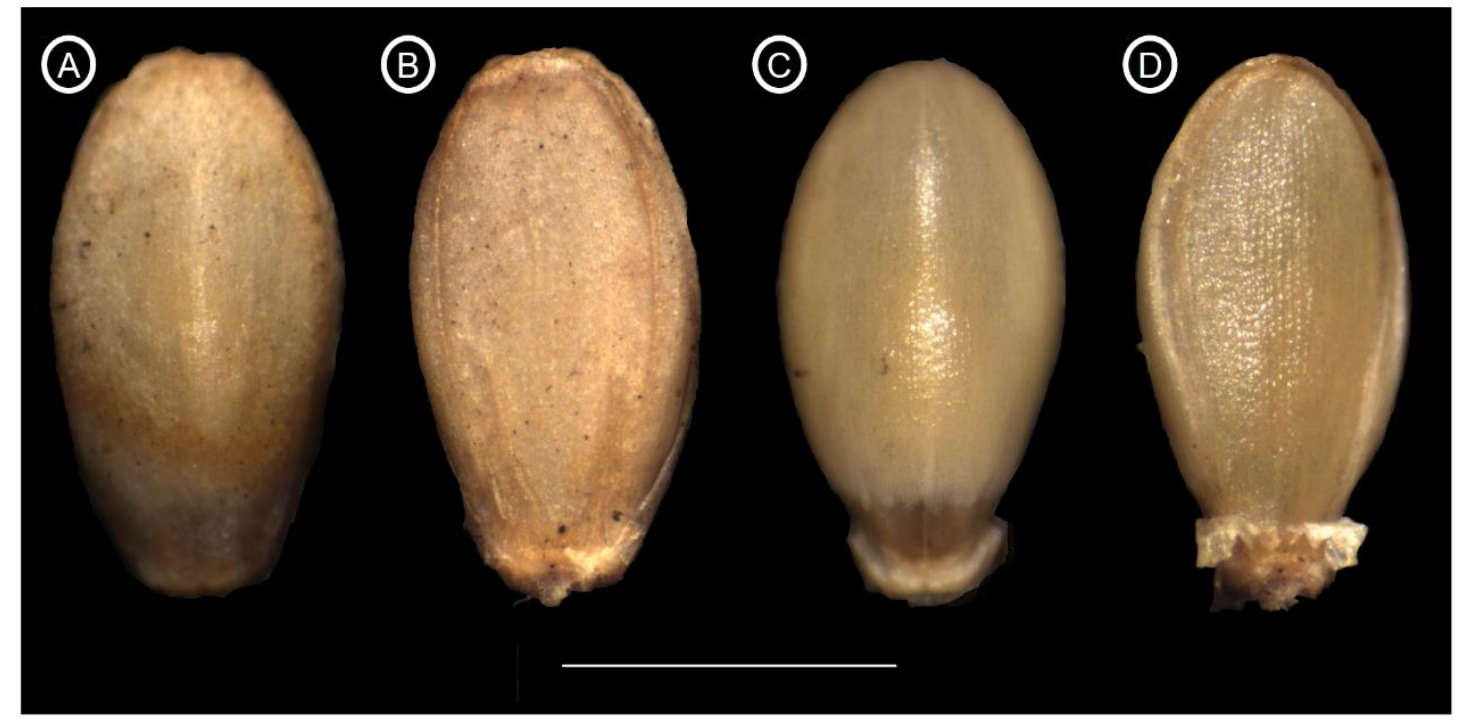

Figura 11. Espigueta de Paspalum minarum (Pimenta, K.M. 275); A - Gluma superior, B - Lema inferior, $C$ - Lema superior, D - Pálea. Barra de escala $=1 \mathrm{~mm}$.

P. minarum não apresenta tricomas ornamentando a gluma superior e lema inferior, e possui papilas simples na superfície do lema superior e pálea superior (FIGURA 12). 

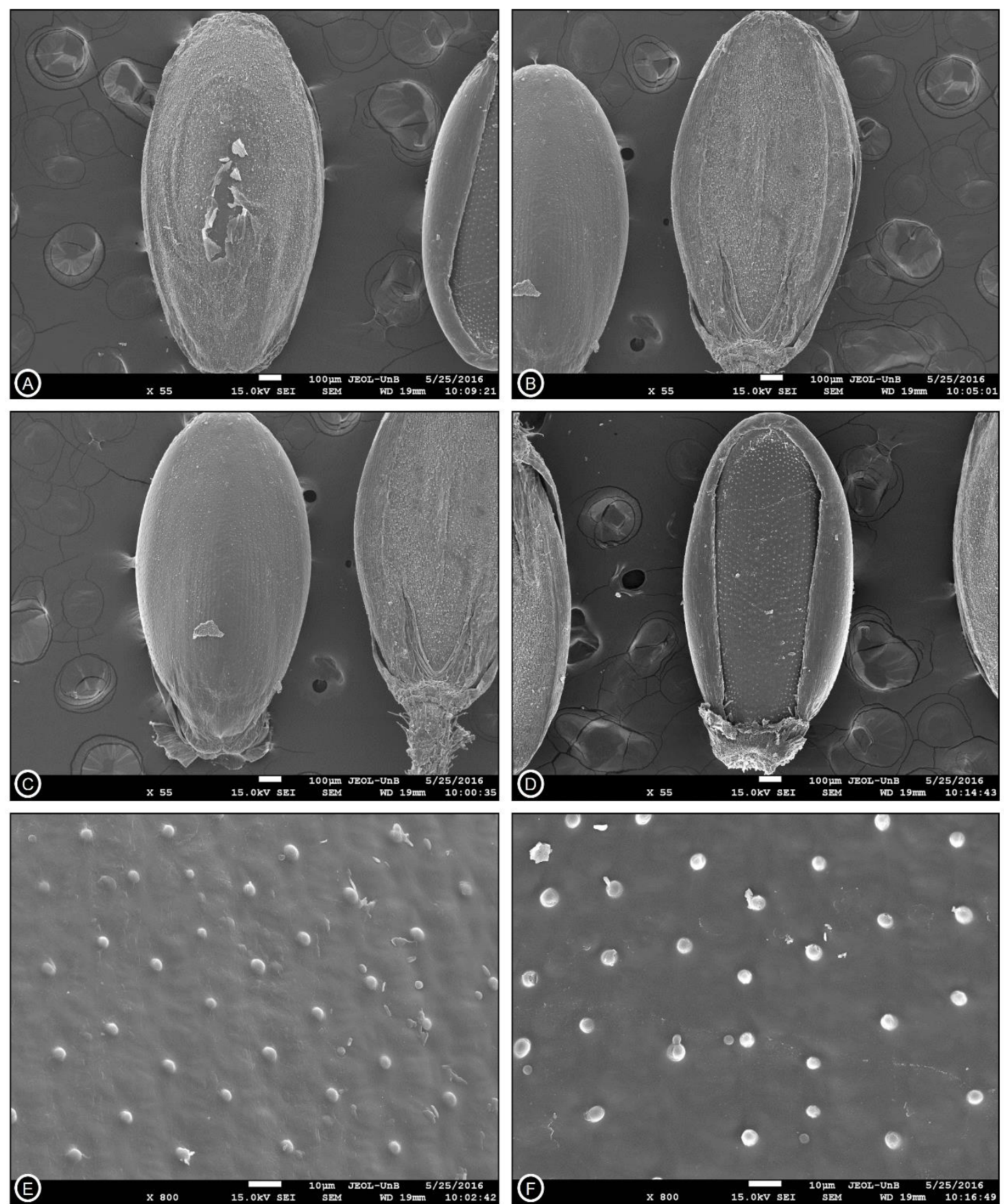

Figura 12. Microfotografia de Paspalum minarum (Pimenta, K.M. 275); A - Gluma superior, B Lema inferior, C - Lema superior, D - Pálea, E e F - Papilas simples.

\section{Distribuição geográfica e aspectos ecológicos}

Ocorre na região Neotropical e possui registro apenas para o Brasil, onde ocorre nos estados da Bahia, Goiás e Minas gerais (FIGURA 13). Possui registro para os domínios da Caatinga e Cerrado. Está presente em formações campestres e savânicas, habitando 
ambientes de campo limpo, seco e úmido, campo rupestre, cerrados, veredas geralmente em terrenos arenosos e/ou rochosos, podendo estar presente em borda de mata e locais antropizados, comumente associado a solos arenosos e úmidos.

Época de florescimento e frutificação: durante os meses de Fevereiro, Março, Abril, Maio, Setembro, Outubro e Dezembro.

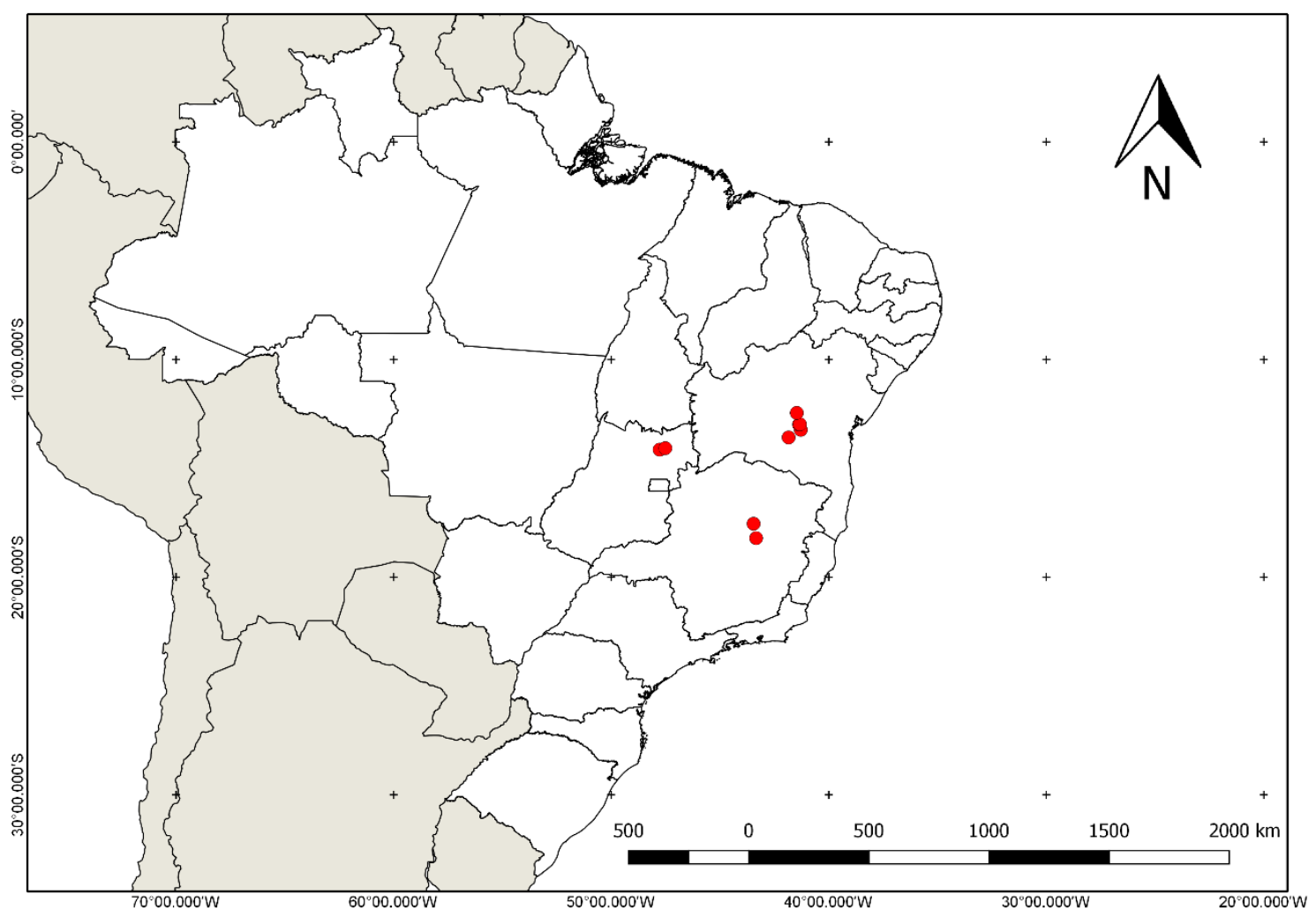

Figura 13. Mapa com os registros de distribuição (pontos vermelhos) confirmados de Paspalum minarum.

\section{Comentários Taxonômicos}

P. minarum é reconhecido por possuir um enrugamento no formato da letra ' $\mathrm{V}$ ', na base do lema inferior, característica marcante que a distingue das demais espécies, dentro do grupo e também fora. É frequentemente confundido com $P$. hyalinum, dentro do grupo, porém diferencia-se desta por não possuir porções hialinas no lema inferior 
(eventualmente podendo aparecer manchas mais delicadas na gluma superior), possuir cicatriz em ' $V$ ' e normalmente possui o ápice da espigueta em formato arredondado ou obtuso, enquanto que $P$. hyalinum possui o ápice geralmente agudo. Além disso, a nervura central do lema inferior, raramente aparece em $P$. minarum, enquanto que em P. hyalinum essa característica possa ser mais comum.

Outra espécie comumente identificada como $P$. minarum é $P$. brachytrichum Hack. (e vice-versa). Além da ausência da cicatriz em ' $V$ ', $P$. brachytrichum também possui normalmente a nervura central, da gluma superior e lema inferior, bem desenvolvida. $P$. minarum possui espiguetas que variam de $1,8-2,5 \mathrm{~mm}$ de comprimento, enquanto que P. brachytrichum essa variação vai de $2,5-3,0 \mathrm{~mm}$ de comprimento.

\section{Materiais Examinados}

BAHIA. Andaraí: Andaraí arredores, Setembro, 1984, G. Hatschbach 48332 (MBM). Chapéu: Em lagedo, Outubro, 1970, Geraldo Pinto s/n (CEN). Ibicoara: Gerais de Machombongo, Chapada Diamantina, 13113'44"S 4116'58W, 2012, K.M. Pimenta 390 (UB). Mucugê: Estrada Andarai - Mucuje, Km 34, 1259S 04122W, Agosto, 1981, L.

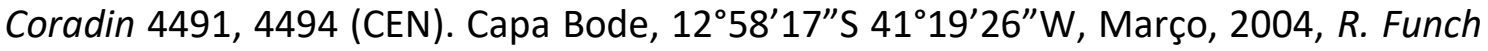
294 (UB). Palmeiras: Morro do Pai Inácio, Chapada Diamantina, 1227'S 4128W, Maio, 2011, C. Silva 310 (HUEFS). Rio de Contas: Caminho da cidade, em direção da Serra de Marsalina, próximo da base da serra. $13^{\circ} 34^{\prime} 47^{\prime \prime S} 41^{\circ} 50^{\prime} 30^{\prime \prime} \mathrm{W}$, Agosto, 2006, R. M. Harley 55526. GOIÁS. Alto Paraíso de Goiás: Fazenda Água Fria, cerca de 10Km em direção a Teresina de Goiás, 140''ㄱ"S 47ํ30'336"W, 2000, C. Munhoz 1082 (IBGE,UB). C. Munhoz 1908 e 1397 (UB). Parque Nacional Chapada dos Veadeiros, 
140'24"S 47ํ6'11"W, 1995, M.L. Fonseca 581 (IBGE). MINAS GERAIS. Diamantina: Parque Nacional das Sempre Vivas, 1732'44"S 4327'11"W, Abril, 2010, T.R.B. Mello 115 (UB). Dezembro, 1929, A. Chase 10324 (RB). São Gonçalo do Rio Preto: Parque Estadual do Rio Preto, 1812'25,3"'S 4320'00,4"W, Março, 2004, P.L. Viana 1636 (BHCB). 
4.1.6 Paspalum multicaule Poir., Encycl., Suppl. 4: 309. 1816.

Tipo: R.L. Desfontaines s.n., BRASIL (HT: FI, IT: P!, US).

Paspalum papillosum Spreng., Novi Provent. 47-48. 1819.

Tipo: s.a. s.n., BRASIL (HT: B), L. Riedel s.n., BRASIL (IT: LE-TRIN, US).

Plantas monocárpicas, cespitosas, colmo florífero de $4,5-48 \mathrm{~cm}$, ramificações proximais e raramente distais, 2 a 6 nós, geralmente glabros; bainhas foliares de 2,0 7,6 $\mathrm{cm}$ de comprimento, pilosa na face abaxial, os tricomas lineares de base tuberculada concentrados principalmente próximos à nervura central e margens; colar presente, geralmente uma linha em coloração amarelada, roxa ou acastanhada. Porém, as vezes inconspícuo; lígula membranosa, cerca de 0,2 mm de comprimento, com cílios ao redor, maiores que a lígula, até 0,8 mm; lâmina foliar 1,3-11X0,09-0,20 cm, planas, lineares a linear-lanceoladas, base truncada a levemente obliqua, ápice agudo, pilosa em ambas as superfícies, os tricomas lineares de base tuberculada, de até $5 \mathrm{~mm}$, margem ciliada, com tricomas escabrosos intercalados com tricomas lineares de base tuberculada, estes em menor concentração. Sinflorescências terminais e eventualmente axilares, com 1 a 2 ramos unilaterais espiciformes, quando 2 , conjugados no ápice do colmo florífero, de 0,6 - 5,8 cm de comprimento, normalmente terminando com uma espigueta subdesenvolvida; pedúnculo de 0,9-12 cm de comprimento; ráquis membranácea, de 0,5-0,9 mm de largura; pedicelos de 0,5-1,0 $\mathrm{mm}$ de comprimento, pilosos; espiguetas 1,0-1,4 X0,9-1,1 mm, plano-convexas, orbiculares, solitárias; gluma superior $0,9-1,4$ X 0,8 - 1,1 mm, membranácea, delicada (frequentemente dando aparência de estar aderida ao antécio), trinervada, geralmente do mesmo tamanho do antécio superior, podendo ser pouco menor, com tricomas capitados geralmente recobrindo toda 
superfície; lema inferior 1,0 - 1,4 X 0,9-1,1 mm, membranáceo, bi ou trinervado, geralmente com porção levemente hialina no centro, tricomas capitados, comumente concentrados nas margens; antécio superior 0,9-1,4 X 0,9-1,1 mm, crustáceo, estramíneo, papiloso, lustroso (FIGURA 14); lodículas com cerca de 0,2 mm; 3 anteras, roxas e 2 estigmas roxos; cariopse $0,7-1,0 \times 0,7-0,9 \mathrm{~mm}$, orbicular; hilo oboval.

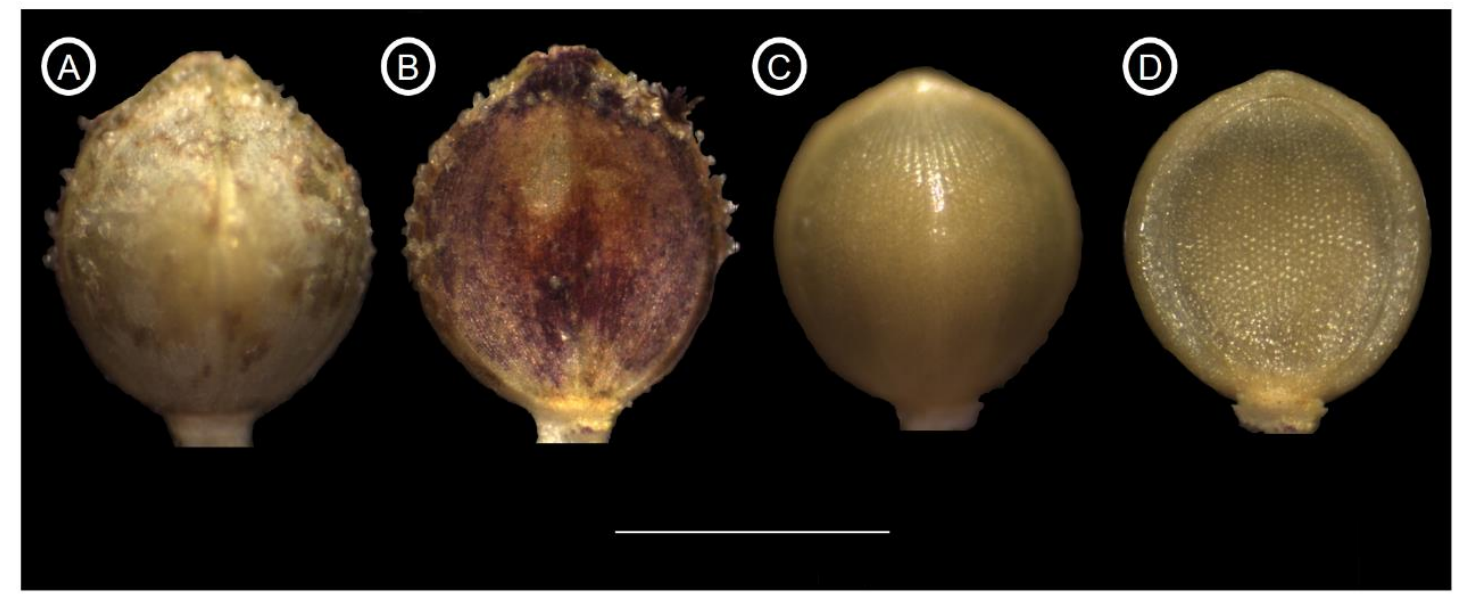

Figura 14. Espigueta de Paspalum multicaule (Moura, C.O. 46); A - Gluma superior, B - Lema inferior, C - Lema superior, D - Pálea. Barra de escala $=1 \mathrm{~mm}$.

P. multicaule apresenta tricomas capitados ornamentando a gluma superior e lema inferior, e papilas conjugadas na superfície do lema superior e pálea superior (FIGURA 15). 

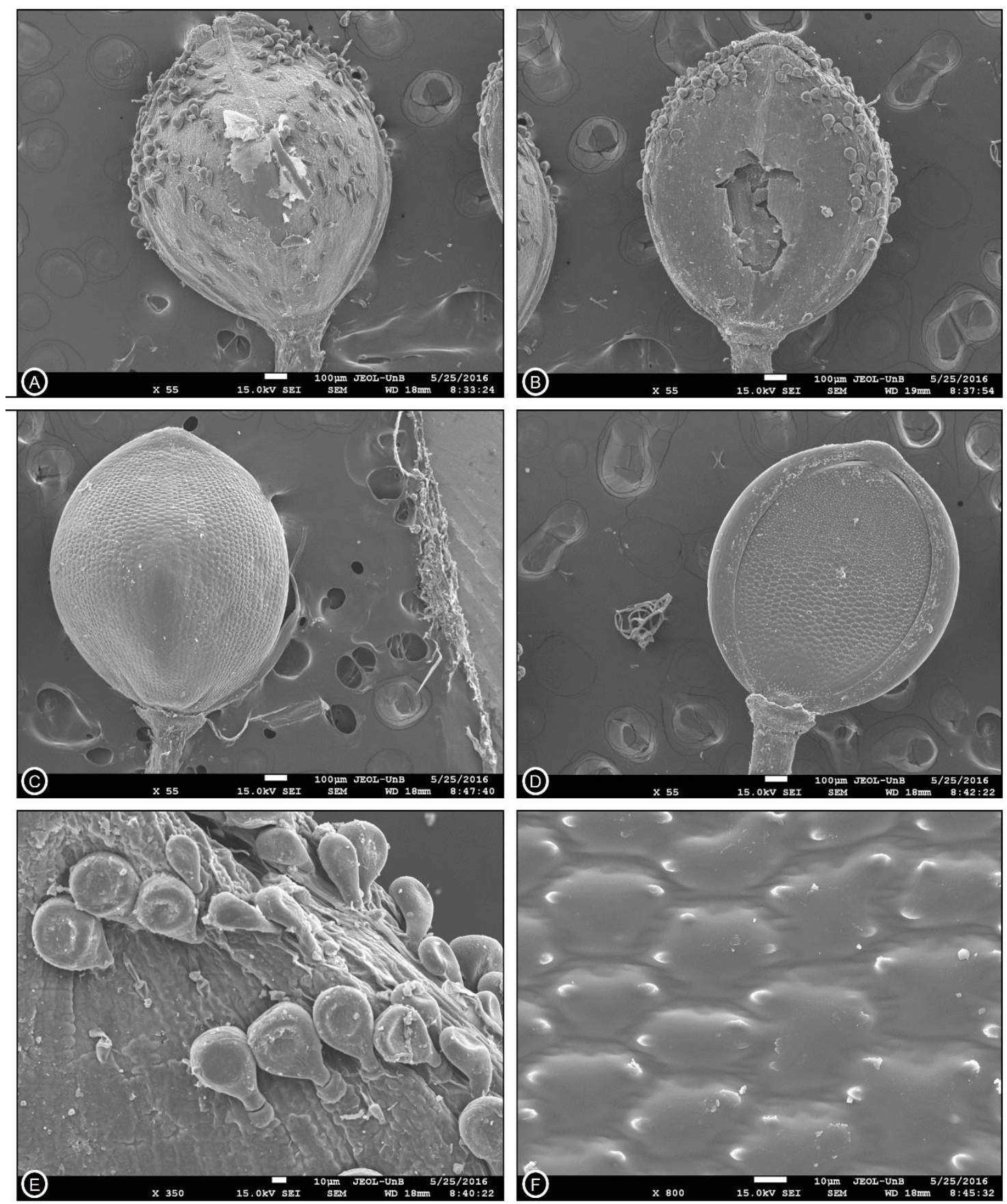

Figura 15. Microfotografia de Paspalum multicaule (Moura, C.O. 46); A - Gluma superior, B Lema inferior, C - Lema superior, D - Pálea, E - Tricomas capitados, F - Papilas conjugadas.

\section{Distribuição geográfica e aspectos ecológicos}

Ocorre na região Neotropical, desde o México e Caribe até o Brasil e Paraguai. No Brasil é encontrado nos estados do Amazonas, Amapá, Bahia, Distrito Federal, Espírito Santo, Goiás, Maranhão, Mato Grosso, Mato Grosso do Sul, Minas Gerais, Pará, Paraíba, 
Pernambuco, Piauí, Rio Grande do Norte, Rondônia e São Paulo (FIGURA 16). Possui registro para os domínios da Amazônia, Caatinga, Cerrado, Mata Atlântica e Pantanal. Está presente em formações campestres, savânicas e florestais, habitando em ambientes de campo, seco e úmido, campo rupestre, cerrados, cerradão, veredas, floresta estacional semi-decidual, mata mesófila, ambientes antropizados, como beira de estrada e borda de cerrado e de mata, é comumente associado a solos arenosos, rochosos e úmidos.

Época de florescimento e frutificação: durante os meses de Janeiro, Fevereiro, Março, Abril, Maio, Junho, Julho, Agosto, Outubro e Novembro.

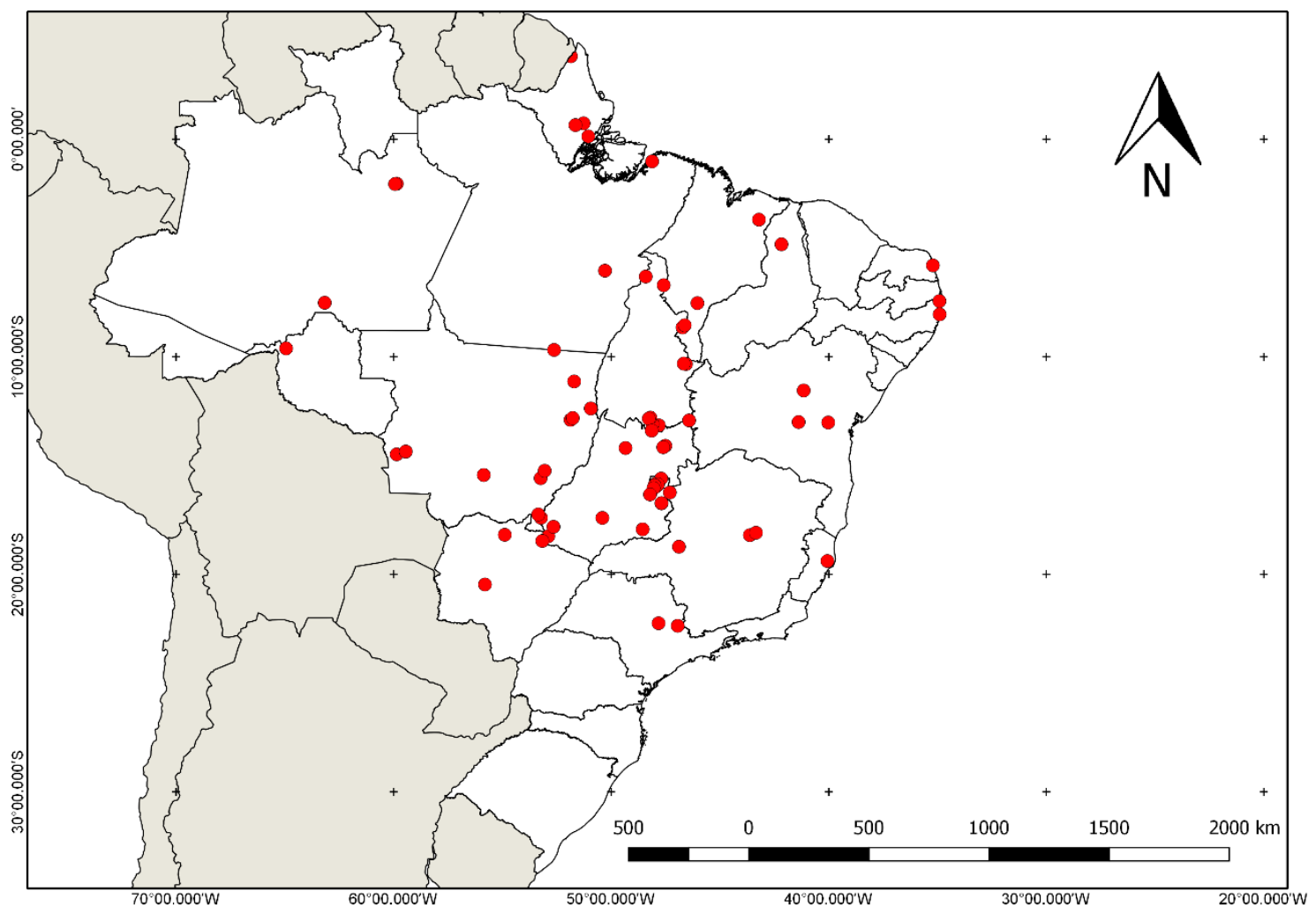

Figura 16. Mapa com os registros de distribuição (pontos vermelhos) confirmados de Paspalum multicaule.

\section{Comentários Taxonômicos}


Dentro do grupo Parviflora é próxima a $P$. clavuliferum, porém distingue-se desta, principalmente, por possuir espiguetas orbiculares, sempre solitárias e ramos unilaterais espiciformes terminando em uma espigueta subdesenvolvida, por vezes a ráquis e mais de uma espigueta podem estar também subdesenvolvidas.

Embora o habitual seja a presença de espiguetas subdesenvolvidas, no ápice do ramo unilateral espiciforme, em alguns exemplares o ramo pode terminar com uma espigueta totalmente desenvolvida, como é o caso dos vouchers C.O. MOURA 46 e D.C. ZAPPI 3113. Porém, mesmo nestes casos, mais incomuns, quando um dos ramos apresenta uma espigueta desenvolvida no ápice, outros ramos na planta apresentam espiguetas subdesenvolvidas, normalmente.

Foram encontrados colmos floríferos de até $48 \mathrm{~cm}$, enquanto que CHASE (1939 não publicado) descreve colmos de até $50 \mathrm{~cm}$ e raramente chegando a $60 \mathrm{~cm}$. Além disso, CHASE (1939 - não publicado) também relata que $P$. multicaule apresenta normalmente dois ramos unilaterais espiciformes e que a presença de apenas um ou três ramos seriam características raras, diferindo em parte dos resultados obtidos, que demonstram que a presença de apenas um ramo é frequente. ZULOAGA \& MORRONE (2005), relatam lígulas de até $0,4 \mathrm{~mm}$ comprimento, e as lígulas analisadas, neste estudo, possuem cerca de $0,2 \mathrm{~mm}$.

\section{Histórico dos sinônimos}

A espécie foi descrita por J. L. M. Poiret, na obra Encyclopedie methodique botanique par M. Lamarck. Continuee par J.L.M. Poiret (1816), com base no exemplar "Cette plante croît au Brasél (V. s. in herb Desfont. \& Desv.)". CHASE (1929; 1939 - não 
publicado), analisou material correspondente a descrição no herbário FI e destacou que o material possuía poucos tricomas globulares, concentrados nas margens da gluma superior e lema inferior, assim como vários materiais analisados aqui. Só foi visto o material (foto) indicado como isótipo, presente em P (P00745771), doado do Herbier de A.N. Desvaux, e corresponde com as descrições.

Em 1819 C. P. J. Sprengel, descreve P. papillosum Spreng., com base em uma coleta com descrição "Habitat in Brasilia, Otto." Esse material foi analisado por CHASE (1929; 1939 - não publicado), em B, que destacou que as espiguetas variavam de escassamente a densamente ornamentadas com tricomas globulares. Além disso, CHASE (1939 - não publicado) destaca o fato de que Otto foi diretor do Royal Botanical Garden de Berlim, e que nunca esteve no Brasil, portanto, o exemplar deve ter sido repassado para Sprengel, por Otto, sem indicação de coletor.

Outros materiais são indicados como tipos deste nome, por TROPICOS (2017) e ZULOAGA \& MORRONE (2005), sendo: L. Riedel s.n., coletado na Bahia, indicado como isótipo, em LE-TRIN (0502.02) e fragmento em US (951732), e s.a. s.n., coletado também na Bahia e indicado somente como tipo, em LE-TRIN (0502.03), com legenda "Bahia, in locis cultis maritimis. Salzmann.", provavelmente coletado por P. Salzmann. Não foi possível analisar nenhum destes materiais. J. C. Döll cita na Flora Brasiliensis (1877), o nome P. hortícola var. maritimum Salzm. ex Döll, como sinônimo de P. papillosum, juntamente com Paspalus multicaulis Poiret. O exemplar "Paspalum horticola maritimum Salzmann in schedulis n. 677" foi analisado por CHASE (1929; 1939 - não publicado), que descreve o material com espiguetas abundantemente cobertas por tricomas globulares. 


\section{Materiais Examinados}

AMAZONAS. Humaitá: 500 metros Oeste da Transamazônica km 2, perto de Humaitá, Dezembro, 1979, A. Janssen 14 (CEN). 15 km estrada 319 ao lado esquerdo, 7³1'S, 63¹0’W, Dezembro, 1979, 14 (CEN). Campo no km 8 da estrada Humaitá-Lábrea, Junho, 1966, Andrade-Lima 66-4618 (CEN, IPA). Fazenda do Flávio Neri, ao Sul da BR 319 km $658,7^{\circ} 31^{\prime} \mathrm{S}, 63^{\circ} 10^{\prime} \mathrm{W}$, Maio, 1980, A. Janssen 334 (CEN). Manaus: $29 \mathrm{~km}$ de Manaus along highway. By the creek, "Igarapé do Leão". Weed grass inpineaple \& cassava field, Janeiro, 1963, G. Eiten 5152 (MBM, UB). Presidente Figueiredo: Estacionamento da cachoeira Santuário. 203'23"S, 5956’00”W, Abril, 2015, R. C. Oliveira 3014 (CEN, UB). Beira da estrada para babilna, $2^{\circ} 02^{\prime} 35^{\prime \prime} \mathrm{S} 59^{\circ} 51^{\prime} 16^{\prime \prime} \mathrm{W}$, Abril, 2015, R. C. Oliveira 3012 (CEN, UB). AMAPÁ. Macapá: Primeira ilha de vegetação arbórea após a ponte do canal de Curiau, junto ao lago de Curiau, 0008N, 05103W, Maio, 1988, J.F.M. Valls 11673 (CEN, MBM). Oiapoque: Colônia Agrícola Clevelândia do Norte, $03^{\circ} 49^{\prime} 00^{\prime \prime} \mathrm{N}, 51^{\circ} 51^{\prime} 00^{\prime \prime} \mathrm{O}$, Agosto, 1988, N. M.S. Costa 2201 (CEN). Paredão: Próximo a bomba de gasolina da Companhia - EletroNorte, $0^{\circ} 44^{\prime} 00^{\prime \prime} \mathrm{N}, 51^{\circ} 16^{\prime} 00^{\prime \prime} \mathrm{O}$, Agosto, 1988, N. M. S. Costa 2162 (CEN). Porto Grande: Estrada para Cupixi em direção à Serra do Navio, Rod Perimetral Norte, Km 132, $0^{\circ} 38^{\prime} 66^{\prime \prime} \mathrm{N}, 51^{\circ} 37^{\prime} 93^{\prime \prime} \mathrm{W}$, Junho, 2011, R. P. Oliveira 1842 (HUEFS). Macapá: Primeira Ilha de vegetação arbórea após a ponte do canal de Curiau junto ao lago de Curiau, 0008N, 05103W, Maio, 1988, J. F. M. Valls 11673 (CEN). BAHIA. Ilhéus: BA - 001 - Olivença - Una, km 12, Julho, 1980, L. Coradin 2868 (CEN). Morro do Chapéu: Serra do Tombador, Rio Ferro Doido, Fevereiro, 1971, H.S. Irwin 32514 (UB). Mucugé: Serra do Sincorá, By Rio Cumbuca, about $3 \mathrm{~km} \mathrm{~N}$ of Mucugé on the Andaraí road, on conglomerate sandstone rock by river and neghbouring hillside $13^{\circ} 00^{\prime} \mathrm{S}, 41^{\circ} 23^{\prime} \mathrm{W}$, Fevereiro, 1974, R. M. Harley 16023 (CEN, IPA). 
DISTRITO FEDERAL. Brasília: Fazenda Sucupira, Borda de mata de galeria, próximo ao bambuzal, $15^{\circ} 54^{\prime} 40^{\prime \prime} \mathrm{S}, 48^{\circ} 00^{\prime} 11^{\prime \prime} \mathrm{O}$, Maio, 2007, C. G. Fontes 188 (UB). Jardim Botânico de Brasília, $15^{\circ} 52^{\prime} 0^{\prime \prime} \mathrm{S}, 47^{\circ} 51^{\prime} 0^{\prime \prime} \mathrm{W}$, Abril, 2003, R. Rodrigues-da-Silva 780 (HEPH). Estação Ecológica Jardim Botânico de Brasília, Estrada da Mata do Taquara, à esquerda, Março, 2015, R. G. Chacon 1275 (HEPH). (Gama): Parque Vivencial do Gama (Prainha), 1602'20.0”S 4803'04.0”W, Abril, 2015, C.O. Moura 41 (UB). (Gama): Parque Recreativo e Reserva Ecológica do Gama. 1603'S 48 03'W, Abril, 2001, B. M. Gomes 285 (UB). (Park Way): Fazenda Água Limpa, 1554'44”S 47ํ5'33.3”W, Maio, 2015, C.O. Moura 45 (UB). (Park Way): Fazenda Água Limpa, 155ㄱ'37.8”S 47ํ56'40.7”W, Maio, 2015, C.O. Moura 46 (UB). (Planaltina): Campo de cultivo de arroz entre Córrego Sarandi e Lagoa Bonita, $15^{\circ} 36^{\prime} \mathrm{S}, 47^{\circ} 42^{\prime} \mathrm{W}$, Abril, 1983, F. P. Cupertino 12, 20, 31, 33 (UB). (Planaltina): Várzea, à direita da Rodovia CPAC - Sarandi, cerca de $2 \mathrm{~km}$ do CPAC, $47^{\circ} 42^{\prime} 30^{\prime \prime} \mathrm{N}$, Abril, 1985, S. P. Almeida 1040 (UB). (Riacho Fundo): ARIE Santuário de Vida Silvestre do Riacho Fundo, $15^{\circ} 50^{\prime} 55^{\prime \prime} \mathrm{S} 47^{\circ} 56^{\prime} 50^{\prime \prime} \mathrm{W}$, Fevereiro, 2000, R. Rodrigues-daSilva 505 (UB). (Lago Sul): Área do Cristo Redentor, mata do Taquara, divisa com IBGE, $15^{\circ} 55^{\prime} 47^{\prime \prime} \mathrm{S}, 47^{\circ} 53^{\prime} 58^{\prime \prime} \mathrm{O}$, Fevereiro, 2008, R. G. Chacon 348 (HEPH). (Lago Sul): EEJBB Poção, Fevereiro, 2010, J. B. Bringel 608 (HEPH). (Lago Sul): EEJBB - Borda esquerda da mata do Taquara, Março, 2012, R. G. Chacon 956 (HEPH). ESPÍRITO SANTO. Linhares: Reserva Natural da CVRD, Agosto, 2001, D.A. Folli 4038 (HUEFS). GOIÁS. Acreúna: Cerca de $3 \mathrm{~km} \mathrm{~W}$ de Acreúna, na BR 060. Borda mata no lado $S$ da estrada, $17^{\circ} 24^{\prime} 26^{\prime \prime}$, 50²4'43"W, Abril, 2011, G. H. Rua 930 (UB). Cerca de 200 m N da BR 060 numa estrada

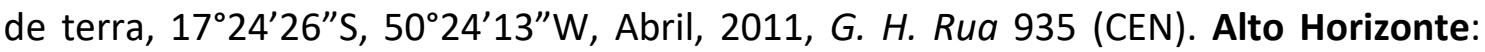
Coleta na fazenda do Senhor Manoel Braz, divisa com a Fazenda Sucuriú, Proprietário 


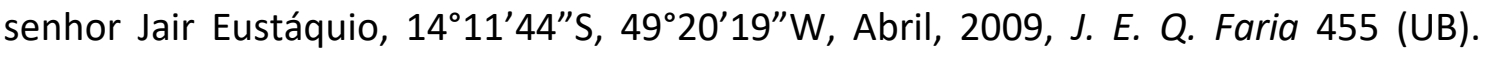
Fazenda do Sr. Manoel Braz, Sururuca, Março, 2013, J. E. Q. Faria 3352 (CEN, UB). Alto Paraíso de Goiás: Água fria 3, cerca de $8 \mathrm{~km}$ a direita de Alto Paraíso para Teresina de

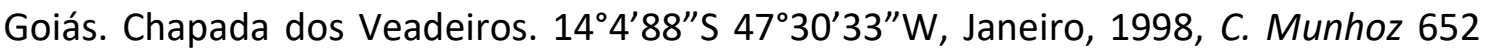
(UB). Março, 1999, T. S. Filgueiras 3505 (IBGE). Chapada dos Veadeiros, estrada GO 239. Alto Paraíso - São Jorge, cerca de $10 \mathrm{~km}$ de Alto Paraíso, beira da estrada, $14^{\circ} 09^{\prime} 37^{\prime \prime S}, 47^{\circ} 36^{\prime} 21^{\prime \prime}$, Julho, 2005, G. H. Rua 627 (CEN). Cachoeira de Goiás: Fazenda Biquinha (estrada Cachoeira de Goiás - Aurilândia, km 5 próximo à vereda da sede.), $16^{\circ} 44^{\prime} 5^{\prime \prime}$ S, $05^{\circ} 04^{\prime} 5^{\prime \prime}$ W, Janeiro, 1982, G. P. Silva 4184 (CEN). Caldas Novas: Alternativa 4 régua de leitura da Vazão da Hidrometria, 1756S, 04833W, Fevereiro, 1996, G. P. Silva 3385 (CEN). Campos Belos: Estrada para Pouso Alto, cerca de 18 km a direita da Usina Mosquito, $12^{\circ} 55^{\prime} 29^{\prime \prime}$ S, 46 $25^{\prime} 06^{\prime \prime}$ W, Abril, 2001, M. L. Fonseca 2605 (CEN). Cavalcante: Balsa Serra Branca (Rio Tocantins) Serra Branca km 05, 13²3'43"S, 4808'07"O, Janeiro, 2001, G. Pereira-Silva 4568 (CEN). Chapadão do Céu: Parque Nacional das Emas, 1815’01.0”S 5253'10.9”W, Fevereiro, 2016, C.O. Moura 106 (UB). Chapadão do Céu Mineiros: Parque Nacional das Emas, $17^{\circ} 49^{\prime}-18^{\circ} 28^{\prime} \mathrm{S}$ e $52^{\circ} 39^{\prime}-53^{\circ} 10^{\prime} \mathrm{W}$, Maio, $1999, \mathrm{M}$.

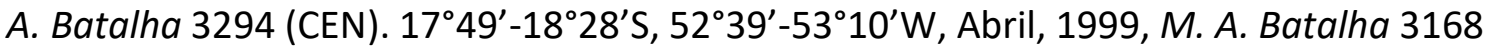
(CEN). Cristalina: Junto à porteira de entrada da RPPN Linda Serra dos Topázios, $16^{\circ} 44^{\prime} 25^{\prime \prime}$, $47^{\circ} 41^{\prime} 12^{\prime \prime}$ O, Maio, 2010, J. F. M. Valls 15458 (CEN). Serra dos Cristais, $2 \mathrm{~km}$ Norte de Cristalina, $17^{\circ} \mathrm{S}, 48^{\circ} \mathrm{W}$, Março, 1966, H. S. Irwin 13329 (NY - Imagem). Cerca de $15 \mathrm{~km}$ oeste de Cristalina, $17^{\circ} \mathrm{S}, 48^{\circ} \mathrm{W}$, Março, 1966, H. S. Irwin 13622 (NY - Imagem). Serra dos Cristais, Cerca de $8 \mathrm{~km}$ Sul de Cristalina, $17^{\circ} \mathrm{S}, 48^{\circ} \mathrm{W}$, Março, 1966, H. S. Irwin 13657 (NY - Imagem). Goiás: Serra Dourada, Cerca de 15km (linha reta) Sul de Goiás Velho, Maio, 1973, W. R. Anderson 10040 (NY - Imagem). Luziânia: Gramíneas em torno 
de área de campo plantada com abacaxi na chácara do Eustáquio Santos, próximo à cerâmica à direita da Sede Campestre do Clube do Exército (Km 20 da BH/Brasília), Abril, 1981, J. C. Dianese 22 (UB). Fazenda do Sr. José Rodrigues, próximo à Sede, 16¹9’49”S, 48¹2'49"O, Abril, 2003, G.Pereira-Silva 7494 (CEN). Niquelândia: Ponte sobre o rio Bagagem, distante $32,5 \mathrm{~km}$ da cidade de Niquelândia, estrada Niquelândia/Colinas do Sul, 1422S, 04812W, Abril, 1992, B. Walter 1109 (CEN). Cidade de Goiás: Cachoeira Grande, Janeiro, 1969, J. F. M. Valls 674 (ICN). Cristalina: RPPN - Linda Serra dos Topázios, beira do Rio Topázio, 1643'56"S, 4741'10"O, Março, 2013, R. G. Chacon 1015 (HEPH). Na entrada da RPPN à direita, depois das mangueiras, do outro lado do rio Topázios, cerca de $900 \mathrm{~m}, 1^{\circ} 43^{\prime} 36^{\prime \prime} \mathrm{S}, 47^{\circ} 40^{\prime} 57^{\prime \prime} \mathrm{W}$, Maio, 2015, R. G. Chacon 1301 (HEPH). Caldas Novas: Bairro Caldas Novas, Chácara Buriti, Abril, 1999, T. S. Filgueiras 3525 (IBGE). Santo Antonio do Descoberto: Cerca de 5 km W da cidade, Março, 8*, T. S. Filgueiras 688 (IBGE). MATO GROSSO. Água Boa: 20,7 km ao norte do rio Areões e cerca de 49 km ao sul de Água Boa, ao longo da BR 158, Junho, 1990, J. F. M. Valls 12509 (CEN). Alto Araguaia: Próximo aos trilhos do trem, 17ํ24'08.2”S 531'28.6”W, Fevereiro, 2016, C.O. Moura 96 (UB). 172ㄴ'18.7'S 5313'20.3”W, Fevereiro, 2016, C.O. Moura 102 (UB). $15 \mathrm{~km}$ NO de Alto do Araguaia na estrada para Itiquira, $17^{\circ} 15^{\prime} 0^{\prime \prime} \mathrm{S} 53^{\circ} 21^{\prime} 0^{\prime \prime} \mathrm{W}$, Setembro, 1996, C. Proença 1515a (UB). Aquidauana: Distrito de Camisão, Morro do Paxixi, Julho, 2006, A. Guglieri 1128 (CGMS). Serra de Maracaju, subida para a estação repetidora de Paxixi, Fevereiro, 1993, G. Hatschbach 58959 (MBM). Barra do Garças: cerca de $3 \mathrm{~km}$ da entrada para Novo São Joaquim, 1534'58.0"S 5314'26.8”W, Fevereiro, 2016, C.O. Moura 76 (UB). Ca. 35 km (Straigh line) ENE of Barra do Garças, Maio, 1973, W. R. Anderson 9702 (NY - Imagem) Chapada dos Guimarães: Parque Nacional da Chapada dos Guimarães, Próximo à casa do morro São Jerônimo, 
1526'07.7"S 5551'23.4"W, Fevereiro, 2016, C.O. Moura 91 (UB). 1526'10.9”S 5551'24.1”W, Fevereiro, 2016, C.O. Moura 92 (UB). Conquista d'Oeste: Estrada de Terra de Conquista d'Oeste para Vila Bela da Santíssima Trindade, 14²9'13"S, 5951'30”W, Maio, J. E. Q. Faria 3574 (CEN, UB). Cuiabá: Rota de Cuiabá a Chapada dos Guimarães, km 10, Faz. Bandeira, Março, 1996, G. H. Rua 47 (UFMT). Nova Lacerda: Margem da estrada de Conquista d'Oeste para Serra da Borda, começo da subida da

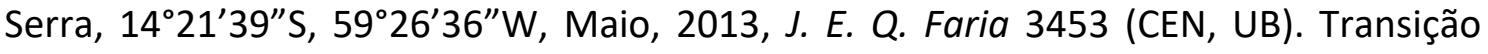
cerradão e mata, $14^{\circ} 21^{\prime} 17^{\prime \prime}$ S 59 $26^{\prime} 31^{\prime \prime}$ W, Maio, 2013, J. E. Q. Faria 3440 (CEN, UB). Novo Santo Antônio: Parque Estadual do Araguaia, Fazenda Queranbrás, $12^{\circ} 22^{\prime} 37,4^{\prime \prime} \mathrm{S}$ $50^{\circ} 56^{\prime} 03,9$ "W, Junho, 2005, H. Jancoski 81 (CEN). Novo São Joaquim: Primeira Fazenda à esquerda depois da ponte sobre o Rio das Mortes (lado norte da ponte), 1514'28.1'”S 5303’25.7”W, Fevereiro, 2016, C.O. Moura 80 (UB). Poconé: Pantanal de Poconé, Fazenda N. S. Aparecida, Maio, 2007, L. Rebellato 208 (UFMT). Santa Cruz do Xingu: Parque Estadual do Xingu, 941'8”S 5237'17'W, Março, 2011, D.C. Zappi 3113 (RB). São Felix do Araguaia: Rodovia Porto Alegre do Norte, entroncamento BR-158/BR-080 $\mathrm{km} \mathrm{71}, 11^{\circ} 08^{\prime} \mathrm{S} 51^{\circ} 42^{\prime} \mathrm{W}$, Setembro, 1984, L. Coradin 7256 (CEN). Xavantina: On the Xavantina - São Felix road, 1254'S 5152'W, Junho, 1968, J. A. Ratter 2001 (UB). MATO

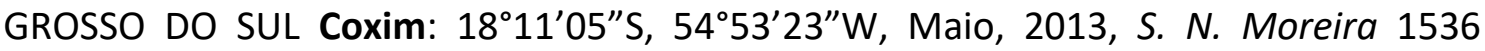
(BHCB). MARANHÃO. Balsas: Gerais de Balsas - Área de Preservação do lote 17, $08^{\circ} 39^{\prime} 00^{\prime \prime} \mathrm{S} 46^{\circ} 43^{\prime} 00^{\prime \prime} \mathrm{W}$, Março, 2000, R. C. Oliveira 1399 (CEN). Mata Roma: Fazenda Rufina, 341'37"S 4312'20”W, Abril, 1998, M.S. Bona Nascimento 1196 (UB). São João dos Patos: BR - 230, São João dos Patos - Floriano, km 35, Maio, 1979, L. Coradin 1553 (CEN). Perizes: Julho, 1954, A. G. Black $16718\left(^{* * * *}\right)$. Carolina - San Antonio de Balsas: Edge of small stream, Março, 1934, J. R. Swallen 4075 (IAC). São Luiz: Granja Barreto, 
Maio, 1949, R. L. Fróes 24311 (IAC). Balsas: Projeto Geral de Balsas - 8 km da Vila, $46^{\circ} 5^{\prime} 0^{\prime \prime} \mathrm{S}, 3^{\circ} 35^{\prime} 0^{\prime \prime}$ W, Março, 1997, R. C. Oliveira 706 (HEPH, FURB). Agrovila Nova de Carli, lote pivo Central, $08^{\circ} 32^{\prime} 57^{\prime \prime S}, 46^{\circ} 37^{\prime} 02^{\prime \prime} \mathrm{W}$, Julho, 1998, R. C. Oliveira 1199 (HEPH, FURB). Projeto Geral Balsas - Próximo ao Rio Tem Medo, $46^{\circ} 05^{\prime} 0^{\prime \prime} \mathrm{S}, 07^{\circ} 35^{\prime} 0^{\prime \prime} \mathrm{W}$, Março, 1997, R. C. Oliveira 631 (HEPH). Fazenda Brejo Comprido, 07³1'57"S, 4602'08"O, Março, 1994, J. H. de Carvalho 612 (CPAMN). MINAS GERAIS. Diamantina: Para Biri-Biri, $18^{\circ} 11^{\prime} 59^{\prime \prime} \mathrm{S} 43^{\circ} 37^{\prime} 26^{\prime \prime} \mathrm{W}$, Março, 2005, Longhi-Wagner 9623 (CEN, BHCB). Itumirim: 9km W of Itutinga along highway 265 to Barbacena, Fevereiro, 1976, G. Davidse 10751 (MBM). Patrocínio: Morro das Pedras, 1844S, 04653W, Fevereiro, 1989, A. O. Scariot 283 (CEN). Unaí: Entrada da fazenda à direita, na estrada de acesso para a UHE

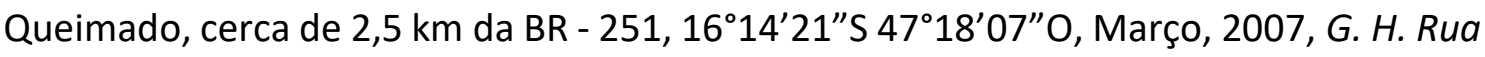
864 (CEN). São Gonçalo do Rio Preto: Parque Estadual do Rio Preto, junto ao córrego da Lapa, $18^{\circ} 05^{\prime 2} 28^{\prime \prime}$ S, 4320'32”W, Abril, 2000, J. A. Lombardi 3735 (BHCB). Catas Altas: RPPN Caraça, Abril, 2005, P. L. Viana 2195 (BHCB). Conceição do Mato Dentro: Parque Natural Municipal Ribeirão do campo, Setembro, 2003, P. L. Viana 394 (BHCB). Uberlândia: Estação Ecológica do Ponga, Vereda 4, Maio, 1999, M. T. O. Lemos (CESJ). Diamantina: Estrada que liga Diamantina a Biri-Biri, Abril, 2010, M. T. Eichemberg 781 (HRCB). Uberlândia: Between Sucupira and Omega, south of Uberlândia (Uberabinha), Março, 1930, Agnes Chase 11204 (ESAU). PARÁ. Fabrica moji, Maio, 1924, J.G. Kuhlmann 2134 (RB). 30,8 km do entroncamento da BR - 316 para Vigia, $01^{\circ} 01^{\prime} \mathrm{S} 48^{\circ} 07^{\prime} \mathrm{W}$, Outubro, 1987, Veiga \& Silva 188 (CEN). PARÁ. Conceição do Araguaia: terreno úmido e arenoso, Junho, 1953, R. L. Fróes 29918 (UB). Parauapebas: FLONA de Carajás - Área N1.. Canga.. $6^{\circ} 02^{\prime} 31^{\prime \prime} \mathrm{S}, 50^{\circ} 16^{\prime} 55^{\prime \prime} \mathrm{W}$, Março, 2011, R. C. Oliveira 2576 (UB). São Geraldo do Araguaia: Parque Estadual das Andorinhas, margem esquerda do rio Araguaia, $06^{\circ} 18^{\prime} 44^{\prime \prime} \mathrm{S}$ 
48²4'33"O, Abril, 2004, G. Pereira-Silva 9015 (CEN). São Miguel do Guamá: BR - 010, km 142, Belém - Brasília, Setembro, 1979, L. Coradin 2105 (CEN). PARAÍBA. Alhandra: Divisa com município, proximidades de um riacho, Fevereiro, 1969, E. Tenório 516 (CEN, UB). PERNAMBUCO. Recife: Novembro, 1933, Pichel 3439B (RB). PIAUÍ. Campo Maior: Km 276,5 da BR-343. Beira de estrada, Maio, 1988, L. B. Bianchetti 660 (CEN). RIO GRANDE DO NORTE. Estremoz - Natal: Junho, 1934, J.R. Swallen 4785 (RB). RONDÔNIA. Porto Velho: Jaci parana, estrada de acesso ao porto Prainha (balsa da mineradora) próximo ao povoado Mutum Paraná, 0936'53"S 6456'31”W, Março, 2010, G. PereiraSilva 15009 (CEN, RB). Janeiro, 1974, J. Jung 225 (CEN). SÃO PAULO. Mogi-Guaçu: Fazenda Campininha, Janeiro, 1996, H.M. Longhi-Wagner 3297 (ICN, UEC). Itirapina: Itirapina, I. Sendulsky 195 (HEPH). TOCANTINS. Darcinópolis: Margem do rio Curicaca, cachoeira da fazenda do Sr. Marcelo, $06^{\circ} 42^{\prime} 29^{\prime \prime S} 47^{\circ} 35^{\prime} 01^{\prime \prime} \mathrm{W}$, Abril, 2008, G. PereiraSilva 12994 (CEN). Mateiros: Região do Jalapão, estrada Mumbuca - Boa Esperança, povoado da Mumbuca, trilha para o Brejo do Ciado, $10^{\circ} 19^{\prime} 57^{\prime \prime} \mathrm{S} 46^{\circ} 33^{\prime} 34^{\prime \prime} \mathrm{O}$, Dezembro, 2005, G. H. Rua 706 (CEN). Vereda do Porco Podre, 10¹8’52"S 46³9’38"O, Dezembro, 2005, G. H. Rua 705 (CEN). 10¹8’52"S 46³9’38”O, Março, 2006, G. H. Rua 796 (CEN). Paranã: Serra do Mocambo, povoado de Campo Alegre, 13099'10"S 47ㄴ8'35"W, Janeiro, 2017, C. O. Moura 112 (UB). Margem direita do rio Custódio, 1305’05”S 48 $05^{\prime} 51^{\prime \prime}$, Junho, 2006, G. Pereira-Silva 10563 (CEN). Estrada de acesso ao vilarejo rozario, cerca de $3 \mathrm{~km}$ após a entrada principal da obra, $12^{\circ} 47^{\prime} 42^{\prime \prime} \mathrm{S} 48^{\circ} 11^{\prime} 58^{\prime \prime} \mathrm{O}$, Março, 2007, G. Pereira-Silva 11459 (CEN). São Salvador do Tocantins: Margem esquerda do lago da UHE São Salvador, 1250’37"S, 48¹6’07"O, Março, 2009, G. Pereira-Silva 14159 (CEN). 
4.1.7 Paspalum parviflorum Rhode ex Flüggé, Gram. Monogr., Paspalum 98. 1810.

Tipo: Rhode s.n., PUERTO RICO (HT: FI, IT: B-W, BM, US, Provável IT: P!).

Paspalum parviflorum var. humile Nees ex Döll, Fl. Bras. 2(2): 45. 1877.

Tipo: Sellow 275, BRASIL (HT: B destruído IT: P, K!, US, Prováveis IT: G, P!, W).

Planta monocárpica, cespitosa, colmo florífero de 2,0-21 cm, com ramificações proximais, raramente distais, 2 a 6 nós, glabros; bainhas foliares de 0,4 $-3,2 \mathrm{~cm}$ de comprimento, pilosa na face abaxial, tricomas lineares de base tuberculada, chegando até $6,0 \mathrm{~mm}$ de comprimento; colar presente, frequentemente pouco perceptível, geralmente uma linha em coloração amarelada; lígula membranosa, de 0,1-1,0 mm de comprimento, com cílios ao redor, de até 3,0 mm de comprimento; lâmina foliar 0,8 $6,5 \times 0,04-0,2 \mathrm{~cm}$, planas, lineares a linear-lanceoladas, base truncada, ápice agudo, pilosa em ambas as superfícies, tricomas lineares, de dois tipos, pequenos ca. de 1,0 $\mathrm{mm}$, mais comuns na face adaxial e longos de base tuberculada com até $6,0 \mathrm{~mm}$ de comprimento, margem ciliada, tricomas lineares de base tuberculada. Sinflorescências terminais e axilares, com 1 a 4 (5) ramos unilaterais espiciformes, patentes, não conjugados, de $0,2-3,1 \mathrm{~cm}$ de comprimento, geralmente terminando com uma espigueta desenvolvida; pedúnculo de $1,0-6,0 \mathrm{~cm}$ de comprimento; ráquis membranácea, com ca. de 0,4 $\mathrm{mm}$ de largura; pedicelos de 0,4 - 0,9 $\mathrm{mm}$ de comprimento, pilosos, tricomas menores que $0,5 \mathrm{~mm}$ de comprimento; espiguetas $0,6-$ 1,0 X 0,4-0,6 mm, plano-convexas, elípticas, solitárias; gluma superior 0,6 - 0,9 X 0,40,6 $\mathrm{mm}$, membranácea, delicada, binervada, nervuras marginais, podendo ser pouco maior ou menor que o antécio superior, com pequenos tricomas colunares, geralmente concentrados nas margens, com porção central glabra e hialina; lema inferior 0,6 -0,9 X 
0,4 - 0,6 mm, membranáceo, geralmente bi(tri)nervado, a central ausente, com pequenos tricomas colunares, geralmente concentrados nas margens, com porção central glabra e hialina; antécio superior 0,6-0,9 X0,4-0,6 mm, crustáceo, estramíneo, glabro, liso, lustroso (FIGURA 17); lodículas ca. de 0,1 mm; 3 anteras roxas ou amarelas e 2 estigmas amarelos; cariopse 0,5-0,7 X0,3-0,4 mm, elíptico-oboval, castanha; hilo oboval.

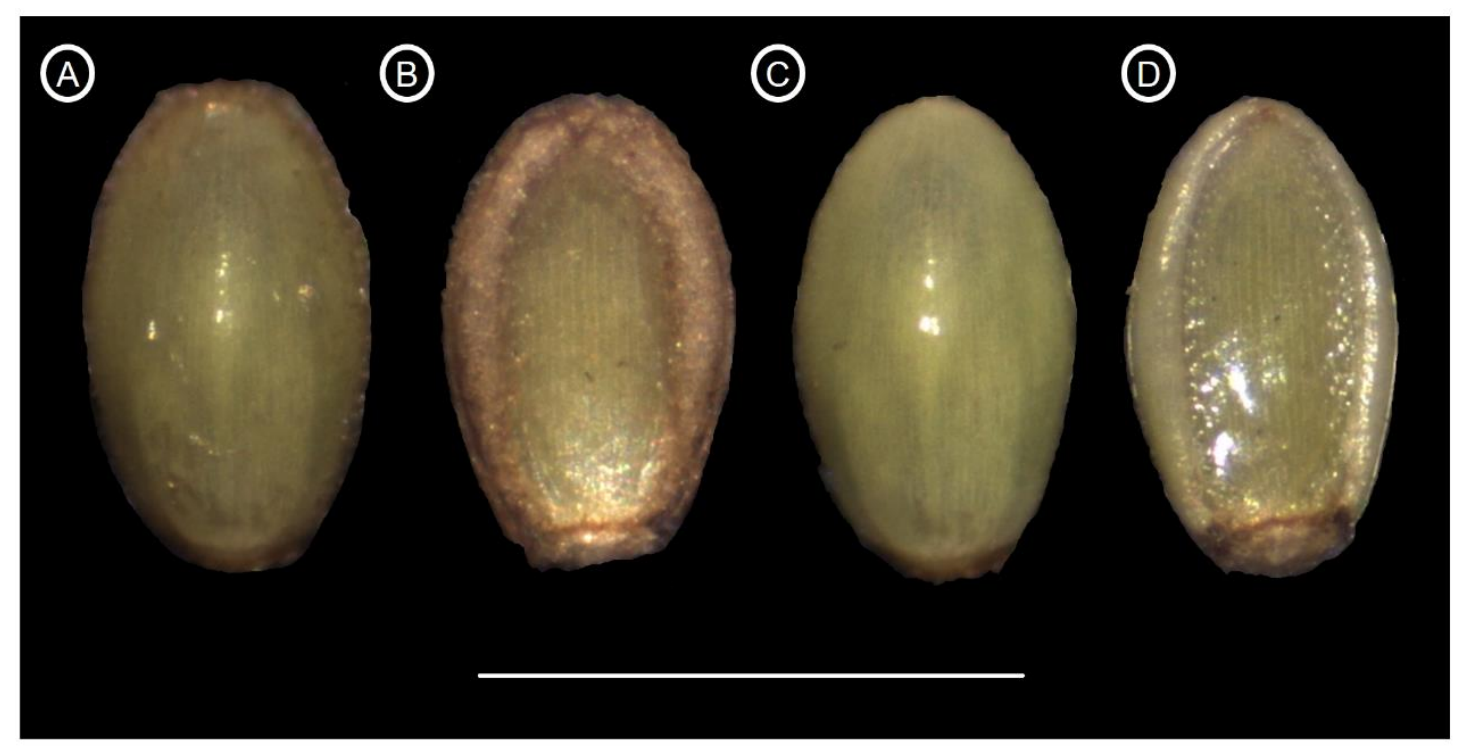

Figura 17. Espigueta de Paspalum parviflorum (Faria, J.E.Q. 3506 - 35x029); A - Gluma superior, $B$ - Lema inferior, $C$ - Lema superior, D - Pálea. Barra de escala $=1 \mathrm{~mm}$.

P. parviflorum apresenta tricomas colunares ornamentando a gluma superior e lema inferior, e papilas conjugadas na superfície do lema superior e pálea superior (FIGURA 18). 

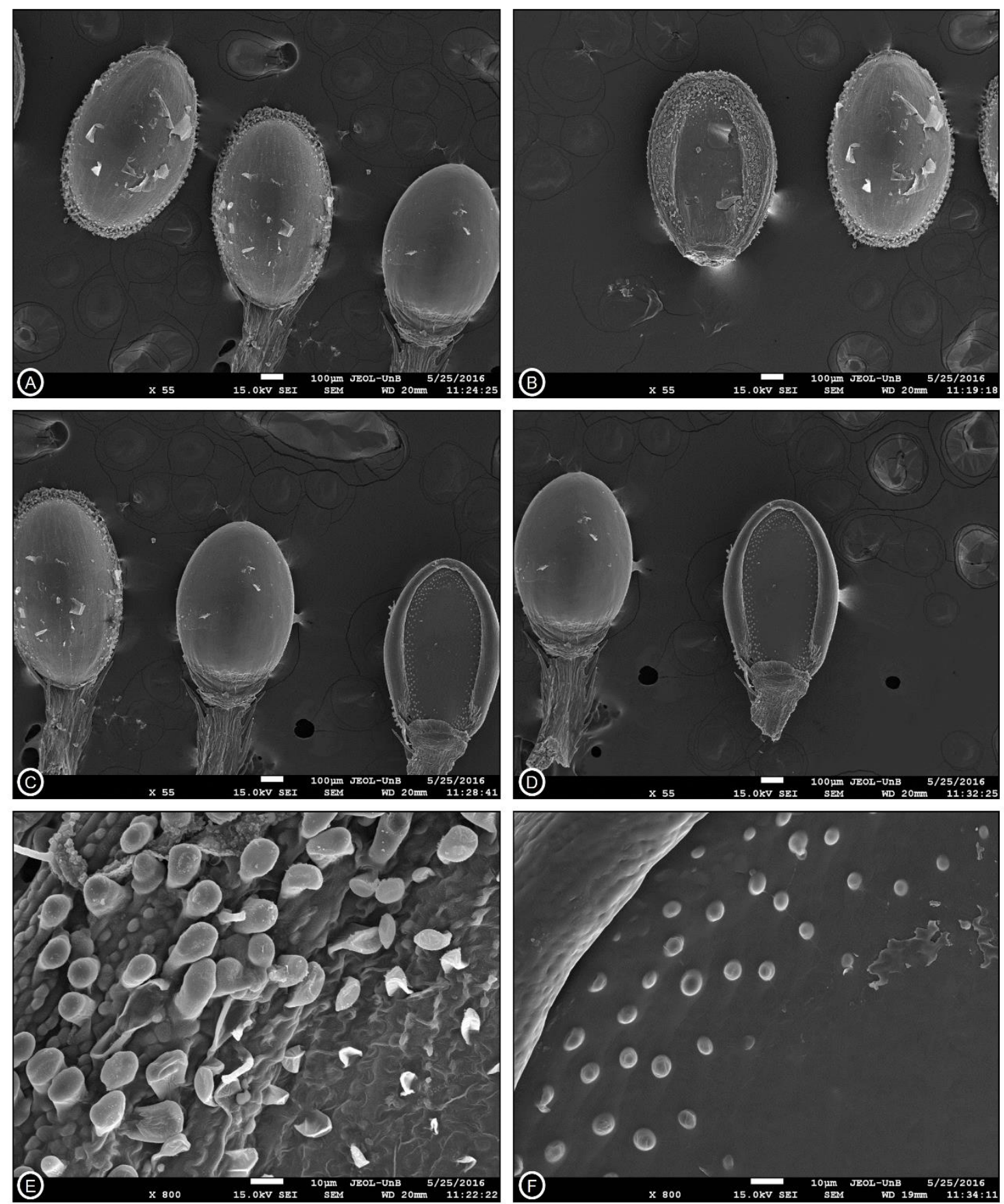

Figura 18. Microfotografia de Paspalum parviflorum (Faria, J.E.Q. 3506); A - Gluma superior, B - Lema inferior, C - Lema superior, D - Pálea, E - Tricomas colunares, F - Papilas simples.

\section{Distribuição geográfica e aspectos ecológicos}

Ocorre na região Neotropical, desde o Panamá e Porto Rico até a Bolívia e Brasil.

No Brasil é encontrado nos estados do Amapá, Bahia, Goiás, Maranhão, Mato Grosso,

Minas Gerais, Pará, Paraíba, Pernambuco e Piauí (FIGURA 19). Possui registro para os 
domínios da Amazônia, Caatinga, Cerrado e Mata Atlântica. Está presente em formações campestres, savânicas e florestais, geralmente habitando ambientes de campo limpo, campo úmido, campo e mata de restinga, cerrados e tabuleiros, geralmente associados a solos arenosos e úmidos.

Época de florescimento e frutificação: durante os meses de Março, Abril, Maio, Junho, Julho, Agosto, Setembro, Outubro e Novembro.

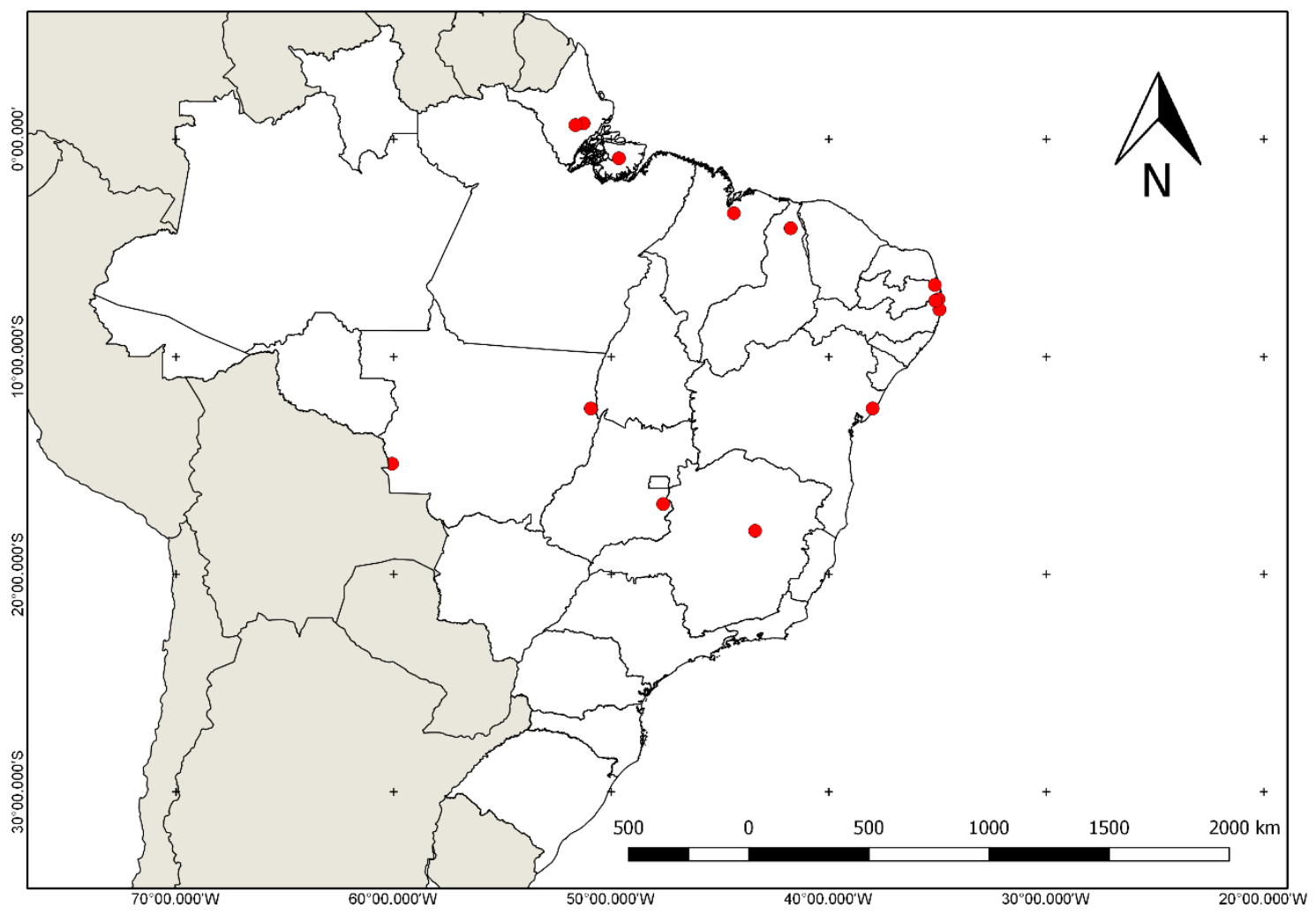

Figura 19. Mapa com os registros de distribuição (pontos vermelhos) confirmados de Paspalum parviflorum.

\section{Comentários Taxonômicos}

Paspalum parviflorum é caracterizada por suas espiguetas diminutas, solitárias e principalmente pela gluma superior e lema superior binervada e hialina na porção central, muito delicadas e com pequenos tricomas colunares marginais. 
Diferente dos demais exemplares analisados, os acessos M. R. A. Mendes 107 e G. M. Barroso 259, coletados no Piauí, na região do Parque Nacional de Sete Cidades, possuem tricomas por toda a superfície da gluma superior e lema inferior, inclusive sobre a porção central, levemente hialina, característica rara. ZULOAGA \& MORRONE (2005), relatam colmos de até $35 \mathrm{~cm}$, enquanto que neste estudo e em Chase (1939 - não publicado), com até $21 \mathrm{~cm}$ de comprimento. As lígulas nestes autores variam até $0,5 \mathrm{~mm}$, aqui foram encontradas com até $1,0 \mathrm{~mm}$ de comprimento.

\section{Histórico dos sinônimos}

Paspalum parviflorum foi descrita por J. Flüggé, em sua obra Graminum Monographiae (1810). Nesta obra uma coleta de J. G. Rhode, feita em Porto Rico, é indicada como tipo, porém esta não foi encontrada (CHASE 1929; 1939 - não publicado). CHASE (1929; 1939 - não publicado) indica que uma coleta feita por Rhode em Porto Rico, de 1809, presente em BM e outra em B-W (Willdenow Herbarium) poderiam ser parte da coleção tipo, concordando com outros autores que indicam o exemplar presente em B-W como holótipo (POHL \& DAVIDSE 2009). Diferindo dos autores anteriores, informações disponíveis em TROPICOS (2017) e em ZULOAGA \& MORRONE (2005), sugerem que o holótipo seja uma coleta de Rhode presente em FI.

Existem dois nomes como sinônimos de P. parviflorum, um deles Paspalum vestitum Steud., que não possui descrição válida e tem o voucher Wallich s.n., presente em P, indicado como holótipo do nome (CHASE 1929; 1939 - não publicado). E Paspalum parviflorum var. humile Nees ex Döll, com holótipo, em B, destruído. J. C. Döll quando descreveu a variedade na Flora Brasiliensis, indicou como tipos coletas de Sellow, na 
Bahia e de Riedel, no Mato Grosso, ambas sem número. CHASE (1929; 1939 - não publicado) indica o acesso Sellow 275, em B, como tipo da variedade, material provavelmente destruído. Entretanto, duplicatas presentes em K, que combinam coletas de Sellow e Riedel, da Bahia e Mato Grosso contemplam as indicações de Döll e devem ser partes da coleção tipo.

\section{Materiais Examinados}

AMAPÁ. Porto Grande: Estrada para Cupixi em direção à Serra do Navio, 038'66"N 51ํ37'93”W, Junho, 2011, R.P. Oliveira 1843 (HUEFS). Macapá: Paredão próximo a bomba de gasolina da Companhia - EletroNorte, $0^{\circ} 44^{\prime} 00^{\prime \prime} \mathrm{N} 51^{\circ} 16^{\prime} 00^{\prime \prime} \mathrm{W}$, Agosto, 1988,

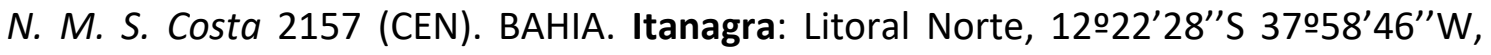
Setembro, 2008, A.R. Prates 118 (ALCB, MBM). (BOLÍVIA) SANTA CRUZ. Ñuflo de Chavez: Concepción, 28 a 29 km al Sur de Concepción sobre el camino a Lomerio, 16²3'39” S 615'12" W, Abril, 2008, J.R.I. Wood 24224 (UB). GOIÁS. Cristalina: RPPN Linda Serra dos Topázios, Maio, 2015, R.G. Chacon 1312 (HEPH). MARANHÃO. Itapicurú: 1954, G.A. Black 54-16682 (P - REFLORA). MATO GROSSO. Salto Belo, Rio Sacre, Linha teleg., Abril, 1918, J.G. Kuhlmann 1682 (RB). Novo Santo Antônio: Parque Estadual do Araguaia, Fazenda Queranbrás, $12^{\circ} 22^{\prime} 37,4^{\prime \prime} \mathrm{S} 50^{\circ} 56^{\prime} 03,9^{\prime \prime} \mathrm{W}$, Junho, 2005, H. Jancoski 86 (CEN). Santo Antonio do Leverger: 4,7 km após o cemitério de S. A. do Leverger, na estrada para Barão de Melgaço, Junho, 1990, J. F. M. Valls 12584 (CEN). Vila Bela da Santíssima Trindade: Topo da Cachoeira do Jatobá, $14^{\circ} 55^{\prime} 06^{\prime \prime} \mathrm{S} 60^{\circ} 04^{\prime} 26^{\prime \prime} \mathrm{W}$, Maio, 2013, J. E. Q. Faria 3506 (CEN). MINAS GERAIS. São Gonçalo do Rio Preto: Parque Estadual do Rio Preto, 1800's 4323’W, 2003, P.L. Viana 830 (BHCB). PARÁ. Marajó: Rio Cará-Carí, 
Junho, 1914, A. Goeldi 95 (RB). PARAÍBA. Mata Redonda: Setembro, 1954, J.L. Falcão 1126 (RB). PARAÍBA. Mamanguape: Reserva biológica Guaribas, Área 1 - Capim Azul, $06^{\circ} 41^{\prime} 54^{\prime \prime} \mathrm{S} 35^{\circ} 07^{\prime} 20^{\prime \prime} \mathrm{O}$, Agosto, 2002, A. C. Sevilha 2272 (CEN). PERNAMBUCO. Itambé: Agosto, 1952, M. Magalhães 12618 (UB, IPA). Igarassu: Alagadiços da Campina dos Marcos, Junho, 1955, Andrade-Lima 2083 (IPA). PIAUÍ. Parque Nacional, Serra Negra, Bananeiros, Setembro, 1977, G.M. Barroso 259 (RB). Piracuruca: Parque Nacional das Sete Cidades, 0405'20.3"S 4144'55.7'W, Julho, 2007, M.R.A. Mendes 107 (UB). Agosto, 2006, C. B. R. Munhoz 3128 (CEN). 
4.1.8 Paspalum scalare Trin., Sp. Gram. 3(23): 274. 1830.

Tipo: L. Riedel 1042, BRASIL (NT: K!)

Paspalum scalare var. glabriglume Döll, Fl. Bras. 2(2): 50. 1877.

Tipo: J. E. B. Warming s.n., BRASIL (LT: W!, ILT: W!)

Paspalum scalare var. villosulum Döll, Fl. Bras. 2(2): 50. 1877.

Tipo: L. Riedel s.n., BRASIL (US).

\section{Descrição morfológica}

Plantas policárpicas, cespitosas, colmo florífero de $15-75 \mathrm{~cm}$, ramificações proximais e distais, 3 a 20 nós, geralmente piloso; bainhas foliares de 2,5-7,8 cm de comprimento, de glabra a pilosa na face abaxial, os tricomas lineares de até $3 \mathrm{~mm}$; colar presente, geralmente uma linha em coloração acastanhada com tricomas de até $3 \mathrm{~mm}$; lígula membranosa, 0,5-1,4 mm de comprimento, podendo apresentar ou não cílios ao redor; lâmina foliar $0,9-6,5 \times 0,02-0,30 \mathrm{~cm}$, planas a involutas, lineares a linearlanceoladas, base truncada, ápice agudo, geralmente pilosa em ambas as superfícies, as vezes com concentração desigual entre as faces, os tricomas lineares de até $5 \mathrm{~mm}$ de comprimento, margem ciliada, com tricomas escabrosos intercalados com tricomas lineares, estes em menor concentração. Sinflorescências terminais e axilares, com 1 a 5 ramos unilaterais espiciformes, não conjugados, de $1,2-7,0 \mathrm{~cm}$ de comprimento; pedúnculo de 3,5-17,5 cm de comprimento; ráquis membranácea, de 0,3-0,7 $\mathrm{mm}$ de largura; pedicelos de 0,4-1,3 mm de comprimento, pilosos; espiguetas $1,0-1,7 \times 0,4$ - 0,8 mm, plano-convexas, elípticas, pareadas, frequentemente uma das espiguetas do par pode estar ausente; gluma superior $0,9-1,7 \times 0,4-0,8 \mathrm{~mm}$, membranácea, delicada, trinervada, comumente inconspícuas, geralmente do mesmo tamanho do 
antécio superior, mas podendo ser pouco menor ou maior, glabras ou mais comumente com tricomas lineares, recobrindo toda superfície, frequentemente os tricomas caem com a maturidade; lema inferior $1,0-1,6 \times 0,4-0,8 \mathrm{~mm}$, membranáceo, bi a trinervado, glabros ou mais comumente com tricomas lineares, recobrindo toda superfície, frequentemente os tricomas caem com a maturidade; antécio superior 0,9 - 1,6 X 0,40,8 mm, cartáceo, estramíneo, levemente papiloso, levemente fosco (FIGURA 20); lodículas com cerca de 0,2 mm; 3 anteras e 2 estigmas; cariopse 0,8 X 0,4 mm, elíptica; hilo oboval.

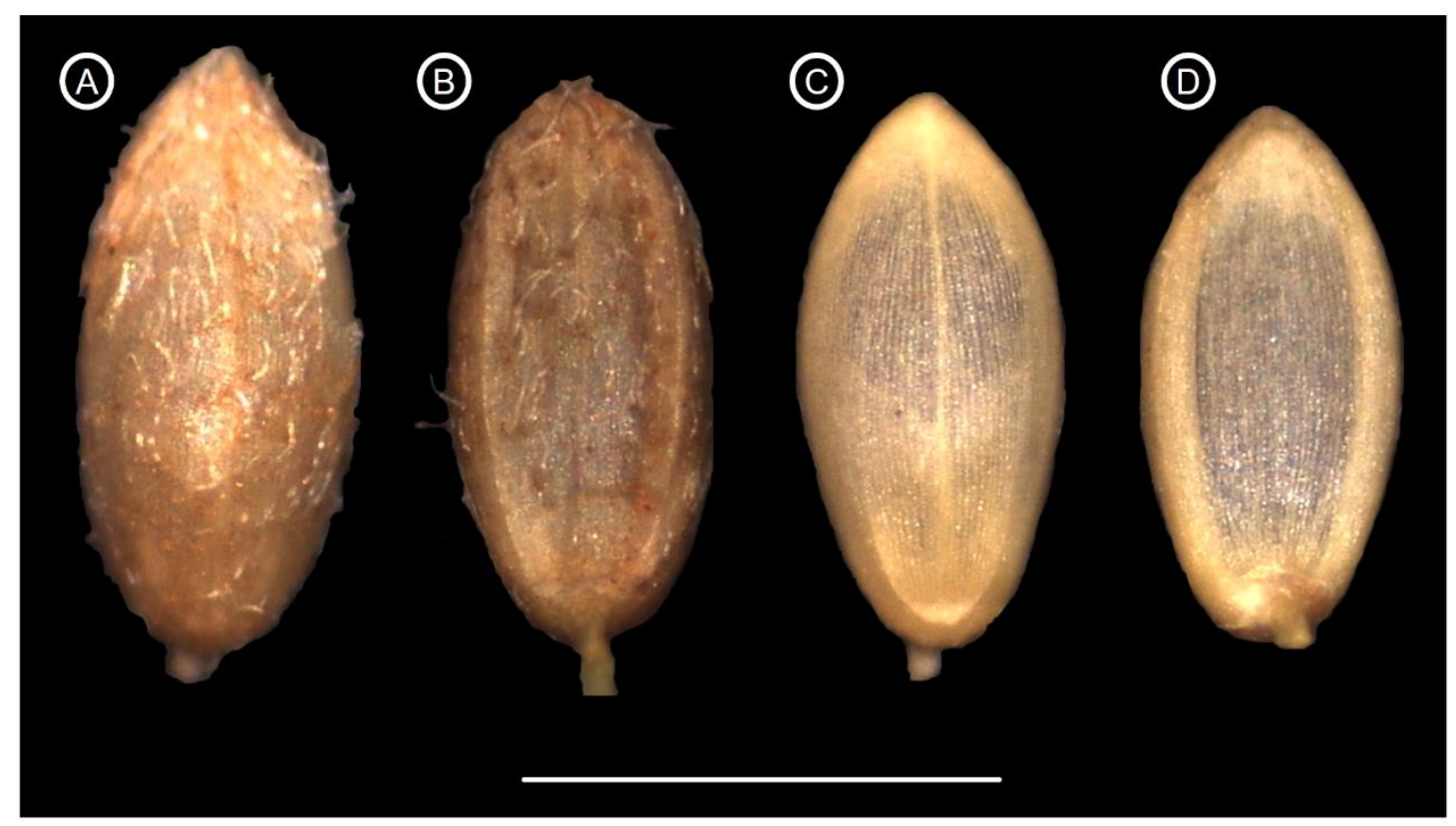

Figura 20. Espigueta de Paspalum scalare (Graciano-Ribeiro 66); A - Gluma superior, B - Lema inferior, $C$ - Lema superior, D - Pálea. Barra de escala $=1 \mathrm{~mm}$.

P. scalare apresenta tricomas falcados ornamentando a gluma superior e lema inferior, e papilas conjugadas na superfície do lema superior e pálea superior (FIGURA 21). 

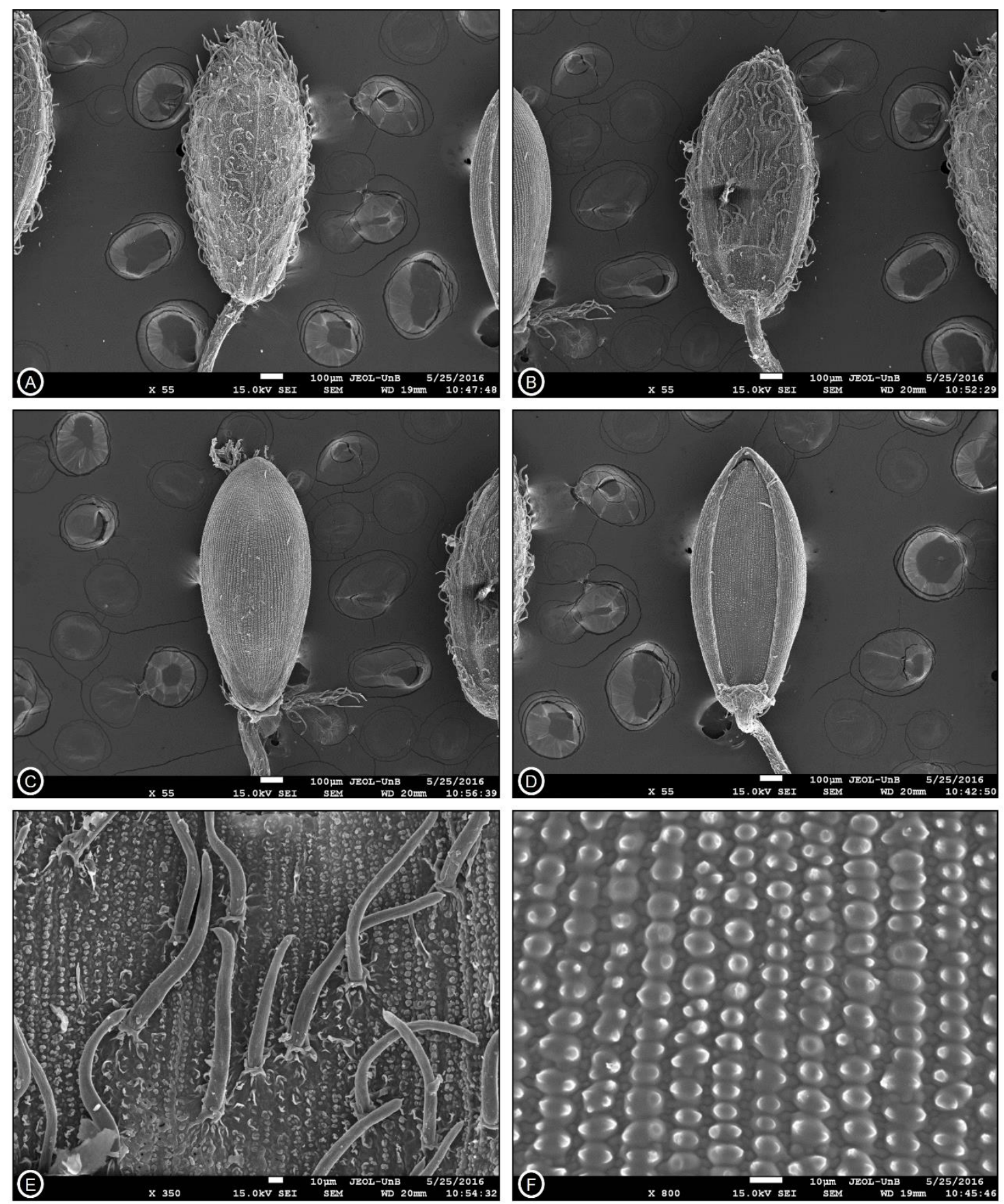

Figura 21. Microfotografia de Paspalum scalare (Graciano-Ribeiro 66); A - Gluma superior, B Lema inferior, C - Lema superior, D - Pálea, E - Tricomas falcados, F - Papilas conjugadas.

\section{Distribuição geográfica e aspectos ecológicos}

Ocorre na região Neotropical e só possui registro para o Brasil, onde ocorre nos estados da Bahia, Distrito Federal, Goiás, Mato Grosso e Minas Gerais (FIGURA 22). Possui registro apenas para o domínio do Cerrado. Está presente em formações 
campestres e savânicas, habitando campos rupestres, e ambientes rochosos em bordas de curso d'água.

Época de florescimento e frutificação: durante os meses de Fevereiro, Março, Abril, Maio, Junho, Julho, Outubro e Dezembro.

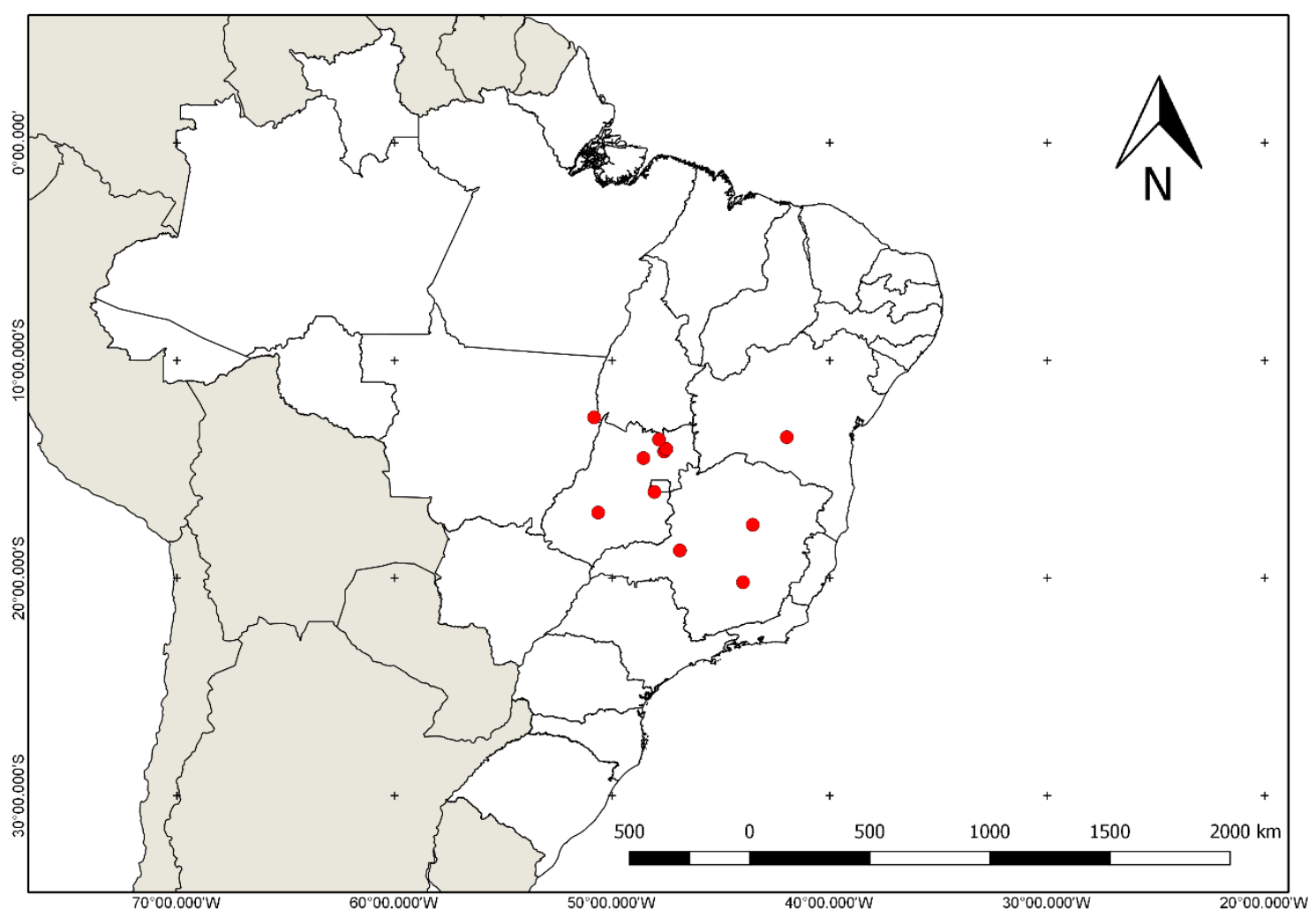

Figura 22. Mapa com os registros de distribuição (pontos vermelhos) confirmados de Paspalum scalare.

\section{Comentários Taxonômicos}

Espécie afim de $P$. crispatum, dentro do grupo Parviflora, $P$. scalare distingue-se por apresentar tricomas falcados ornamentando a gluma superior e lema inferior, diferente de $P$. crispatum, que apresenta tricomas encaracolados. Ademais, $P$. scalare apresenta, eventualmente, uma pequena porção sulcada na base do lema inferior, próximo à inserção do pedicelo, e $P$. crispatum apresenta porção sulcada por toda a 
extensão do lema inferior.

P. scalare é uma espécie que possui grande variação morfológica, em suas populações. Uma das principais características utilizadas para dividir as variedades, em P. scalare, é a presença/ausência de tricomas na gluma superior e lema inferior. Através de observações feitas em campo, foi possível verificar que a concentração/quantidade de tricomas, bem como a ausência ou presença, pode variar dentro de indivíduos de uma mesma população e que estejam em períodos fenológicos diferentes; com a senescência, os tricomas tendem a cair, podendo gerar interpretações equivocadas na hora da identificação.

\section{Histórico dos sinônimos}

Descrito por C. B. v. Trinius em 1830 na obra Species Graminum (sem indicação de uma coleta tipo, porém com ilustração), $P$. scalare possui dois sinônimos (variedades), $P$. scalare var. glabriblume Döll e P. scalare var. villosulum Döll. As duas variedades foram descritas por J. C. Döll na Flora Brasiliensis (1877), e possuem coletas de J. E. B. Warming e L. Riedel como tipo, respectivamente. Entretanto, não foram indicados números de coleta, apenas as localidades Serra da Chapada (Riedel) e Serra da Piedade (Warming), ambas no estado de Minas Gerais.

Não existem indicações claras sobre o status de tipo em P. scalare, por isso, indicase que o voucher Riedel 1042, coletado no Brasil e depositado em K (K000643777) seja elevado ao status de Neótipo. Em relação a variedade $P$. scalare var. glabriblume, a coleção tipo presente em W (coletas de Warming em Minas Gerais - Serra da Piedade) possui duas exsicatas, W1904-0012167 e W1904-0012168, recomenda-se aqui a 
promoção destes exemplares para lectótipo e Isolectótipo, respectivamente. Não foi possível analisar aqui o voucher de Riedel indicado como isótipo, presente em US (US2855984).

Adota-se no presente trabalho a não utilização das variedades descritas, uma vez que o principal caráter (que dá nome as variedades) presença/ausência de tricomas, na gluma superior e lema inferior, que justifica a separação não é um bom caráter intraespecífico em $P$. scalare, já que foi observado, além da ampla variação na concentração de tricomas, a queda dos mesmos com a senescência das espiguetas.

\section{Materiais Examinados}

BAHIA. Rio de Contas: Pico das Almas, lado esquerdo da trilha sentido topo, $13^{\circ} 31^{\prime} 34^{\prime \prime} \mathrm{S}$ $41^{\circ} 57^{\prime} 52^{\prime \prime} \mathrm{W}$, Janeiro, 2003, M. C. Ferreira 1321 (UB). DISTRITO FEDERAL. Rocky hillside overlooking River Paranoá S.E. of dam, Maio, 1968, D. Philcox 4911 (UB). Brasília (Gama), 1981, B. A. S. Pereira 48 (IBGE,UB). GOIÁS. Alto Paraíso de Goiás: Almécegas II - Fazenda São Bento, 1411'11.1'S 47ํ36'15.5”W, Julho, 2015, C.O. Moura 60, 61, 62, 63, 64 (UB). Fazenda Água Fria, cerca de 10Km em direção a Teresina de Goiás,

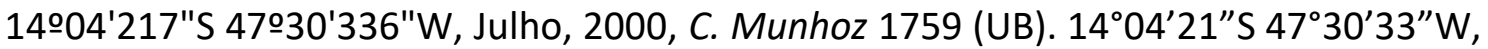
Maio, 2007, C. B. R. Munhoz 3267 (CEN). Chapada dos Veadeiros, Portal da Chapada, estrada GO - 239 Alto Paraíso - São Jorge, 9 Km de Alto Paraíso, Junho, 2005, G. H. Rua 622 (CEN). Fazenda Água Fria, cerca de 10Km em direção a Teresina de Goiás, 140''217"S 47ํ30'336"W, Janeiro, 2001, C. Munhoz 2678 (CEN). Fazenda São Bento, Cachoeira de Almécegas I, margem de cachoeira com relevo acidentado e substrato rochoso, Dezembro, 2009, R. C. Oliveira 2727 (UB). Caldas Novas: Margem direita do 
Rio Corumba, próximo ao eixo da barragem em frente a S.O.1, Abril, 1994, H. G. P. Santos 252 (CEN). Cavalcante: RPPN Serra do Tombador, Rio Conceição, 13³8'04"S 4750'26”W, Outubro, 2011, A. R. O. Ribeiro 297 (CEN,UB). Niquelândia: Estrada de terra - Km 08 da rodovia Niquelândia/Uruaçu. Fazenda Traíras, 1429'19" S 48ํ3'26"W, 1996, F.C.A. Oliveira 590 (IBGE). Paraúna: Parque Estadual de Paraúna, Serra das Galés, cerrado rupestre, $16^{\circ} 59^{\prime} 23^{\prime \prime} \mathrm{S} 50^{\circ} 38^{\prime} 13^{\prime \prime} \mathrm{W}$, Maio, 2013, J. E. Q. Faria 3666 (CEN). Pirinópolis: Pirineus, Outubro, 1956, A. Macedo 4807 (UB). MATO GROSSO. Barra do Garças: Estrada Barra do Garças-Nova Xavantina (BR-158), 5 Km NW da BR-158 na estrada de chão que sai, 2011, G. H. Rua 1014 (UB, CEN). Novo Santo Antônio: Parque Estadual do Araguaia, $12^{\circ} 36^{\prime} 55,4^{\prime \prime} \mathrm{S} 50^{\circ} 49^{\prime} 23,9^{\prime \prime}$, Outubro, 2005, H. Jancoski 311 (CEN). Nova Xavantina: Cerrado próximo ao distrito de Vale dos Sonhos, Agosto, 1997, A. M. Giulietti 69 (UB). Xavantina: 85km S. of Xavantina, lower slopes, Serra Azul, 1966, H.S. Irwin 17155 (UB). MINAS GERAIS. Belo Horizonte: Serra do Curral, Abril, 1925, A. Chase 9315 (RB). Inhaí: Fazenda do "Seu Geraldão", Acesso por Inhaí, Parque Nacional das Sempre Vivas, $17^{\circ} 33^{\prime} 14^{\prime \prime S} 43^{\circ} 31^{\prime} 51^{\prime \prime}$, Maio, 2010, T. R. B. Mello 223 (UB). Nova Lima: Rampa de decolagem Clube de Vôo livre Belo Horizonte, Serra da Moeda, 20¹1'42"S 4358'44"W, Março, 2005, H.M. Longhi-Wagner 9530 (CEN). Patrocínio: Morro das pedras, 1844S 04653W, Fevereiro, 1989, A. O. Scariot 281 (CEN). 


\section{REFERÊNCIAS}

ALISCIONI, S.; BELL, H. L.; BESNARD, G.; CHRISTIN, P. A.; COLUMBUS, J. T.; DUVALL, M. R.; EDWARDS, E. J.; GIUSSANI, L.; HASENSTAB-LEHMAN, K.; HILU, K. W.; HODKINSON, T. R.; INGRAM, A. L.; KELLOGG, E. A.; MASHAYEKHI, S.; MORRONE, O.; OSBORNE, C. P.; SALAMIN, N.; SCHAEFER, H.; SPRIGGS, E.; SMITH, S. A.; ZULOAGA, F. New grass phylogeny resolves deep evolutionary relationships and discovers $\mathrm{C} 4$ origins. New Phytologist, v. 193, n. 2, p. 304-312, 2012.

ALISCIONI, S. S.; DENHAM, S. S. Rachis of the genus Paspalum L. (Poaceae: Panicoideae: Paniceae): Anatomy and taxonomic significance of the primary branches of the inflorescences. Flora: Morphology, Distribution, Functional Ecology of Plants, v. 203, n. 1, p. 60-76, 2008.

BARRETO, I. L. O gênero Paspalum (Gramineae) no Rio Grande do Sul. Tese de Livre Docência. Universidade Federal do Rio Grando do Sul. 1974.

BOUCHENAK-KHELLADI, Y.; VERBOOM, G. A.; SAVOLAINEN, V.; HODKINSON, T. R. Biogeography of the grasses (Poaceae): A phylogenetic approach to reveal evolutionary history in geographical space and geological time. Botanical Journal of the Linnean Society, v. 162, n. 4, p. 543-557, 2010.

CHASE, M. A. The North American Species of Paspalum. Contributions from the United States National Herbarium, v. 28, n. 1, p. 1-310, 1929.

CHASE, M. A. Paspalum of South America. 1939, não publicado.

DENHAM, S. S.; ZULOAGA, F. O.; MORRONE, O. Systematic Revision and Phylogeny of Paspalum Subgenus Ceresia (Poaceae: Panicoideae: Paniceae). Annals of the 
Missouri Botanical Garden, v. 89, n. 3, p. 337, 2002.

DENHAM, S. S. Revision sistemática del subgénero Harpostachys de Paspalum (Poaceae: Panicoideae: Paniceae). Annals of the Missouri Botanical Garden, v. 92, n. 4, p. 463-532, 2005.

FLORA DO BRASIL 2020 - Poaceae in Flora do Brasil 2020 em construção. Jardim Botânico do Rio de Janeiro. Disponível em: <http://floradobrasil.jbrj.gov.br/reflora/floradobrasil/FB193>. Acesso em: 31 Jan. 2017

FURTADO, A. T.; SCANDIFFIO, M. I. G.; CORTEZ, L. A. B. The Brasilian sugarcane innovation system. Energy Policy, v. 39, p. 156-166, 2011.

GIUSSANI, L. M.; ZULOAGA, F. O.; QUARÍN, C. L.; COTA-SÁNCHEZ, J. H.; UBAYASENA, K.; MORRONE, O. Phylogenetic Relationships in the Genus Paspalum (Poaceae: Panicoideae: Paniceae): An Assessment of the Quadrifaria and Virgata Informal Groups. Systematic Botany, v. 34, n. 1, p. 32-43, 2009.

HACKEL, E. Oesterreichische Botanische Zeitschrift. v. 51, p. 234-235, 1901.

JONES, S. S.; BURKE, S. V.; DUVALL, M. R. Phylogenomics, molecular evolution, and estimated ages of lineages from the deep phylogeny of Poaceae. Plant Systematics and Evolution, v. 300, n. 1, p. 1421-1436, 2014.

LU, F.; LIPKA, A. E.; GLAUBITZ, J.; ELSHIRE, R.; CHERNEY, J. H.; CASLER, M. D.; BUCKLER, E. S.; COSTICH, D. E. Switchgrass Genomic Diversity, Ploidy, and Evolution: Novel Insights from a Network-Based SNP Discovery Protocol. PLoS Genetics, v. 9, n. 1, 2013. 
MORRONE, O.; AAGESEN, L.; SCATAGLINI, M. A.; SALARIATO, D. L.; DENHAM, S. S.; CHEMISQUY, M. A.; SEDE, S. M.; GIUSSANI, L. M.; KELLOGG, E. A.; ZULOAGA, F. O. Phylogeny of the Paniceae (Poaceae: Panicoideae): Integrating plastid DNA sequences and morphology into a new classification. Cladistics, v. 28, n. 4, p. 333356, 2012.

NASH, G.V. Paspalum. p. 165-195. In Britton, N. L. North American Flora. v. 17, pt. 2, 1912. NICOLA, M. V.; SALOMÓN, L.; ZULOAGA, F. O.; MORRONE, O. Revision of Paspalum group Gardneriana (Poaceae, Paspaleae). Darwiniana, nueva serie, v. 2, n. 1, p. 154-173, 2014.

PIMENTA, K. M. Paspalum L. (POACEAE: PANICOIDEAE) na Chapada Diamantina, Bahia, Brasil. Dissertação de Mestrado. Universidade Estadual de Feira de Santana, 2013. POHL, R.W. \& DAVIDSE, G. Paspalum parviflorum Rhodé ex Fluegge. Flora Mesoamericana. Disponível em: <www.tropicos.org/Project/FM>. Acesso em: 31 Jan. 2016.

PRASAD, V.; STRÖMBERG, C. A. E.; LEACHÉ, A. D.; SAMANT, B.; PATNAIK, R.; TANG, L.; MOHABEY, D. M.; GE, S.; SAHNI, A. Late Cretaceous origin of the rice tribe provides evidence for early diversification in Poaceae. Nature Communications, v. 2, p. 480, 2011.

PRESL, J. S. Tribus II - Paspalineae in: PRESL, K. B. Reliquiae Haenkeanae, seu, Descriptiones et icones plantarum quas in America Meridionali et Boreali. v. 1, n. 4-5, p. 208, 1830.

RADFORD, A. E. Fundamentals of plant systematics. New York: Harper \& Row, Publishers 
Inc.

RODRÍGUEZ, R. H. Una nueva sección del género Paspalum L. (Gramineae): Sección Parviflora Rodríguez Ernstia, segunda etapa. v. 8 (4), p. 99-103, 1999.

RODRÍGUEZ, R. H.; TORRES, E. F. C. \& GUEVARA, L. La sección Parviflora Rodríguez del género Paspalum L. (Gramineae) en Venezuela. Ernstia, segunda etapa. v. 10 (3), p. 117-143, 2000.

RUA, G. H. The inflorescences of Paspalum (Poaceae, Paniceae): The Quadrifaria group and the evolutionary pathway towards the fully homogenized, truncated common type. Plant Systematics and Evolution, v. 201, n. 1-4, p. 199-209, 1996.

RUA, G. H.; SPERANZA, P. R.; VAIO, M.; ARAKAKI, M. A phylogenetic analysis of the genus Paspalum (Poaceae) based on cpDNA and morphology. Plant Systematics and Evolution, v. 288, n. 3-4, p. 227-243, set. 2010.

SCATAGLINI, M. A.; ZULOAGA, F. O.; GIUSSANI, L. M.; DENHAM, S. S.; MORRONE, O. Phylogeny of New World Paspalum (Poaceae, Panicoideae, Paspaleae) based on plastid and nuclear markers. Plant Systematics and Evolution, v. 300, n. 5, p. 1-20, 2014

SILVA, A. S.; RIBEIRO, A. R. O.; SOUZA, M.W.S.; FAGG, C.W.; OLIVEIRA, R. C. Micromorphology of the upper anthecium in Mesosetum and related genera (Poaceae, Arthropogoninae) and its taxonomic applications.. Rodriguésia (Impresso), v. 66, p. 645-657, 2015.

SORENG, R. J.; PETERSON, P. M.; ROMASCHENKO, K.; DAVIDSE, G.; ZULOAGA, F. O.; JUDZIEWICZ, E. J.; FILGUEIRAS, T. S.; DAVIS, J. I.; MORRONE, O. A worldwide 
phylogenetic classification of the Poaceae (Gramineae). Journal of Systematics and Evolution, v. 53, n. 2, p. 117-137, 2015.

SOUZA-CHIES, T. T.; ESSI, L.; RUA, G. H.; VALLS, J. F. M.; MIZ, R. B. A preliminary approach to the phylogeny of the genus Paspalum (Poaceae). Genetica, v. 126, p. 15-32, 2006.

STRÖMBERG, C. A. E. Evolution of Grasses and Grassland Ecosystems. Annual Review of Earth and Planetary Sciences, v. 39, p. 517-544, 2011.

THIERS, B. Index Herbariorum: A global directory of public herbaria and associated staff. Disponível em: <http://sweetgum.nybg.org/ih/>. Acesso em: 31 Jan. 2017.

TROPICOS. Tropicos.org Missouri Botanical Garden. Disponível em: <http://www.tropicos.org/Name/40002243>. Acesso em: 31 Jan. 2017.

WALTER, B. M. T.; CAVALCANTI, T. B. Fundamentos para a coleta de germoplasma vegetal. Brasília: EMBRAPA Recursos Genéticos e Biotecnologia. 778p., 2005.

ZILLI, A. L.; HOJSGAARD, D. H.; BRUGNOLI, E. A.; ACUÑA, C. A.; HONFI, A. I.; URBANI, M. H.; QUARIN, C. L.; MARTÍNEZ, E. J. Genetic relationship among Paspalum species of the subgenus Anachyris: Taxonomic and evolutionary implications. Flora Morphology, Distribution, Functional Ecology of Plants, v. 209, p. 604-612, 2014.

ZULOAGA, F. O.; MORRONE, O. Revisión de las Especies de Paspalum para América del Sur Austral (Argentina, Bolivia, sur del Brasil, Chile, Paraguay, y Uruguay). Monographs in Systematic Botany from the Missouri Botanical Garden, v. 102, p. 1-297, 2005. 


\title{
ANEXO I - Artigo submetido a revista Phytotaxa (Magnolia Press).
}

\section{A new species of Paspalum, Recta group (Poaceae, Paspaleae), from the cangas of the Serra dos Carajás, Pará state, Brazil.}

CLAPTON OLIMPIO DE MOURA ${ }^{1}$, PEDRO LAGE VIANA ${ }^{2}$ \& REGINA CÉLIA OLIVEIRA $^{1 *}$

${ }^{1}$ Programa de Pós-Graduação em Botânica, Instituto de Ciências Biológicas, Bloco D, Térreo, Universidade de Brasília. Brasília - DF, 70919-970, Brasil.

${ }^{2}$ Museu Paraense Emílio Goeldi, Avenida Magalhães Barata, 376, São Braz. Belém - PA, 66040-170, Brasil.

\begin{abstract}
A new species, Paspalum sp. nov, morphologically related with P. brachytrichum, is described. While both occur in canga vegetation, P. brachytrichum is endemic to Minas Gerais state and the new species only occurs in Serra dos Carajás, Pará state, Brazil. These species can be distinguished from each other mainly by their height, length, number of racemes and by the length of their pedicels and spikelets.
\end{abstract}

Key words: Amazon, Gramineae, Ironstone outcrops, IUCN Red List., Paniceae l.s.

\section{Resumo}

Uma nova espécie, Paspalum sp. nov., morfologicamente relacionada a P. brachytrichum, é descrita. Ambas ocorrem em vegetação de canga, mas P. brachytrichum é endêmica de Minas Gerais e a nova espécie só ocorre na Serra dos Carajás, estado do Pará, Brasil. São distinguidas principalmente pela altura, comprimento e número dos racemos e comprimento dos pedicelos e espiguetas. 


\section{Introduction}

Paspalum L. (1759: 855) is a neotropical genus of Poaceae Barnhart (1895: 7), Paspaleae J. Presl tribe (1830: 208). It contains about 350 species and is most commonly found in open grasslands and savanic environments of the american continent, with few representatives in the old world (Rua et al. 2010, Zuloaga \& Morrone 2005, Catanzaro et al. 2015).

The genus is characterized by plane-convex or concave-convex spikelets, arranged unilaterally along the rachis; the lower glume is generally absent while the superior glume is turned toward the rachis; lower anthecium with lower palea generally absent and upper anthecium contain palea with a hard and membranous consistency (Chase 1929, Aliscioni \& Denham 2008, Zuloaga \& Morrone 2005, Rua 1996). The informal groups of Paspalum, which are still widely accepted, were originally proposed by Chase (1929), based on morphological similarites.

Serra dos Carajás is a mountainous complex, located in the southeastern region of Pará state, within the domain of the Amazon. A peculiar type of open vegetation, locally named "Canga", grows associated with ironstone outcrops of the noticeable iron rich plateaux in the region (Secco \& Mesquisa 1986; Silva et al. 1986, Silva 1991, Silva et al. 1996 e Rayol 2006; Viana et al. 2016). Several endemic plant species are known to occur in this environment, including some grasses, such as Axonopus carajasensis N.Bastos, Paspalum carajasense S.Denham and Sporobolus multiramosus Longhi-Wagner \& Boechat. As part of an ongoing research aiming to document the flora of the cangas of Serra dos Carajás (Viana et al. 2016), a comprehensive treatment of Poaceae species is being prepared. A distinctive species of Paspalum collected in this area, morphologically related to $P$. brachytrichium from the cangas of Minas Garais state, is here presented as a novelty for the brazilian flora. 


\section{Taxonomy}

Paspalum sp. nov. C.O.Moura, P.L.Viana \& R.C.Oliveira (Fig. 1, 2).

Similar to P. brachytrichum, but differs by possessing 8 to 23 racemes, the proximals branches with $7.0-10.7 \mathrm{~cm}$ long, pedicels $0.8-1.5 \mathrm{~mm}$ long and spikelets $1.9-2.2 \mathrm{~mm}$ long.

Type:-BRAZIL. Pará: Parauapebas, FLONA de Carajás, caminho para a Serra Sul, Campo úmido metalófilo (Canga), $623 \mathrm{~m}, 6^{\circ} 17^{\prime} 04.0^{\prime \prime} \mathrm{S}, 50^{\circ} 20^{\prime} 12.0^{\prime \prime} \mathrm{W}, 17$ March 2011, R.C. Oliveira, W.O.O. Edward, L. Tyski, D.F. Silva 2595 (Holotype UB!, Isotype MG!).

Caespitose perennial herb; culms $90-140 \mathrm{~cm}$ tall, internodes glabrous, nodes glabrous or densely appressed-pubescent, the trichomes ca. de $2.0 \mathrm{~mm}$ or glabrous; leaf sheaths usually longer than internodes, 8.0-20.0 cm long, pilose or glabrous on abaxial surface, the trichomes concentrated usually in the proximal region, trichomes up to $4.0 \mathrm{~mm}$ long; collar glabrous or with few trichomes, with different color or inconspicuous; ligules membranous, $0.3-0.5 \mathrm{~mm}$ long, with dorsal trichomes ca. $3.0 \mathrm{~mm}$ long; auricles absent; blades 4.5-45.0 × 0.10-0.30 cm, folded or occasionally flat, linear, base slightly narrower than sheath; apex acute, the adaxial surface densely papilose, glabrous or pilose, abaxial surface glabrous or with trichomes up to $5 \mathrm{~mm}$ long. Synflorescences terminal, long exserted or included; racemes 8 to $23,1.0-10.7$ $\mathrm{cm}$ long, the proximal branches longer than distal, with piramidal aspect; rachis mambranous, ca. $0.5 \mathrm{~mm}$ wide, glabrous or pilose, ending in a spikelet; pedicels solitary $0.8-1.5 \mathrm{~mm}$ long, glabrous. Spikelets solitary, 1.9-2.2 × 0.8-1.0 mm, elliptic, dorsiventrally compressed; lower glume absent; upper glume 1.8-2.1 × 0.8-1.0 mm, membranous, slender, 5-nerved, usually smaller than upper anthecium, glabrous; lower lemma 1.9-2.2 $\times 0.8-1.0 \mathrm{~mm}$, membranaceous, 3 or 5-nerved, glabrous; upper anthecium 1.9-2.1 $\times 0.8-1.0 \mathrm{~mm}$, cartaceous, stramineous, glabrous, papilose, slightly lustrous; lodicules ca. $0.2 \mathrm{~mm}$ long; stamens 3 . Caryopsis ca. de $1.2 \times 0.5 \mathrm{~mm}$, ellliptic or orbicular, hilum elliptic. 


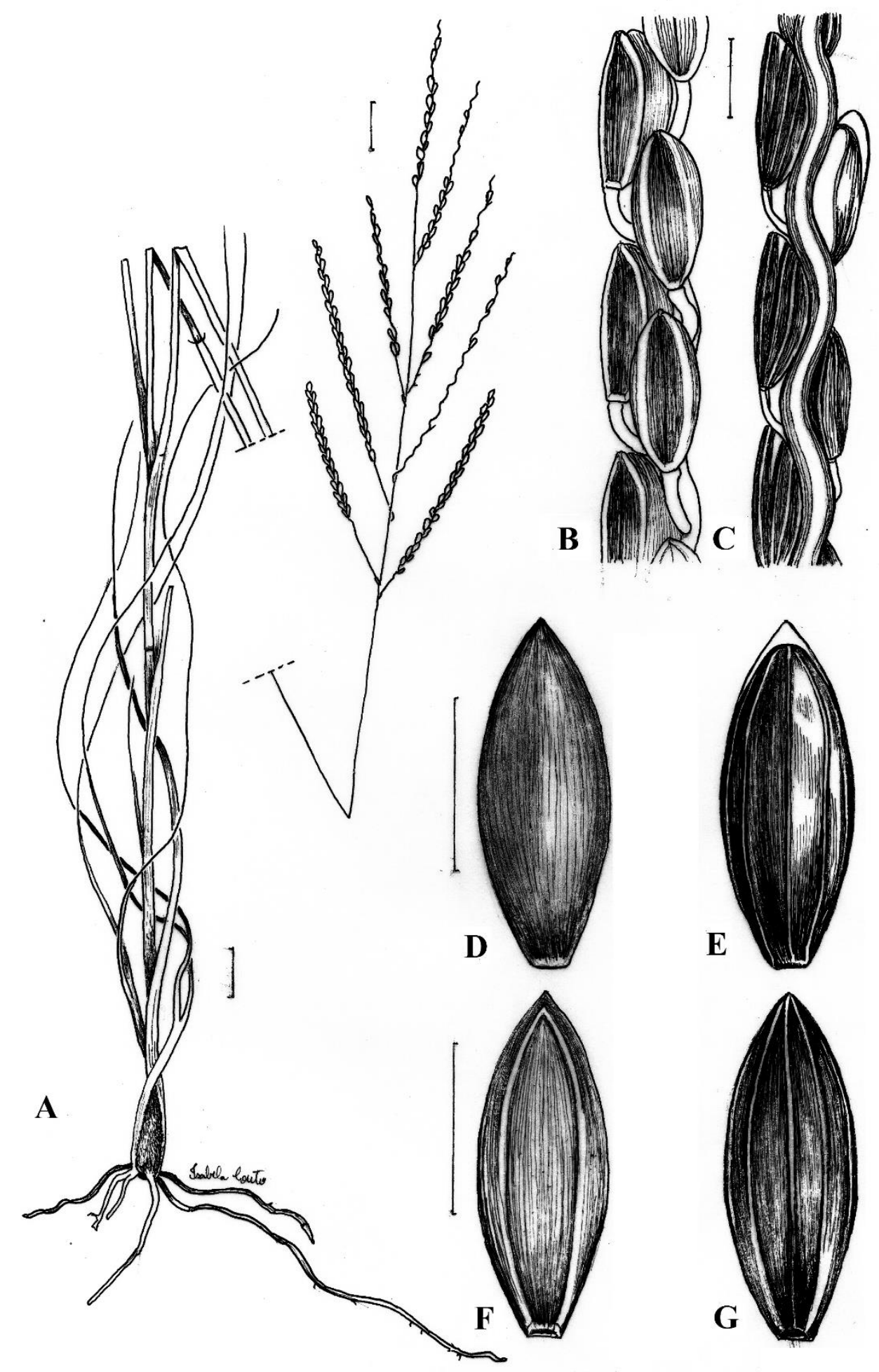

FIGURE 23: Illustration of Paspalum sp. nov. A. Habit. B. and C. Racemes with solitary spikelets. D. upper lemma. E. Upper glume. F. Upper anthecium, palea view. G. Lower lemma. Scale bar: $\mathbf{A}=1 \mathrm{~cm} ; \mathbf{B}, \mathbf{C}, \mathbf{D}, \mathbf{E}, \mathbf{F}$ and $\mathbf{G}=1 \mathrm{~mm}$. 

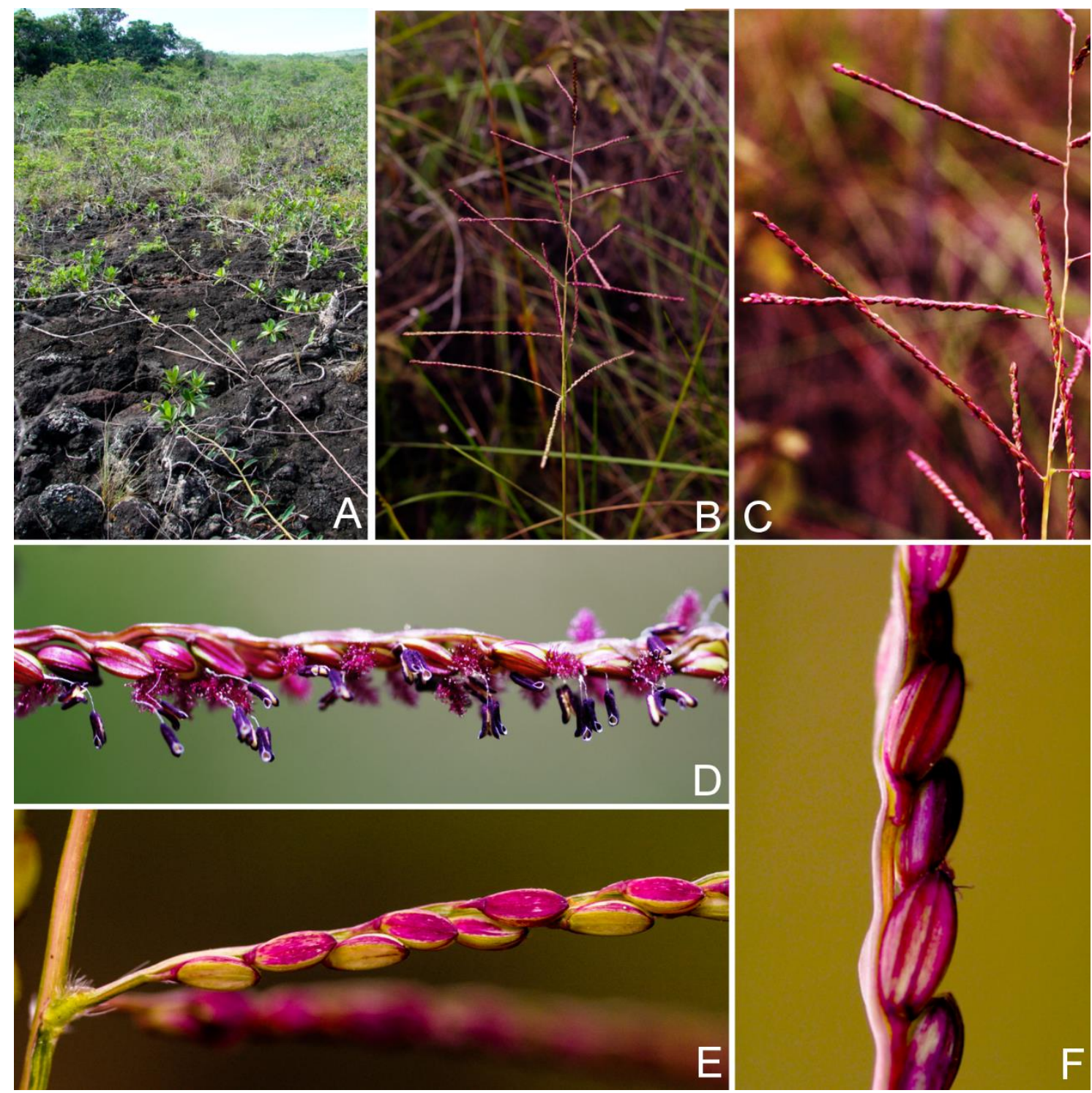

FIGURE 24: Photographs of Paspalum sp. nov. in the field. A. Canga vegetation, on the ironstone outcrops. B. and C. Inflorescences. D. Raceme woth spikelets showing anthers and stigmas. E. Basal portion of a receme. F. Spikelets in detail. 
Etymology:- The specific epithet refers to the "Canga" vegetation, where the species is belived to be endemic.

Distribution and habitat:- Found in open areas upon the canga, Paspalum sp. nov. is endemic to Serra dos Carajás, Pará, Brazil. In the Serra dos Carajas range, it was recorded only in the Serra Sul (S11) and Serra da Bocaina plateaux (Fig. 3).

Though the holotype marks the municipal of Parauapebas, the geographic coordinates indicate that the original collection point was in the neighbouring city, Canaã dos Carajás.

Conservation Status:-According to the IUCN Red List criteria (IUCN 2012) Paspalum sp. nov. should be classified as endangered, based on the extent of occurence (EOO) estimated in $727 \mathrm{~km}^{2}$ and $144 \mathrm{~km}^{2}$ of area of occupancy (AOO). The population recorded in the Serra da Bocaina is protected once it is situated within the limits of the recently created Campos Ferruginosos National Park, a full protection conservation unit. On the other hand, the populations of Serra Sul are situated in the Carajás National Forest, a sustainable use conservation unit, in which mining activities are allowed (MMA 2014) (Fig. 3). 


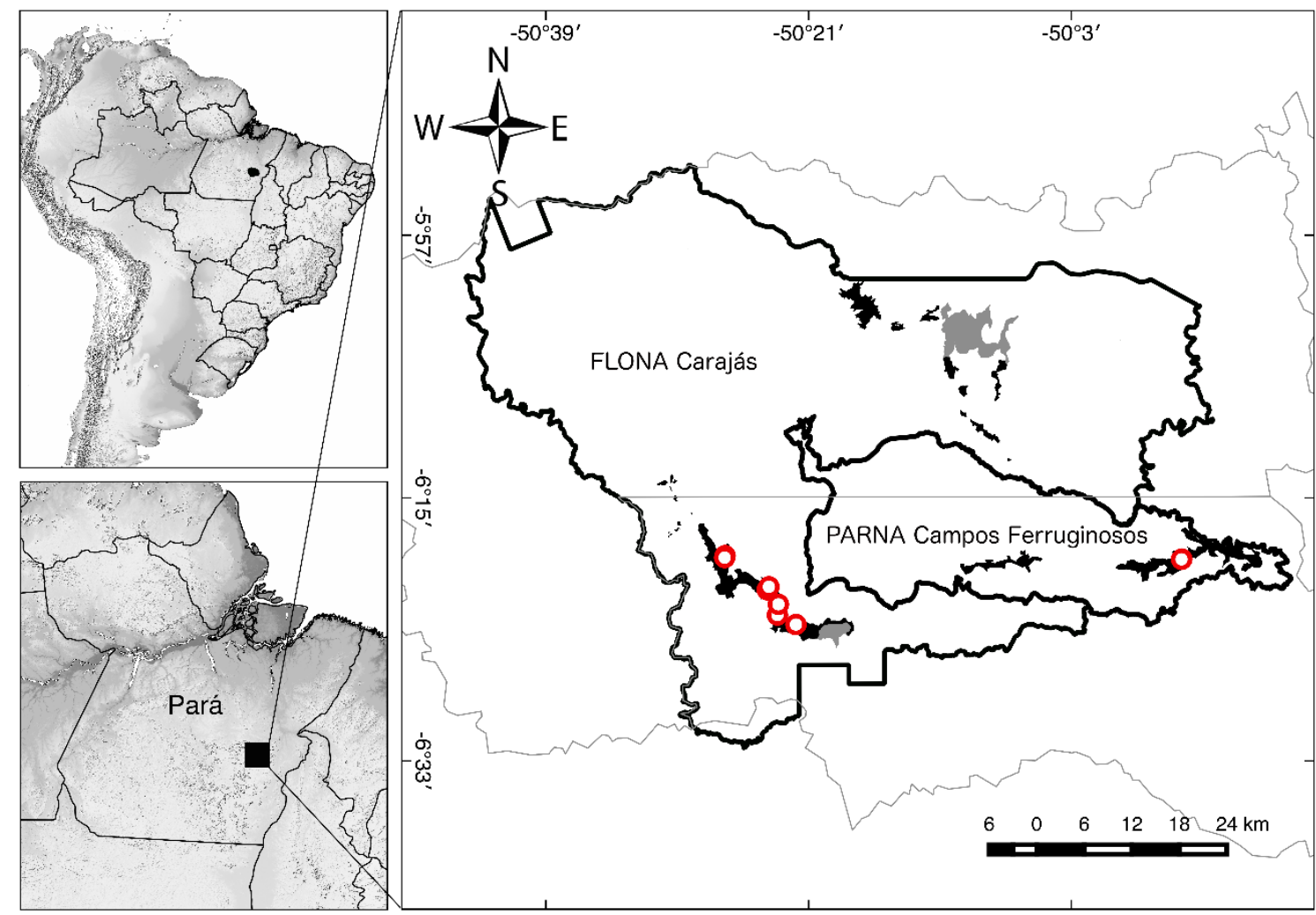

FIGURE 25: Distribution map of Paspalum $s p$. nov. The dark lines indicate the Carajás National Forest (FLONA Carajás) and the Campos Ferruginosos National Park (PARNA Campos Ferruginosos); red circles are occurrence sites; black patches, canga plateaus; grey, mining pits.

Paratypes:- BRAZIL. Pará: Canaã dos Carajás, Serra Sul, S11A, Campo graminoso sobre canga, $737 \mathrm{~m}, 6^{\circ} 18^{\prime} 57^{\prime \prime S}, 50^{\circ} 26^{\prime} 43^{\prime \prime} \mathrm{W}, 21$ March 2012, P.L. Viana, F. Marino, A.J. Arruda, T.B. Jorge, P.B. Meyer 5251 (BHCB); S11A, Campo graminoso, 717 m, 6 19'05"S, 50²6'45"W, 15 January 2016, B.F. Falcão, F.M.A Peixoto, F.M.G Santos, S. Sakagawa 64 (MG); S11B, Lageado associado a campo graminoso, $715 \mathrm{~m}, 6^{\circ} 21^{\prime} 17^{\prime \prime S}, 50^{\circ} 23^{\prime} 50^{\prime \prime} \mathrm{W}, 17$ February 2016, B.F. Falcão, F.M.A Peixoto, F.M.G Santos, S. Sakagawa 107 (MG); S11B, Campo rupestre, 724 m, 6²1'05"S, 50²3'43"W, 31 March 2016, B.F. Falcão, F.M.A Peixoto, F.M.G Santos, S. Sakagawa 322 (MG); S11C, Vegetação rupestre, 699m, 6²3'01"S, 
50²3'08"W, 16 March 2009, P.L. Viana, L.M. Versieux, L.C. Garcia, V.T. Giorni, L.V.C. Silva, D.F. Silva 4080 (BHCB); S11D, Campo graminoso sobre canga, $733 \mathrm{~m}, 6^{\circ} 23^{\prime} 40^{\prime \prime} \mathrm{S}$, 50²1'51"W, 20 March 2012, P.L. Viana, F. Marino, A.J. Arruda, T.B. Jorge, P.B. Meyer 5225 (BHCB); estrada S11D até S11A, vegetação de campo rupestre (canga), 6²2'17"S, 50²3'04"W, 23 March 2015, L.C. Lobato, F. Peixoto, L.V. Ferriera, A. Rodrigues 4412 (MG); Serra da Bocaina, Campo graminoso/lageado, 721 m, 6¹9'11"S, 4955'26"W, 18 June, 2016, B.F. Falcão, F.M.A Peixoto, F.S.R Pena, S. Sakagawa 412 (MG); Serra da Bocaina, Campo graminoso, 723 m, 6¹9'12"S, 4955'27"W, 19 April 2015, B.F. Falcão, F.M.A Peixoto, F.M.G Santos, S. Sakagawa 439 (MG).

Taxonomic relationships:- Paspalum sp. nov. is related to P. brachytrichum Hack. (1901: 234), which Chase treats as a member of the informal group Recta (1939 unpublished). The group was characterized by Chase as plants with "culms slender, simple; blades slender, folded; spikelets glabrous or nearly. All species apparently rare". Inside this group, $P$. brachytrichum and the new species described are the only ones with solitary spikelets. Both species occur in canga vegetation but, $P$. brachytrichum is endemic to Minas Gerais state.

Paspalum sp. nov. can be distinguished by the characteristics listed in Table 1. $P$. brachytrichum has culms that are between 45-70 cm long, while P. sp. nov. 's culms are 90$140 \mathrm{~cm}$ long; In P. sp. nov., the difference in length between the pedicels and spikelet is smaller in P. sp. nov., compared to the variations of P. brachytrichum. Paspalum sp. nov. also presents (longer) and a larger number of racemes, from 8 to 23, while $P$. brachytrichum varies from 2 to 5 . 
TABLE 1. Morphology distinction among P. brachytrichum and $P$. sp. nov. species.

\begin{tabular}{|c|c|c|}
\hline & Paspalum brachytrichum & Paspalum sp. nov. \\
\hline Culm (height) & $45-70 \mathrm{~cm}$ & $90-140 \mathrm{~cm}$ \\
\hline Racemes (№) & $2-5$ & $8-23$ \\
\hline $\begin{array}{l}\text { Proximal branches of the } \\
\text { sinflorescences (length) }\end{array}$ & $2.5-5.5 \mathrm{~cm}$ & $7.0-10.7 \mathrm{~cm}$ \\
\hline Pedicels (length) & $0.5-1.0 \mathrm{~mm}$ & $0,8-1,5 \mathrm{~mm}$ \\
\hline Spikelet (length) & $2.3-2.8 \mathrm{~mm}$ & $1.9-2.2 \mathrm{~mm}$ \\
\hline
\end{tabular}

\section{Acknowledgements}

The research for this paper was financially supported by FAP-DF (process 0193.000.979/2015), CNPq (process 455505/2014-4) and the agreement MPEG/ITV/FADESP (01205.000250/2014-10). The master's scholarship of the first author was provided by CNPq. We thank the curator of BHCB's herbarium for lending us their materials. 


\section{References}

Aliscioni, S.S.; Denham, S.S. (2008) Rachis of the genus Paspalum L. (Poaceae: Panicoideae: Paniceae): Anatomy and taxonomic significance of the primary branches of the inflorescences. Flora: Morphology, Distribution, Functional Ecology of Plants 203 (1): $60-76$.

Barnhart, J.H. (1895) Oesterreichische Botanische Zeitschrift 51: 234. 1901.

Catanzaro, M. P.; Bonasora, M.G.; Speranza, P.R.; Medina-Nicolas, M.; Valls, J.F.M.; RUA, G.H. (2015) Paspalum chilense (Poaceae, Paspaleae): A new species from southern South America. Phytotaxa 197 (4): 245-256. doi: 10.11646/phytotaxa.197.4.2

Chase, M. A. (1929) The North American Species of Paspalum. Contributions from the United States National Herbarium 28 (1): 1-310.

Chase, M. A. (1939) Paspalum of South America. unpublished.

Hackel, E. (1901) Oesterreichische Botanische Zeitschrift 51: 234.

IUCN - International Union for Conservation of Nature. (2012) IUCN Red List Categories and Criteria: Version 3.1. Second edition. Gland, Switzerland and Cambridge, UK: IUCN. iv $+32 p p$.

Linnaeus, C. V. (1759) Systema Naturae, Editio Decima (2): 846, 855, 1359.

MMA - Ministério do Meio Ambiente. (2014) Sistema Nacional de Unidades Conservação SNUC. Available from: http://www.mma.gov.br/areas-protegidas/sistema-nacional-deucs-snuc (accessed 22 June. 2017).

Nunes, C. S.; Gil, A. S. B. \& Trevisan, R. (2016) Eleocharis pedrovianae, a new species of Cyperaceae from Northern Brazil (Serra dos Carajás, Pará State). Phytotaxa 265 (1): 
85-91. doi: 10.11646/phytotaxa.265.1.9

Presl, J. S. (1830) Reliquiae Haenkeanae 1 (4-5): 208.

Rayol, B.P. Análise florística e estrutural da vegetação xerofitica das savanas metalófilas na Floresta Nacional de Carajás: subsídios à conservação. Masters dissertation. Graduation program in Botany. Universidade Federal da Amazônia e Museu Paraense Emílio Goeldi. 2006.

Rua, G. H. (1996) The inflorescences of Paspalum (Poaceae, Paniceae): The Quadrifaria group and the evolutionary pathway towards the fully homogenized, truncated common type. Plant Systematics and Evolution 201 (1-4): 199-209. doi: 10.1007/BF00989061

Rua, G. H.; Speranza, P. R.; Vaio, M. \& Arakaki, M. A. (2010) phylogenetic analysis of the genus Paspalum (Poaceae) based on $c p$ DNA and morphology. Plant Systematics and Evolution 288 (3-4): 227-243. doi: 10.1007/s00606-010-0327-9

Silva, M.F.F. Análise Florística da Vegetação que Cresce sobre Canga Hematítica em Carajás-Pará (Brasil). Boletim do Museu Paraense Emílio Goeldi, Série Botânica, 7(2): 79-108. 1991

Silva, M.F.F.; Mmenezes, N.L.; Cavalcante, P.B. \& Joly, C.A. (1986) Estudos Botânicos: Histórico, atualidade e perspectivas. In: Almeida jr. (Org.). Carajás: desafio político, ecologia e desenvolvimento. São Paulo: Brasiliense. CNPq. p.184-207.

Silva, M.F.F., Secco, R.S. \& Lobo, M.G.A. (1996) Aspectos ecológicos da vegetação rupestre da Serra dos Carajás-Pará, Brasil. Acta Amazônica 26 (1-2): 17-44. doi: 10.1590/180943921996261044

Viana, P. L.; Mota, N. F. O.; Gil, A. S. B.; Salino, A.; Zappi, D. C.; Harley, R. M.; Ilkiu-Borges, A. L.; Secco, R. S.; Almeida, T. E.; Watanabe, M. T. C.; Santos, J. U. M.; Trovó, M.; Maurity, C. \& Giulietti, A. M. (2016) Flora of the cangas of the Serra dos Carajás, Pará, Brazil: history, study area and methodology. Rodriguésia 67 (5): 1107-1124. doi: 
$10.1590 / 2175-7860201667501$

Zuloaga, F. O.; Morrone, O. (2005) O. Revisión de las Especies de Paspalum para América del Sur Austral (Argentina, Bolivia, sur del Brasil, Chile, Paraguay, y Uruguay). Monographs in Systematic Botany from the Missouri Botanical Garden 102: 1-297 